
NATONAL NSSTTUTE OF STANDAROS \& TECHYHOLOGY

Research Information Center

Gaithersburg, MD 20890 

NBSIR 87-3687

\section{Standards for Building Materials, Equipment and Systems Used in Detention and Correctional Facilities}

Robert D. Dikkers

Belinda C. Reeder

U.S. DEPARTMENT OF COMMERCE

National Bureau of Standards

National Engineering Laboratory

Center for Building Technology

Building Environment Division

Gaithersburg, MD 20899

November 1987

Prepared for:

$\begin{array}{ll}-Q C & \text { ment of Justice } \\ 100 & \text { ititute of Corrections } \\ . U 56 & \text { I, DC 20534 } \\ 87-3687 & \\ 1987 & \\ C .2 & \end{array}$



STANDARDS FOR BUILDING MATERIALS, EQUIPMENT AND SYSTEMS USED IN DETENTION AND CORRECTIONAL FACILITIES

Robert D. Dikkers

Belinda C. Reeder

U.S. DEPARTMENT OF COMMERCE

National Bureau of Standards

National Engineering Laboratory

Center for Building Technology

Building Environment Division

Gaithersburg, MD 20899

November 1987

Prepared for:

U.S. Department of Justice

National Institute of Corrections

Washington, DC 20534

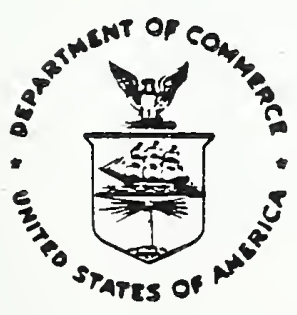

U.S. DEPARTMENT OF COMMERCE, C. William Verity, Secretary NATIONAL BUREAU OF STANDARDS, Ernest Ambler, Director 
Acknowledgements $\ldots \ldots \ldots \ldots \ldots \ldots \ldots \ldots \ldots \ldots \ldots \ldots \ldots \ldots \ldots$

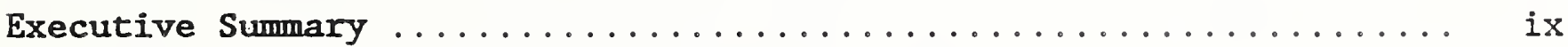

I. INTRODUCTION $\ldots \ldots \ldots \ldots \ldots \ldots \ldots \ldots \ldots \ldots \ldots \ldots \ldots \ldots \ldots \ldots$

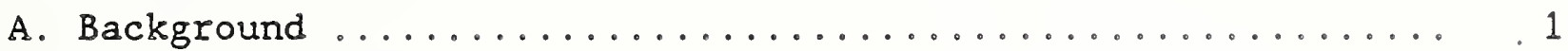

B. Objectives and Scope of NBS Study ................. 3

II. FACILITY DESIGN AND CONSTRUCTION $\ldots \ldots \ldots \ldots \ldots \ldots \ldots \ldots$

A. Facility Development Process .................. 6

1. Needs Assessment ......................... 6

2. Master Plan ............................. 6

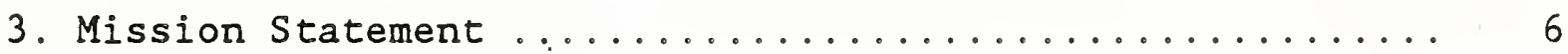

4. Architectural Program .................... 7

5. Schematic Design and Design Development ........... 7

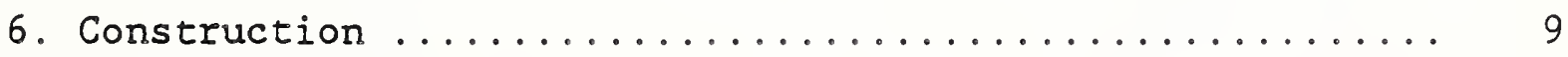

B. Security Levels ......................... 10

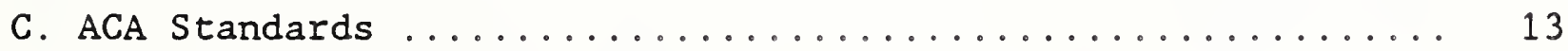

III. MATERIALS, EQUIPMENT AND SYSTFMS $\ldots \ldots \ldots \ldots \ldots \ldots \ldots \ldots \ldots$

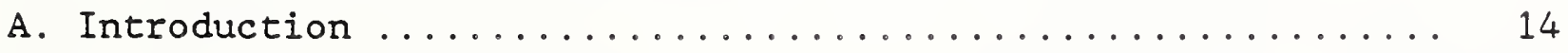

B. Performance Problems ........................ 15

C. Available Standards/Guide Specifications............... 20 
TABLE OF CONTENTS

(continued)

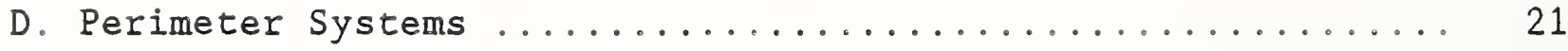

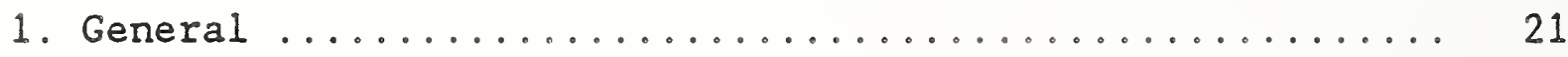

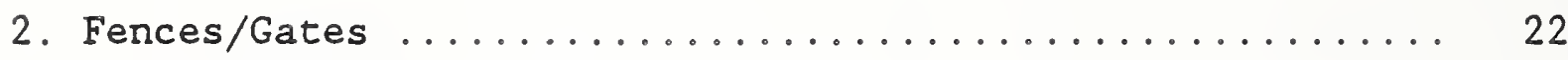

3. Intrusion Detection Systems $\ldots \ldots \ldots \ldots \ldots \ldots \ldots \ldots, 23$

4. Closed Circuit Television .................... 28

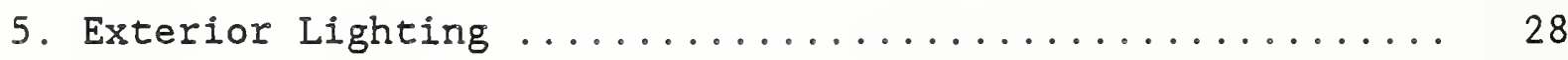

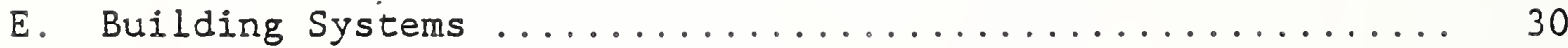

1. General ................................. 30

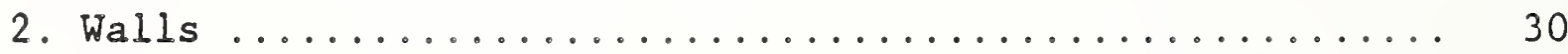

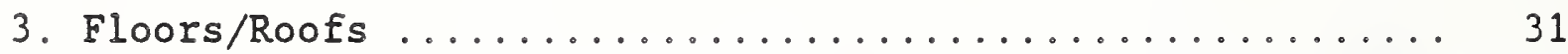

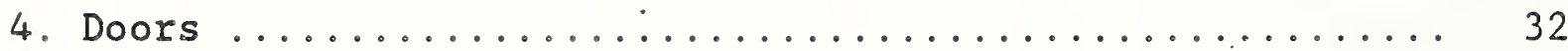

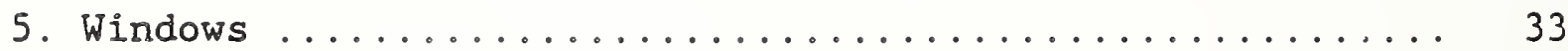

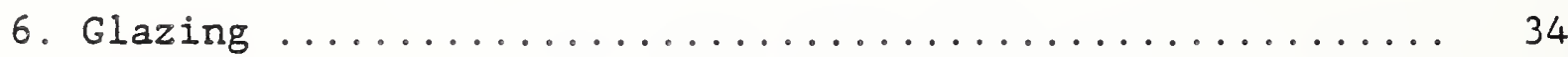

7. Access Controls ......................... 36

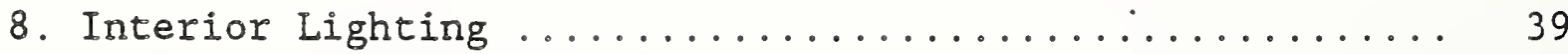

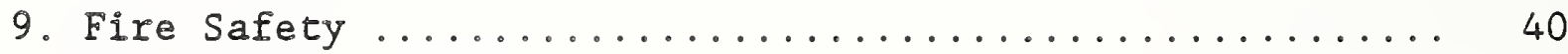

F. Central Control ................................ 45

G. Economic Evaluations ....................... 46

IV. DISCUSSION AND CONCLUSIONS $\ldots \ldots \ldots \ldots \ldots \ldots \ldots \ldots \ldots \ldots \ldots \ldots, 48$

A. General .................................... 48 
TABLE OF CONTENTS

(continued)

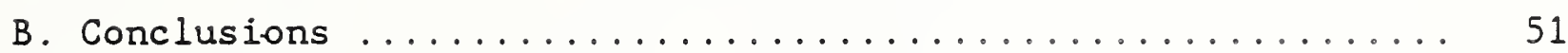

1. Performance Criteria for Correctional Facilities ....... 51

2. Standards for Materials, Equipment and Systems ....... 53

3. Data Base for the Performance of Materials, Equipment,

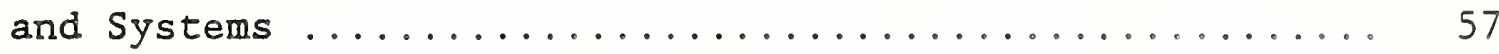

4. Economic Guide or Handbook ................. 57

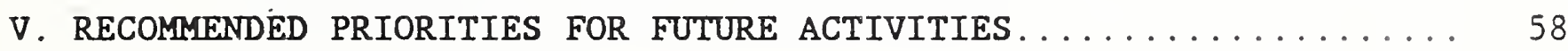

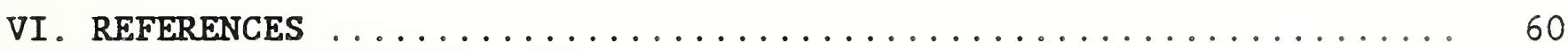

APPENDIX A - - An Overview of Standards Terminology and the Standards Development Process ............... 67

APPENDIX B -- Brief Descriptions of Selected Standards for Materials, Equipment, and Systems .............7 73 


\section{PREFACE}

This study was sponsored by the National Institute of Corrections, U.S. Department of Justice. Points of view or opinions stated in this report do not necessarily represent the official position or policies of the U.S. Department of Justice. 


\section{ACKNOWLEDGEMENTS}

The authors are grateful for the contributions and support of numerous individuals who assisted in the conduct of this study and the preparation of this report. We especially appreciate the advice of James E. Murphy, Criminal Justice Consultant, College Park, MD, who helped to plan and gather information for this study, and also commented on several report drafts; Bernard Levin, NBS Center for Fire Research, who prepared the report sections on fire safety; and Peter S. Unger, CASSI, Gaithersburg, MD, who prepared most of the standards descriptions contained in Appendix B.

The helpful comments and suggestions of the following individuals who represented organizations interested in this study and who agreed to serve on a Review Committee to help develop recommendations and priorities for future activities are also greatly appreciated:

Sheriff James W. Black
Larimer County Sheriff's office
Ft. Collins, Co
Harold A. Farrier, Director
Department of Corrections
Des Moines, IA
Norma Phillips Lammers
Executive Officer
State Board of Corrections
Sacramento, CA
James E. Murphy
Criminal Justice Services
College Park, MD
William E. Prindle, II
Prindle Associates, Inc.
Clearwater, FL
Francis J. Sheridan, Director
Facilities Planning and Development
NY Dept. of Correctional Services
Albany, NY

National Sheriffs'
Association

Association of

State Corrections

Administrators

American Jail

Association

ACA Adult Detention

Committee

\begin{abstract}
AIA Committee on
Architecture in

Justice
\end{abstract}

ACA Design and

Technology

Committee

We also gratefully acknowledge many helpful comments and information received from various state and local correctional officials, architects, contractors, testing laboratories, and manufacturers during the conduct of this study. Special thanks also to Peter Smeallie, Building Research Board, National Research Council, for assisting in the collection of information.

Finally, we greatly appreciate the financial sponsorship received from the National Institute of Corrections (NIC), and the advice and encouragement obtained from NIC staff (Raymond C. Brown, Director; William K. Wilkey; Aaron A. Brown; Dennis R. Liebert; and Paul Macias). 
viii 
EXECUTIVE SUMMARY

Background

To help alleviate $\mathrm{jail}$ and prison overcrowding, over $\$ 1.5$ billion per year was spent in both 1985 and 1986 to construct new detention and correctional facilities. Because of the rapid increase in such construction and the lack of data and information on building materials, equipment and systems to be used in jails and prisons, many correctional agencies have experienced equipment and system performance problems in their facilities which, in some instances, have resulted in expensive lessons. In response to an expressed need from California and other states for assistance in addressing these problems, the National Institute of Corrections (NIC), U.S. Department of Justice, initiated a study at the Center for Building Technology, National Bureau of.Standards (NBS) in September 1986. The general objective of this study is to develop guidelines, test methods and the technical bases for standards which would assist in the selection, application, and maintenance of building materials, equipment and systems for use in detention and correctional facilities.

During the first year of this study, the primary focus has been on determining the state-of-the-art in the design and construction of detention and correctional facilities. Specific emphasis was placed on identifying performance problems associated with various materials, equipment and systems, as well as reviewing available guidelines, standards, etc. which are or can be used by architects and correctional officials in the planning and design of new correctional facilities. During the conduct of this study and the preparation of this report, valuable information, comments, and recommendations were received from many individuals involved in the planning, design and operation of jails and prisons (see Acknowledgements).

\section{Materials, Equipment and Systems}

Performance Problems. The selection of materials, equipment and systems for jails and prisons is a formidable and complex challenge for architects and correctional officials. The equipment and systems selected should match the facility's desired security, safety and supervision level(s); withstand inmate abuse; be reliable and easy to maintain, repair, and operate; and be cost effective over the useful life of the facility. If reliable performance data and information is unavailable during the selection process, the possibility of costly future repairs, modifications and maintenance is significantly increased. To perform as anticipated, equipment and systems must also be installed properly, and facility staff must be adequately trained to operate and maintain them.

Based on information collected in this study, as well as in prior studies, performance problems have occurred in a wide variety of materials, equipment and systems. Among equipment, systems, etc. frequently cited in regard to problems were: electronically controlled locking devices, electronic perimeter intrusion detection systems, security glazing, communication systems, doors and locks, fire protection systems, and lighting systems. 
Available Standards/Specifications.

The identification and review of existing standards (test methods, specifications, recommended practices, etc.) carried out for this study focused primarily on the availability of standards for: (1) physical security and safety, and (2) the various types of materials, equipment, and systems mentioned previously. A brief description of standards reviewed is contained in Appendix B of this report. Available construction specifications and state guidelines and standards for jails and prisons were also reviewed.

Perimeter and Building Systems. Descriptive information, performance data, and relevant standards and criteria details are presented herein for a majority of the important materials, components and equipment which comprise the perimeter and building systems of a detention or correctional facility. In regard to perimeter systems -- fences/gates, intrusion detection systems, closed circuit television, and exterior lighting - - are discussed. For building systems -- walls, floors/roofs, doors, windows, glazing, access controls (locks, etc.), interior lighting, fire safety, and control center (communication systems, etc.) -- are reviewed.

Conclusions/Recommendations

In general, there are only a few standards (test methods, specifications, practices) available which directly relate to special materials, equipment and systems used in detention and correctional facilities. Accordingly, when the architect and correctional official specify and select equipment and systems for a new facility, they have to rely, in most instances, on data from non-standard test methods, performance information based on prior use, recommendations from manufacturers and consultants, and their own judgement. In addition, the lack of standards makes if difficult, if not impossible, to match performance levels of the various components which comprise a particular system. Similarly, where equipment, etc. is specified for different security levels (i.e., maximum, medium, minimum), the general approach is to use prescriptive standards instead of performance standards because of the lack of performance test methods. (The various types of standards are discussed in Appendix A.)

Based on data and information presented in this study, there are many important criteria and standards which need to be developed for improving the state-of-the-art of selecting materials, equipment and systems for use in detention and correctional facilities. These criteria and standards activities, along with priorities as recommended by a review committee, are listed below.

Criteria and Standards Development Activity

- Test Methods for Locks and Access Control Systems

- Test Methods for Flaming Ignition of Mattresses

- Performance Criteria for Correctional Facilities

- Test Methods for Security Doors and Hardware
Priority

High

High

High

High 
- Laboratory Test Methods for Security Glazing

High

- Data Base - Performance of Materials, Equipment, \& Systems

High

- Specifications for Perimeter Intrusion Detection Systems

High

- Guide for the Integration of Electronic Security/

Communication/Safety Systems

Medium

- Guide for the Physical Security of Correctional Facilities

Medium

- Test Methods for Intrusion Detection Sensors \& Systems

Medium

- Specifications/Guidelines for Fire Detectors \& Alarms

Medium

- Guide for Developing Fire Emergency Plans

Medium

- Specifications for Security Lighting Fixtures

Low

- Guide for a Post-Occupancy Evaluation of a Correctional Facility

- Economic Guide or Handbook

Low

- Laboratory Test Methods for Durability of Lighting Fixtures

- Specifications for Security Fences and Gates

Low

- Revisions to the Life Safety Code

Low

- Guide for the Maintenance of Equipment and Systems

Low

Because this report is the result of an initial study to identify needed criteria and standards for materials, equipment and systems used in detention and correctional facilities, comments and suggestions on the data, information, and recommendations presented would be appreciated. Any comments and suggestions should be sent to Robert D. Dikkers, Group Leader, Building Security, National Bureau of Standards, Building 226, Room B320, Gaithersburg, MD, 20899. 
xii 
Standards for Building Materials, Equipment and Systems

Used in Detention and Correctional Facilities

\section{INTRODUCTION}

\section{A. Background}

The significant growth in the Nation's jail and prison population which has occurred over the past decade is shown in figure $1[1,2,3,4]^{1}$. As reported by the U.S. Department of Justice in 1983, the rate of growth in prisoner populations has rapidly exceeded available capacity and officials are unable to build sufficient new facilities to keep pace with the increasing number of inmates. The problems of overcrowding are compounded by the number of facilities which are deteriorating due to age. A Bureau of Justice Statistics census revealed that 35 percent of the Nation's jails and 47 percent of the prisons were built before 1950 [5].

The jail and prison overcrowding crisis has produced unprecedented spending for the construction of new facilities - over $\$ 1.5$ billion in 1985 and 1986. As shown in figure 2, construction awards for prisons have almost tripled between 1980 and 1985 [6]. California, which operates the largest prison system (about 60,000 inmates) in the U.S., has spent $\$ 2$ billion over the past three years and needs $\$ 1.4$ billion to $\$ 2.5$ billion more through the late $1980^{\prime} \mathrm{s}$ to keep pace with the need for more inmate housing. In 1982 the Ohio General Assembly authorized $\$ 638$ million to construct twelve new institutions (9,083 additional beds) [7]. Recently the Massachusetts legislature approved a $\$ 213$ million bill to increase the number of prison beds by $2,000[8]$.

Because of the rapid increase in new jail and prison construction, and the lack of information on building materials, equipment and systems to be used in such facilities, some expensive lessons have been learned by correctional officials. The impact of some new techniques and technologies has been a mixed success. In 1986 the President of the American Correctional Association stated: "Our headlong rush to replace poorly designed, antiquated, and unconstitutional institutions with the new architecture of the 1970's, without considering the staffing and budgetary effects, led in many cases to modern, spacious, and privacy-conscious facilities that were doomed to constant understaffing, and becoming modern, but unconstitutional, facilities [9]."

1. Numbers in brackets pertain to references listed in Section VI of this report. 


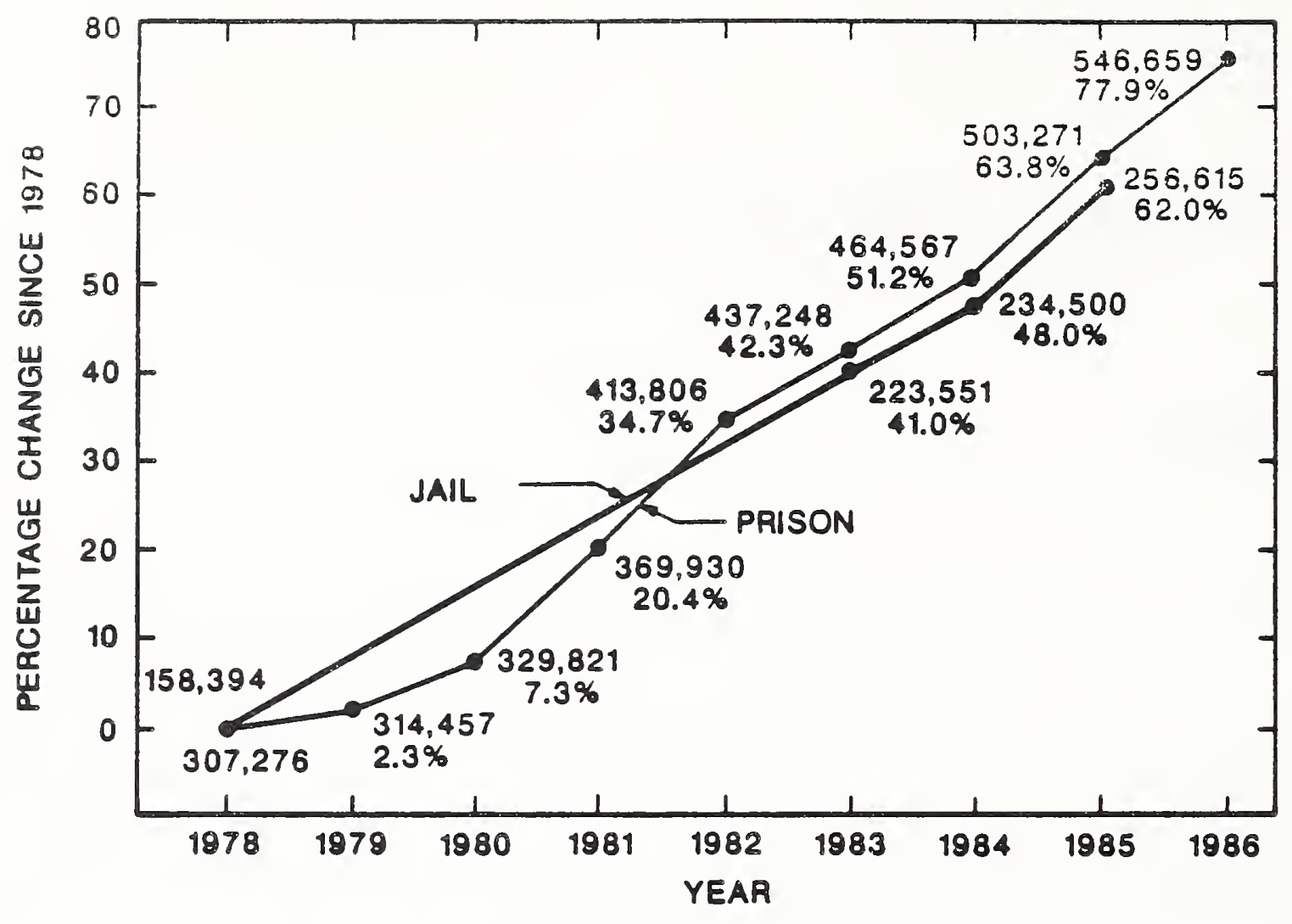

Figure 1. Jail and Prison Population (1978 - 1986)

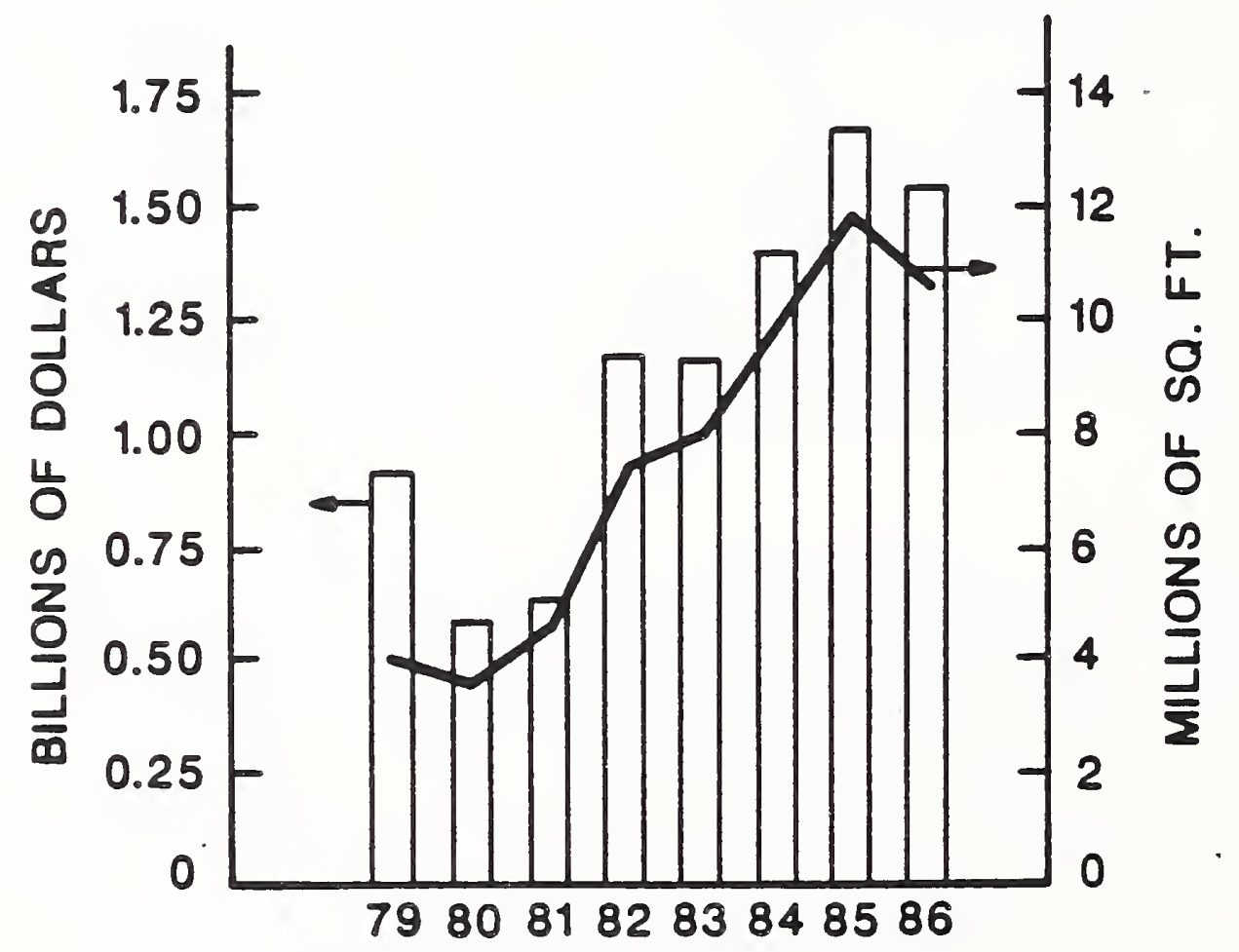

Sources: ENR, F.W.Dodge

Figure 2. Total U.S. Contract Awards for Prisons (From Reference 6) 
The California State Board of Corrections wrote to the National Bureau of Standards (NBS) in 1985 requesting possible assistance to help develop performance criteria and standards which would aid California as well as other state and local jurisdictions in evaluating new equipment and systerns (glazing, locks, communication, alarms, etc.) for jail and prison construction [10]. As a result of expressed interest by the Center of Building Technology (CBT) at the NBS to assist by conducting research which would provide the technical bases for needed standards, California also canvassed seventeen other states to determine their support for a national standards development program. Nine states (Alaska, Florida, Hawaii, Michigan, Minnesota, Ohio, Pennsylvania, Texas, Washington) responded to the California canvas letter. All states reported they were investing substantial sums in prison and jail construction -- amounts ranged from $\$ 56$ million to $\$ 650$ million. With regard to the type of failures experienced in technology and hardware, the following items were mentioned: electronically controlled locking devices, security glazing, and communication and lighting systems. All nine states felt that a national standards and testing program would be very valuable.

\section{B. Objectives and Scope of NBS Study}

In September 1986, based on the above background, the National Institute of Corrections (NIC), U.S. Department of Justice, funded a study to be conducted at the Center for Building. Technology, National Bureau of Standards. The general objective is to develop guidelines, test methods and the technical bases for standards to assist in the selection, application, and maintenance of building materials, equipment and systems used in detention and correctional facilities ${ }^{2}$.

During the first year of this study, the primary focus has been on determining the state-of-the-art in the design and construction of correctional facilities. Specific emphases were placed on identifying performance $^{3}$ problems associated with various materials, equipment and systems, as well as reviewing available guidelines, standards, etc. intended to assist architects and correctional officials in planning and designing new correctional facilities. As a result of this first year's efforts, specific recommendations are being made concerning future activities which

2. Although it is recognized that jails or detention facilities and prisons or correctional facilities are significantly different in their mission and management, this report generally uses "correctional facilities" when referring to both $\mathrm{j}$ ails and prisons.

3. In this report, "performance" is viewed as the fulfillment, in a functional sense, of the material, equipment or system. Performance is effected by many factors during the design/construction process. These factors include design, selection, specification, and application of the materials, equipment, and systems; installation, and use. Accordingly, performance problems may result from any one or a combination of these factors. 
should be carried out to aid governmental agencies (local, state and federal) in reducing design, construction and operational costs for correctional facilities, and to help improve the security, safety, and durability of these facilities. Accordingly, the main activities during this first year have been:

1. Collection and review of performance data and information (typical problems, test data, etc.) on building materials, equipment, and systems used in correctional facilities.

2. Collection and review of existing standards (test methods, specifications, recommended practices, etc.) which are being used (or which could be used) in the design and construction of correctional facilities.

Data and information relating to the first activity were obtained by: 1) a review of published literature and other sources available at the NIC Information Center, Boulder, Colorado, and the National Institute of Justice(NIJ)/National Criminal Justice Reference Service, Rockville, Maryland; and 2) discussions and correspondence with architects, engineers, contractors, manufacturers, testing laboratories, state purchasing officials, and correctional officials (local, state, and Federal).

Existing standards were identified primarily through the resources of the NBS National Center for Standards and Certification Information (NCSCI). NCSCI has virtually a complete set of standards, either hard copy or on microfilm, of all documents of the major national and international standards writing bodies. Several construction specifications for correctional facilities, prepared by private architectural and engineering firms, were also reviewed. Copies of some state Departments of Corrections design and construction guidelines and state Jail Standards were also reviewed.

Section II of this report presents information on the planning, design and construction of correctional facilities including a brief discussion of facility security levels. The primary intent of this section is to provide some background on important planning considerations which may directly affect the selection of materials, equipment and systems.

Section III reviews available information on the performance of various materials, equipment, and systems, and describes some current guidelines and standards for designing, testing and specifying these systems in correctional facilities.

Based on the information presented in Sections II and III, Section IV contains discussions and related conclusions concerning future criteria and standards development activities which need to be carried out to assist architects, engineers, and correctional officials in the planning, design, and construction of correctional facilities. Section $V$ presents recommended priorities for carrying out these future activities. 
General information on standards (types of standards, organizations involved, benefits of standardization) is contained in Appendix A. Brief descriptive information on various standards reviewed in this study is contained in Appendix B. 
A. Facility Development Process

The various phases of the jail and prison planning, design, and construction process are well documented in guides such as NIC's planning of Ner, Institutions [11]; American Correctional Association's Design Guide for Secure Adult Correctional Facilities [12]; state produced guides such as Nebraska Jail Standard Board's Jail Planning and Construction Guide [13] and the More for LeSS - Jail Construction Cost Management Handbook [14] from the State of California Board of Corrections; and other texts such as Correctional Facility Planning and Design [15]. The facility development process will vary according to the size and nature of the project, but the organizational principles will generally remain the same. The process begins when a jurisdiction recognizes the need for additional detention or correctional space, and ends when this need has been met with new, expanded or remodeled facilities. A brief description of important phases in this process is given in the following sections.

1. Needs Assessment

At the outset of an effort to construct a facility, an assessment is made to fully understand the breadth and the specifics of a project. Typically, a committee that includes policy makers for the facility, liaisons from the county or state criminal justice and planning divisions, public sector representatives, and architectural and engineering consultants is formed to perform this study. The study typically includes a definition of both immediate and long term needs; an analysis of existing facilities; inmate population projections; an examination of how the needs tie in with the existing criminal justice system policies and procedures, and a consideration of anticipated system changes.

\section{Master Plan}

Alternative methods of meeting the needs identified in the needs assessment study are incorporated into a master plan. Among alternatives considered and documented in the master plan are site selection, expansion or remodeling of existing facilities, costs, and current and future dollar resources. Visits to other recently constructed facilities are often conducted during this phase in order to explore alternatives ways of meeting needs.

\section{Mission Statement}

Based on previous planning decisions, a project or "mission" statement is developed to address the purpose of the institution (who will use and operate the facility, what type(s) of offenders are to be incarcerated), the responsibilities of the jail or prison (security, safety, programs, and services) and the philosophical direction which will govern the operation of the facility. The statement should cover all of the owner's needs and objectives, and provide a base for decisions to be made during the remaining phases of the project. 
Policy and operating procedures for the facility are the primary driving forces in setting priorities and giving definition to the architectural program. The program should define the way the facility will function; describe all the spaces and the activities to take place in those spaces; and the relationships between particular spaces. In brief, this programming phase translates the mission statement into information the architect needs to proceed with the design phases.

5. Schematic Design and Design Development

In the schematic design phase, spaces are articulated into an overall scheme and defined in terms of size, shape, and relationships. Site plans, floox plans, elevations, and major building sections are developed. During, this phase, the owner/user receives the first indication of how the facility will perform in regard to functional and organizational expectations [14]. The owner will also obtain a conceptual indication of the building/facility form and overall appearance.

Staffing is the most expensive aspect of life-cycle costs -- over 60\% (Fig. 3). Good design and equipment choices leading to a communicative, visible environment can ease these costs. Space relationships should be organized carefully in response to staff/inmate functions and use patterns. Efficiently separated and/or well circulating space must be articulated among entering/exiting, sleeping, feeding, exercise, counseling, heating, ventilation, and air conditioning (HVAC), storage, program, and service spaces. With the security focus, circulation patterns become more complex and spatial relationships must be scrutinized for potential difficulties and opportunities. The large number of daily admissions and releases in some jails also pose special design considerations.

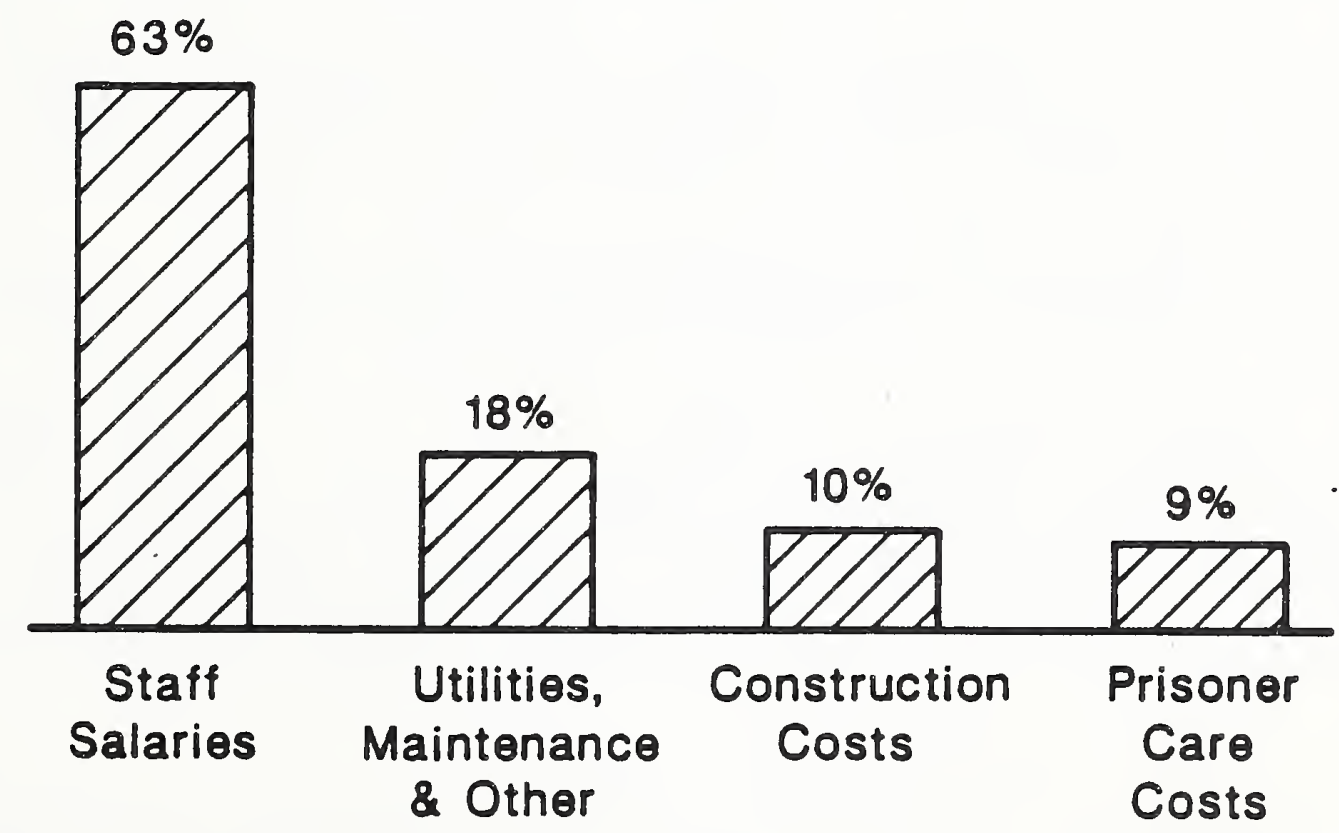

Figure 3. Thirty-Year Life Cycle Costs of a Constitutional Jail (from Reference 16) 
Security, of course, is a primary design consideration. A well designed facility can often respond to security concerns through a careful consideration of functional relationships. The concept of cell clusters around a common space may allow for a reduction in staff for supervision purposes and facilitate more staff/inmate interactions. Some authorities believe physical barriers should be kept to the absolute minimum and physical and visual interaction between a professional staff and inmates encouraged [17]. Likewise, other spatial concepts which could increase security could be considered for possible development in space planning. Locating maximum security spaces within a building's center with lesser security areas organized in relation to the approach toward the building's exterior envelope can assist in providing a secure condition through spatial control of the facility's operations and inmate circulation.

Other facility design considerations include: flexibility and expandability; construction and operating costs; energy considerations, accessibility; and applicable standards. During the design development phase, more detailed drawings are produced and the final image/appearance and characteristics of the facility emerge.

Selection of Materials. Equipment, and Systems. Most of the decisions regarding major materials, equipment, and systems to be used in the facility should be made during the schematic and design development phases. Since the function and the operating costs of the facility are directly affected by the equipment, etc. selected, these decisions are very important.

The maximum security (a term used frequently to denote the highest level of security) population is the most expensive and difficult to house, but accounts for only 5-15\% of a correctional systems population. About one third of the population is in the minimum security category which requires little in the way of special design and construction considerations and hence is less costly to build. Because "maximum" security hardware and equipment is usually more expensive than the "medium" security type, choosing the correct number of each type for a facility is important.

The current and future use of the facility must be examined to accurately and efficiently design and specify space and equipment. How a facility is used over its lifetime varies dependent on its type. For instance, State and Federal institutions tend to retain their security classifications (i.e., maximum. medium, minimum) throughout their useful life. (In some instances, this life has exceeded 100 years. ${ }^{4}$ ) When a medium security institution becomes overcrowded, a new medium security institution is built to relieve the overcrowding conditions. County jails may begin their operation with various security classifications in an uncrowded condition.

4. In 1984, 11.88 of State prison inmates were housed in facilities over 100 years old, and 22.78 were housed in facilities that were 50 to 99 years old. (Data from "Population Density in State Prisons," U.S. Department of Justice, Bureau of Justice Statistics, Special Report NCJ10324, December 1986.) 
Over time, as the jail becomes overcrowded, minimum risk offenders tend to become eligible for pre-trial release and non-jail dispositions while higher risk inmates may be placed in reduced custody housing. Architects and owners should plan for this eventuality and be prepared to either upgrade reduced custody housing for higher security risk inmates or add additional space for the needed classification.

Utility and maintenance costs are about 208 of facility operating costs over a 30-year period (see Fig. 3) [16]. Correctional facilities are built with repetitive, conventional materials and processes as much as possible in order to keep initial and life cycle costs low. Security, safety, maintenance, appearance and interfaces with other building systems are criteria which should guide the selection of many materials and components. In choosing doors, locks, glazing, lighting fixtures, etc., many trade-offs between these different criteria must be considered. An inexpensive security system that needs constant repair is not only expensive but unreliable. The initial intended use of a security system, a locking device or a door may be insufficient in terms of total life and future use of the facility. Decision making based solely on short-term considerations can lead to the need for expensive renovations or premature replacements.

In addition to carefully organized spatial relationships, dependable communication systems are necessary for an efficient, safe and secure facility. Care must be taken to insure that the correct system(s) for the intended use is specified and installed and maintained by competent individuals. The "correctness of fit" between a communication or any other security system and the operating and maintenance personnel may require a simple system. For instance, small county jails may not have the staff expertise or resources to maintain or operate complex electronic security systems. In these instances, the architect should explore the system options with the user to ensure that the final design plan is practical to implement.

Special concerns relating not only to security but also life safety requirements must be kept in mind when designing the facility and choosing equipment. Problem areas include light fixtures, smoke detectors, sprinklers, finishes, plumbing, and HVAC systems. Noise control, which lowers stress levels, is another important consideration that relates to creating a secure, safe and humane environment.

\section{Construction}

After the completion of final drawings and specifications, the construction phase of the project is usually bid and managed in one of three primary ways. A conventional construction contract, a construction management method or a phased (fast track) system may be utilized depending upon the management style and the nature of the committee, the budget, and the time schedule.

A conventional construction contract is typically awarded to the general contractor who is the lowest bidder for the work to be performed. The general contractor's price is based on estimates from his subcontractors who 
will perform most of the work. The general contractor is responsible for completing the project within the agreed upon schedule and price. The single point responsibility/single contact is an advantage, but this is usually the slowest approach to construction.

If the corrections facility committee lacks the resources to coordinate the initial phases of planning, a construction manager or construction management firm may be hired as the owner's agent to begin and complete necessary tasks associated with management of the planning and construction phases. The committee takes on almost a consulting or advisory role, and bidding only occurs on the subcontractor level after the construction management firm has been chosen.

An option currently popular for corrections construction, because of population pressure, is the phased or fast track method. It is a multiple contract procedure that, when organized successfully, is very fast because it overlaps activities in the work schedule that would otherwise be done sequentially. A construction management firm is usually engaged to coordinate the multiple contracts and receives a fixed fee for their work.

Through numerous discussions (as a part of this study) with security equipment manufacturers, architects and contractors experienced in the design and construction of correctional facilities, it was found that testing of equipment and building components prior to and during construction of correctional facilities remains a nebulous issue. In different construction management situations, different representatives are responsible for the testing and its interpretation. Research indicates that construction schedules are slowed by testing and reordering for equipment and systems that fail to meet given requirements. Also, field testing or the failure to test, may result in costly maintenance and replacement tasks after construction completion. Obviously, available standards and performance tests should be reviewed in the earliest stages of design, and testing performed before the start of construction or during the earliest possible stages of construction.

\section{B. Security Levels}

Security for a correctional facility (or any other facility) is a composite system made up of people, physical components and equipment, and policies and procedures. In order for the desired security to be achieved, there must be effective interactive relationships between all parts. If one part should fail or malfunction, the other parts of the security system should respond or compensate for the failed part. These interrelationship are particularly important in contemporary correctional facilities, since designers attempt to achieve "a reasonable balance...between the security features of a secure correctional facility and an architectural environment that projects a spirit of openness and reconciliation [17]."

The elements of good security systems used in jails and prisons are similar. Both require well-trained officers in sufficient numbers, well-designed physical plants, clear-cut rules and procedures, good supervision, communication, fire and safety systems, etc. Both types of facilities 
endeavor to implement security classification systems. When inmates arrive at a prison, they usually have a history of incarceration. However, in a jail, little or nothing is known about new inmates except the cause of arrest [18]. This challenge has prompted one sheriff to suggest, "If we could afford it, we would build everything for maximum security."

The definition and number of security and custody levels for $j a i l s$ and prisons varies among different jurisdictions (local, state, and Federal) and sometimes within the same system. For prisons, NIC has defined security and custody levels as follows [19]:

- Security level -- the type of physical (architectural, environmental) constraints.

- Custody level -- the degree of staff supervision and control provided.

The five different levels of security described by NIC are: Maximum, Close, Medium, Minimum, and Community [19]. Often, different areas of a single institution provide different security levels. The use of measures such as perimeter security, existence and operation of towers, use of external patrols and detection devices, and housing arrangements, to differentiate institutions by security levels is shown in Table 1. Custody level relates to the amount and type of supervision and control provided an inmate during different activities such as movement within the facility for meals, recreation, work, other programs, and leaving institution grounds.

As indicated in Table 1 , an inmate placed in a maximum security setting would ordinarily be housed in a single occupancy, inside cell -- a cell which is contained on all sides within the cellblock or housing unit. (Such an interior location would suggest overhead and indirect daylighting concepts, influencing the building form and vertical organization.) If the inmate escapes from the cell, he/she is still confined to the housing unit. This is one example of the security zone or perimeter concept. Additional zones may be used to help reduce the possibility of escape. Because of site and cost limitations, most facilities will not contain more than four zone types [20]. By order of increasing size, they are:

- Cell - Typically walls, windows, doors, and locking system with electrical indication.

- Housing Unit -- Walls, windows, doors, locking system, electrical indication, electronic monitoring.

- Building Perimeter -- Walls, windows, doors, locking systems, electrical indication, electronic surveillance.

- Site -- Wall, fence, electronic surveillance, human surveillance. 


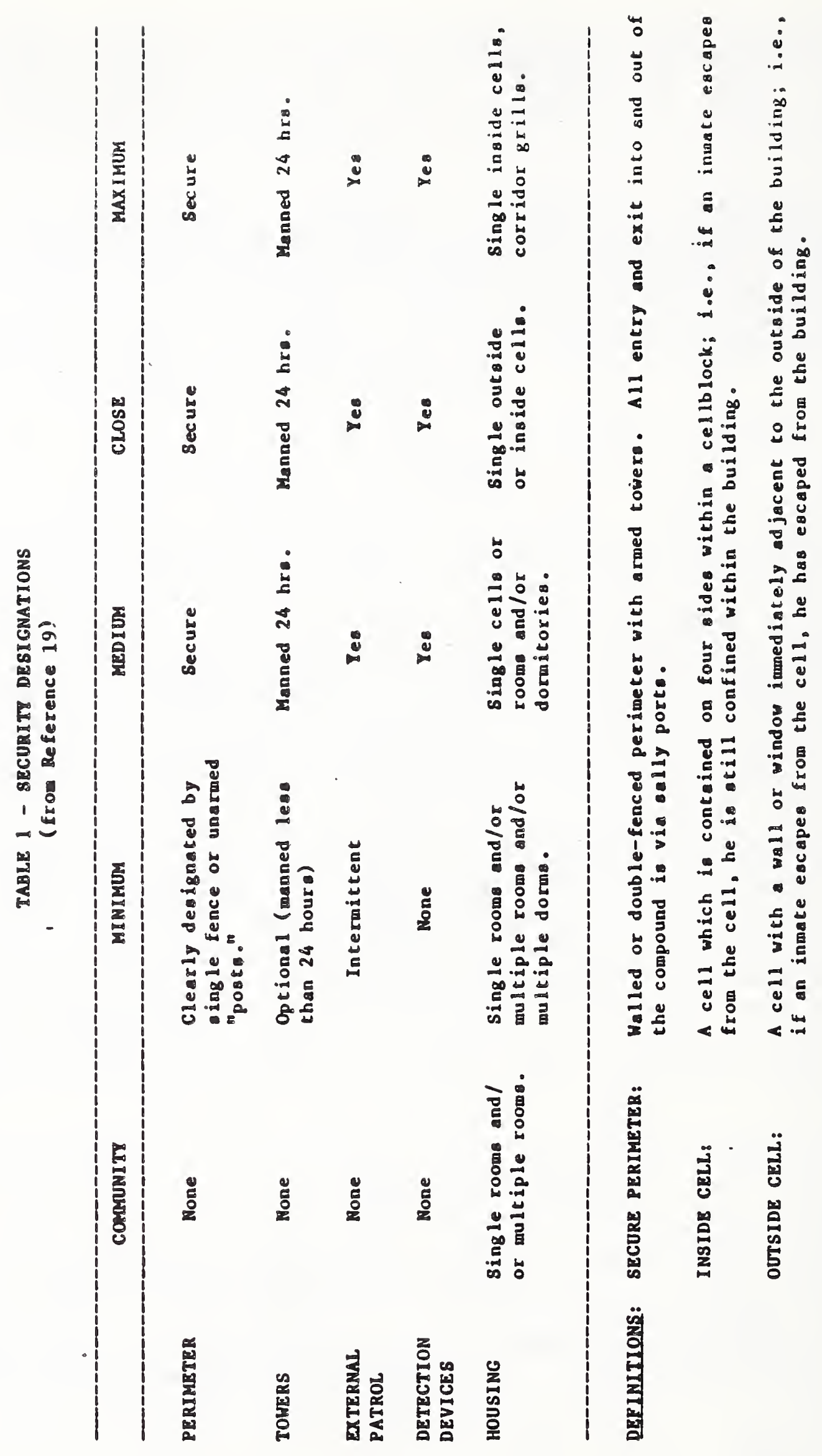


Multiple zones mean multiple delays to escape and/or break in attempts, and multiple opportunities to detect security barrier penetrations, thereby buying time and increasing security by additional intervention opportunities by staff.

\section{ACA Standards}

The standards established by the American Correctional Association (ACA) are generally accepted as benchmarks for the evaluation of correctional facilities and their services. The ACA's goals are: to promote more humane conditions in institutions, to ensure the safety of staff and inmates, and ultimately provide the programs and services necessary to assist offenders in returning to society.

In an effort to motivate jurisdictions undertaking new correction construction to develop more effective institutions and to improve the quality of old institutions, the ACA has developed an accreditation program under which many local, state, and federal institutions have sought to be accredited. Certain standards relating to life, health and safety issues have been labeled 'mandatory' and must be complied with to receive accreditation. All ACA corrections standards now fall into two categories-mandatory and non-mandatory. Currently, accreditation policy requires compliance with $100 \%$ of all applicable mandatory standards and $90 \%$ of all applicable non-mandatory standards .

The ACA has developed standards for the following:

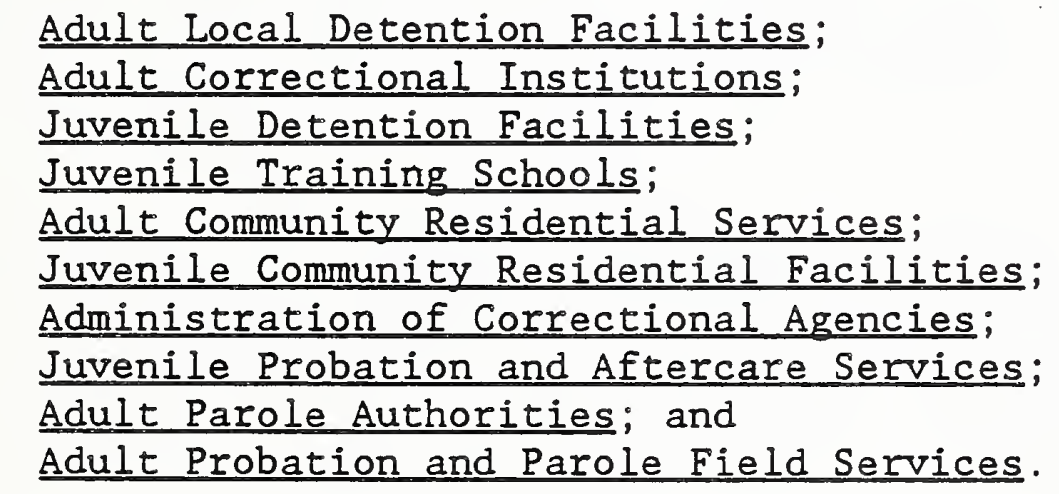

The ACA is very aware of the need for updating and revising their material as new ideas and materials need to be addressed and/or as clarification is necessary and appropriate. The Corrections Standards Supplement [21] includes a form that encourages proposed revisions to the ACA standards. Approximately $15 \%$ of the 495 standards contained in Standards for Adult Correctional Institutions [22] pertain to the physical plant, safety and emergency procedures, and security and control. 
III. Materials, Equipment and Systems

A. Introduction

Architects and correctional officials face a formidable and complex challenge in the selection of materials, equipment and systems for jails and prisons. They must try to select products and systems which will match the facility's desired security, safety and supervision level(s), be reliable and easy to maintain, repair, and operate; withstand inmate abuse; and be cost effective over the useful life of the facility. Changes and improvements in technology (i.e., electronic detection and surveillance systems, computer equipment, security glazing, locking devices) may offer considerable opportunities to reduce operating costs; however, the expected benefits may not be realized if reliable performance data and information is unavailable during the selection process. Also, anticipated equipment and system performance will not be realized unless they are installed properly, and available staff is adequately trained to operate and maintain it.

According to one architect who has designed many correctional facilities, "It's not possible for any architect, no matter how knowledgeable, to say, 'We know all the technology in the field,' because at that moment, there's more, newer material coming out. The technology is arriving so fast that it usually falls to the specialist architect to track it and evaluate it. [23]"

In regard to above mentioned challenges, the following pertinent comments were made by the screening juries for the annual exhibits (1983 - 1985) of justice facility projects sponsored by the American Institute of Architects (AIA) and the ACA:

- 1983 -" "we note an overuse of high-security fixtures and equipment where they are not required or desirable -- high-security fixtures are expensive to install and maintain, and are often inhuman in scale and material;" and "increased awareness and application of the life-cycle cost analyses of materials is needed with respect to maintenance and energy use" [24].

- 1984 - "the jury notices continued examples of overbuilding and of extremely expensive cell and dayroom hardware when experience and example show that cheaper options are available and effective" [25].

- 1985 - "the matexials selected for interior surfaces, furniture and hardware are still sometimes inappropriate to the security level and hamper efforts to achieve normalized environments" [26].

The National. Institute of Justice (NIJ) has recently launched a new corrections construction initiative that shares practical ideas on creative methods to prevent convicted serious criminals from preying on people, communities, and our economy. A key element of this initiative is the 
National Directory of Corrections Construction. The first edition of this directory [27] contains descriptions of designs, construction methods and costs for 102 jails and prisons built between 1978 and June 1986. It also contains brief reports on factors which architects indicated strongly influenced costs and length of time required for completion of the facility. For over one-third of the facilities described in the directory, architects reported that complex electronic, mechanical and electrical systems were negative factors which influenced both costs and time schedules.

As mentioned in Section I.A of this report, various corrections departments have also experienced problems with the performance of different materials, equipment, and systems. As a result, they have had to make costly repairs, modifications, or replacements of the faulty or failed materials or equipment. The next section will describe some performance problems identified in this study or previously reported in the literature. Since the focus of this study is. on the identification of needed standards (test methods, specifications, etc.) for improving the selection of materials, equipment, and systems for correctional facilities, major attention is given to problems or deficiencies, not successful applications. Accordingly, one should not infer from this report that problems exist in all correctional institutions or with all types of materials, components or systems.

\section{B. Performance Problems}

Innumerable "horror stories" can be found in the literature and heard in discussions with correctional officials where improper selection or installation of equipment has resulted in inmates escaping. and/or costly facility repairs and renovations. For example, in one jail, glazing could be melted when inmates had direct access to the windows and had long periods of time without staff supervision. The same windows had frames that so weak they could be pushed out of the wall. In another jail, inmates could cause beds to come loose from the wall by jumping on the edge of them. The beds could then be thrown through the windows and the inmates escape. Inmates were able to escape from another facility by removing an unreinforced concrete block from an exterior wall by chipping away with a shower head and steel shanks. A correctional official has also reported that heavy duty lighting fixtures. were installed to prevent inmate vandalism, but the "ceilings almost weren't strong enough to support them."

Two Department of Justice (DOJ) studies on jail and prison design and construction, published in 1985, contain more complete information on performance problems encountered in new facilities [28,29]. In one study [28], the authors (Dale K. Sechrest and Shelley K. Price) conducted a survey in cooperation with 15 state departments of corrections. All the facilities covered in this survey were occupied after 1977, most having been opened in 1981. The testing, selection, operation and maintenance of durable, efficient and cost-saving hardware and equipment posed a problem for almost all of the institutions surveyed. Among the problems reported were: 
"No reinforcing bars in critical security areas;

"Breakage and maintenance problems resulting from use of traditional building materials such as screws, door hinges, and window stops inappropriately matched with components;

"Doors too heavy for frames;

"Awkward placement of control panels, thermostats and lighting controls; and

"Lack of communication/speaker systems."

A major concern for two-thirds of the respondents was with electronic security systems. In most cases, door control systems had never operated as expected and required constant maintenance and repair. Security perimeter systems were reported as problems in one-half of the institutions. Frequent false alarms symptomized these problems. The overriding concern was with the complexity, difficult maintenance and the cost of using electronic perimeter security systems. Problems with window construction -- glazing, casing, framing, etc. -- were also reported by over one-half the respondents.

A particular difficulty was the identification and selection of hardware and fixtures (e.g., lighting, temperature regulation and locks) that will withstand inmate abuse. Dismantling fixtures and furnishings for use as weapons, or vandalism for no reason were problems cited. As the authors [28] point out, "this relates to defining needs for the materials and hardware to be used in the facilities, the testing of components to establish specifications and, perhaps the most crucial, achieving a match between facility needs and capabilities."

In the other DOJ sponsored study [29], KIMME Planning \& Architecture surveyed 255 jails of 50 beds or less ("small jails"), opened since 1974. The frequency and severity of some of the facility problems reported in this study are listed on the next page. 


\begin{tabular}{ll} 
Facility & Seriousness \\
Problems & of Facility \\
Frequency $(8) *$ & Problems $(8) * * 4$ \\
\hline
\end{tabular}

- Equipment failures 63

- Obtaining replacement parts for equipment 50

- Durability of building materials \& hardware

- Cell window frames \& glass

* - $z$ of respondents answering "yes".

** - $z$ of respondents citing very or somewhat serious problems.

Because about one-half of the small jails do not have cell windows, the author points out that the percentages shown for cell window frames and glass would be almost double that indicated.

In conjunction with this NBS study, various state correctional officials were asked whether they had experienced any significant performance problems or failures with various materials, equipment and systems in jails and prisons. Selected responses received are contained in the following paragraphs :

\section{State A}

"Communication system descriptions are vague and do not always specify its activation capability, or more simply, 'who can initiate conversation with whom.' The term 'intercom' is frequently used, but with several different connotations. Along these same lines, it is difficult to assess the adequacy of sound transmission for the various communication devices used for visitation areas;

"Fire protection systems present similar problems. We find it difficult to determine exactly what the selected equipment will do. Information gleaned from the specifications and drawing legends is often brief and incomplete;

"Selection of glazing, doors, frames, hinges, locks for use in an area or cell must be reviewed for their appropriateness for the security level and type of inmate use/abuse that is anticipated. They must also be considered as a system in reference to their compatibility with one another to maintain the desired security level. Levels of security (minimum, medium, maximum) have numerous meanings and are applied differently by various manufacturers in the item descriptions. 
Therefore, it is difficult to determine if materials selected are appropriate for the areas in question;

"HVAC systems have proven difficult to assess concerning the adequacy of air exchange and the capability of providing sound separation between appropriate prisoner classifications, e.g., males and females; and,

"Finishes are difficult to assess their toxicity in relation to their intended use, and lighting fixtures in reference to the level of light that will be provided based upon proposed location."

\section{State B}

"We have experienced problems with a variety of products and materials; however, the most difficult to solve and often potentially the most dangerous are with electric door locking devices and electronic surveillance equipment. Because of the complexity of this equipment, it can require a great deal of time to solve a malfunction and an even greater period of time to make certain the solution has in fact worked. At one of our recently opened institutions we have had a series of failures with our sliding doors. These doors receive heavy use and the failures have been primarily of a mechanical nature (broken clutches, loose sprockets, bad welds, missing set screw, etc.), and seem to be a combination of under design and poor craftsmanship at the factory. Other recurring problems we have experienced are false readings from door position indicator switches on swinging electric doors, blown fuses on programmable controllers for electric cell locks and protracted problems with perimeter fence motion detection systems (false warnings, dead zones, etc.)."

\section{State C}

"I think the number one problem is plumbing. The valves on push button showers, toilets and laboratories. The chemical build up from the water clogs up the valves. In a lot of instances it is impossible to obtain parts. Most local plumbers can't or won't work on this type of plumbing and a lot of times access to pipes is limited.

"Some of our jails built in the '70's had windows that had to concreted over or closed in some other manner because of escapes. Of course, this left little or no natural light to these areas causing the jail to fail inspection." 
"In general we have had no significant performance problems with any systems, materials or equipment used.

"Some materials where a change in use has occurred are:

"Wire glass - used only where required by code - in the past was used in more areas but it was determined to be a dangerous material (causes major injury when broken and person tries to retract from it) and the cause of litigation.

"Barbed Tape Obstacle - original manufactured design failed due to climatic conditions (collapsed due to wind, snow and ice). Manufacturer changed design and material to rectify problem.

"Casement windows (standard off the shelf models) discontinued use because operators were used to make weapons.

"Lay-in-ceilings - discontinued use in inmate areas due to problem with contraband.

"Other minor issues have come up but nothing major. We have found that in a correctional system that is very conservative in terms of security, we have been able to apply currently available technology, materials, equipment and systems in a creative manner to successfully satisfy their needs."

Discussions with architects, engineers, and contractors experienced in the design and construction of correctional facilities and with security consultants and security equipment manufacturers' representatives has also confirmed the existence of problems identified by state correctional officials as well as others.

The architect is often not directly involved with specifying either the security equipment to be used, or criteria guiding its installation and maintenance (i.e., security consultants are frequently hired to do such specialty work). Often too, there is a lack of communication among the architect, owner and security consultant. Given these conditions, the opportunity for the architect to properly integrate the security equipment and systems with the building's intended use patterns, material and component capabilities, or mechanical and electrical systems is diminished. Also it was revealed that because initial and life cycle cost estimates in the facilities' budgets are low, designers are forced to use standard, low cost materials and equipment that lend themselves to quick and easy construction. Use of nonconventional materials or products or unusual spatial configurations, which may improve security conditions but also may increase cost, are not typically attempted.

Often the program given to the design professional at the onset of the project does not address the overcrowded conditions that tend to prevail after the facility is in use. Consequently, materials, equipment, and 
size/configuration of spaces are designed and specified to a lower density use pattern than actually occurs.

As mentioned previously, on-site performance testing of security equipment often leads to delays when failure occurs. Architects and contractors would like to see standard testing procedures developed and used throughout the security equipment industry. Such test procedures could also provide an uniform basis for laboratory testing in addition to field testing.

Architects and contractors noted that the unreliability of electronic security systems as a major problem. Most felt the problem had to do with system fabrication and installation. Architects also felt that they often had insufficient knowledge of electronic security system operation and performance to specify the appropriate system and to properly integrate it with the other building systems. This condition often suggests the involvement of a security systems consultant. Electronic security systems are frequently installed by a security system subcontractor, not an electrical subcontractor. Because the system, when installed, is usually not subject to inspections for code compliance, it is difficult to enforce standards of accepted practice for such installations.

\section{Available Standards/Guide Specifications}

The identification and review of existing standards (test methods, specifications, recommended practices, etc.) carried out for this study focussed primarily on the availability of standards for: (1) physical security and safety, and (2) the various types of materials, equipment, and systems discussed in the previous section on performance problems. During this standards search, about 300 standards and related documents from over 40 organizations were originally identified. Of these, about one-half were then selected and reviewed for their applicability and suitability for correctional facility needs. In the standards search as well as in this report, no attempt has been made to prepare a complete list or discussion of all standards which may be applicable to correctional facility design or construction. Such a list and discussion would be very lengthy since hundreds of standards for conventional building materials, equipment and systems exist (see appendices A and B), and many are generally satisfactory for testing or specifying such materials, etc. for use in appropriate areas of a correctional facility (depending on the required level of security, etc.).

In addition to the identification and review of standards, a limited number of construction specifications for federal and state correctional facilities, which were prepared by private architectural and engineering firms, were reviewed. Available state guidelines for the design and construction of correctional facilities as well as state jail standards were also examined. Two states (California and New York) have prepared comprehensive guidelines (i.e., design criteria and guide specifications) for correctional facilities $[30,31]$. The several jail standards reviewed were generally similar in content to the ACA standards mentioned previously; however, a few did contain specific requirements for certain types of materials and equipment. 


\section{Perimeter Systems}

1. General

Correctional facility designers increasingly rely on a strong, extremely secure perimeter system around the institution. This is especially true of institutions located in rural areas. The four major elements of perimeter security systems -- fences/walls, towers, electronic detection, and perimeter patrols -- are used with different degrees of frequency in institutions with different security levels (see Table 2) [32].

As indicated in Table 2, maximum and medium security institutions rely substantially on all four elements. One of the most common contemporary perimeter systems for a medium security institution is a double fence and integral electronic intrusion alarm devices, coupled with coils of barbed or razor tape, and mobile patrols [12].

TABLE 2

Types of Perimeter and Prison Security Levels (from Reference 32)

\begin{tabular}{|c|c|c|c|c|}
\hline \multirow{3}{*}{ Perimeter types } & \multicolumn{3}{|c|}{ Prison Security Levels } & \multirow[b]{2}{*}{ Total } \\
\hline & Maximum & Medium & Minimum & \\
\hline & No. 8 & No. & No. & No. \\
\hline Fence/wall & $\overline{164(92.7)}$ & $244(89.4)$ & $129(28.5)$ & $537(59.4)$ \\
\hline Towers & $142(80.2)$ & $183(67.0)$ & $12(2.6)$ & $337(37.4)$ \\
\hline Detection & $68(38.4)$ & $101(37.0)$ & $12(2.6)$ & $181(20.0)$ \\
\hline Patrols & $154(87.0)$ & $232(85.0)$ & $265(58.5)$ & $651(72.0)$ \\
\hline Total institutions & $177(19.6)$ & $273(30.2)$ & $453(50.2)$ & $903(100.0)$ \\
\hline
\end{tabular}

To provide good surveillance, adequate "buffer zones" are suggested both inside and outside the secure compound. Recommendations [12] suggest that the minimum distance between the outer perimeter fence and the institution's property lines be at least 300 feet, but the preferred distance is 600 feet. Similarly, for good surveillance inside the compound, the desired minimum distance between buildings and the inner perimeter is 150 feet of unobstructed space.

With regard to perimeter security, the ACA Standards for Adult Correctional Institutions [22] contains several standards which require: the institution's perimeter to be controlled by appropriate means; the surveillance of all areas adjacent to the perimeter; and limitations on pedestrian and vehicular entrances and exits in the perimeter (Standards 24177 through 2-4180). 


\section{Fences/Gates}

The primary purpose of barriers such as fences and walls is to increase the time it takes for an inmate (or other person) to escape (or enter) the facility. The delay systems (barriers) must provide sufficient time after detection to allow the facility staff to arrive. One of the most common types of perimeter barriers is chain link fencing with gates of comparable materials. Available data [33] suggests that the delay time (penetration) for a single chain link fence is no more than one-half of one minute. The addition of barbed tape coils or obstacles placed on and near the fence will about double the delay time.

Contemporary medium security institutions are usually surrounded by two chain link fences, a minimum of 12 feet high [12]. When topped by a barbed tape coil ( 30 inch diameter), the total fence height is about 14 feet. The two fences should be placed about 20 to 30 feet apart to prevent potential escapees from jumping from one fence to the other, or from straddling the fences with ladders or other devices. When changes in directions of the fence line are required, they should be angled (not curved) to prevent blind spots along the fence line. To inhibit tunneling or pushing out the fence at the bottom, a concrete grade beam should be installed at the base of the inner fence and the bottom horizontal rail should be anchored to the grade beam.

Correctional facility guidelines and specifications which were reviewed generally contained requirements for fence fabric, fence posts and rails, barbed wire and tape which were similar to.the following:

- Fence fabric - No. 9 gage (0.148 inch diameter) steel wire, 2-inch mesh; finish -- zinc, aluminum, or PVC coating.

- Line Posts - Galvanized steel pipe (or equivalent tubing), minimum outside diameter of 2.875 inches; minimum weight, $3.65 \mathrm{lb}$ per lin. ft.

- Terminal Posts (End. Corner, or Gate) - Galvanized steel pipe (or equivalent tubing), minimum outside diameter of 4.0 inches; minimum weight, $9.1 \mathrm{lb}$ per lin. ft.

- Rails \& Post Braces - Galvanized steel pipe (or equivalent tubing), minimum outside diameter of 1.66 to 2.375 inches.

- Barbed Wire - Two strand 12-1/2 gage steel wire, 14 gage 4point steel barbs spaced 5 -in. on center.

- Barbed Tape - 30 in. diameter coil loops of stainless steel tape with long, needle sharp barbs. Some specifications refer to U.S. Army drawings; others specify tape size, etc.

Although requirements for fencing were similar as noted above, correctional facility specifications reviewed differed considerably in referencing available standards (ASTM, U.S. Military, Chain Link Manufacturers 
Institute, etc.). Some specifications also contained detailed provisions for determining the strength of spot weld attachments for barbed tape. Twenty four (24) existing standards pertaining to fences, gates, barbed tape, etc. identified in this study are listed in Appendix $B$.

\section{Intrusion Detection Systems}

General. In addition to physical barriers (walls, fences), intrusion detection systems are another key element in the overall perimeter security system of a facility. The use of such systems has increased significantly as correctional administrators and planners seek to reduce costs associated with building and staffing observation or gun towers, etc. General information on the selection, cost and experiences with intrusion detection systems in correctional institutions is available in a number of recent articles [32,34-38]. One of the best sources of detailed technical information on intrusion detection systems is a handbook published by Sandia Laboratories [39]. Much of the following descriptive information on the various types of intrusion detection systems was taken from this handbook.

Intrusion detection systems (IDS) are comprised of: (1) sensors; (2) alarm assessment systems; (3) alarm reporting systems (including alarm communications and information display equipment). The "sensor" consists of a sensing device in combination with a processor. Performance characteristics commonly associated with sensors are: Probability of Detection (Pd), False Alarm Rate (FAR), Nuisance Alarm Rate (NAR), and Vulnerability To Defeat. Alarm assessment is the process of determining the cause of an alarm. Alarims can be assessed visually (directly by staff or by closed circuit television), audibly (directly or with various listening devices), or electronically (by observing outputs of sensors). Alarm reporting systems include a wide variety of equipment used for communicating alarm information from intrusion detection sensors to correctional facility staff.

The performance of the sensing and assessment equipment is heavily influenced by the physical environment in which it operates; this performance is also influenced by installation and maintenance. The physical and environmental conditions that can affect exterior detection systems include: topography, vegetation, wildlife, background noise, climate and weather, and soil and pavement. Since each correctional facility is unique with regard to location, mission, procedures, etc., a complete IDS can not be purchased as an "off-the-shelf" or standard system.

A sensor or sensor system should have a high probability of detection (Pd) for all expected types of intrusion and have low false and nuisance alarm rates for all expected environmental conditions. No single exterior sensor (as reported by Sandia Laboratories in 1983) meets these criteria. The Pd and FAR of a sensor both tend to increase as the sensor sensitivity is increased. Estimates of the Pd for various types of intrusions are shown in Table 3. The relative susceptibility to false alarms, given in Table 4, are for sensors installed to detect the crawling intruder. 
Table 3

Estimates of Probability of Detection

(from Reference 39)

\begin{tabular}{|c|c|c|c|c|c|c|c|c|}
\hline $\begin{array}{c}\text { System } \\
\\
\text { Type } \\
\text { Intruder }\end{array}$ & 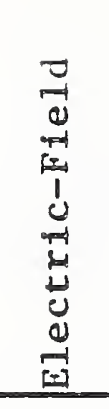 & 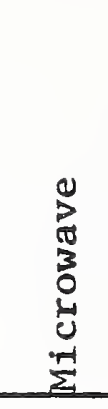 & 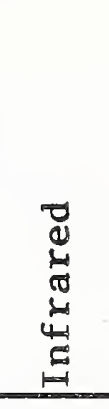 & 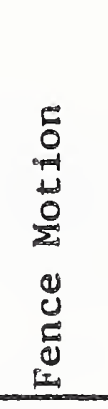 & 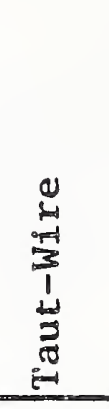 & 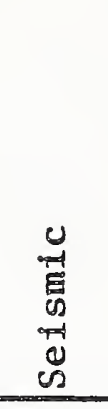 & 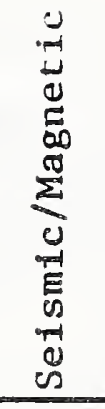 & $\begin{array}{l}x \\
0 \\
0 \\
0 \\
0 \\
0 \\
\pm \\
0 \\
0 \\
0\end{array}$ \\
\hline Wa lking & $\mathrm{VH}$ & $\mathrm{VH}$ & $\mathrm{VH}$ & N/A & $\mathrm{N} / \mathrm{A}$ & $\mathrm{VH}$ & $\mathrm{VH}$ & $\mathrm{VH}$ \\
\hline Slow Walk & $\mathrm{VH}$ & $\mathrm{H}$ & $\mathrm{VH}$ & N/A & $\mathrm{N} / \mathrm{A}$ & $\mathrm{H}$ & $\mathrm{H}$ & $\mathrm{H}$ \\
\hline Running & $\mathrm{VH}$ & $\mathrm{H}$ & $\mathrm{VH}$ & $\mathrm{N} / \mathrm{A}$ & $\mathrm{N} / \mathrm{A}$ & H & $\mathrm{H}$ & $\mathrm{VH}$ \\
\hline Crawling & $\mathrm{H}$ & $M-B$ & $\mathrm{M}-\mathrm{H}$ & N/A & $\mathrm{N} / \mathrm{A}$ & $M$ & $\mathbf{M}$ & $\mathrm{VH}$ \\
\hline Rolling & $\mathrm{VH}$ & $\mathrm{M}-\mathrm{B}$ & $\mathrm{M}-\mathrm{H}$ & N/A & $\mathrm{N} / \mathrm{A}$ & $\mathbf{M}$ & $\mathbf{M}$ & $\mathrm{VH}$ \\
\hline Jump ing & $\mathrm{VH}$ & $\mathrm{M}-\mathrm{B}$ & B & $\mathrm{VH}$ & VH & M & $M$ & $\mathrm{H}$ \\
\hline Tunne ling & VL & VL & $\mathrm{VL}$ & L & VL & I & I & $M$ \\
\hline Trenching & $\mathrm{L}$ & $\mathrm{L}-\mathrm{M}$ & L & L & VL & $M$ & M & $\mathrm{VH}$ \\
\hline Bridging & L & I & $\mathrm{VL}$ & $\mathrm{VL}$ & VL & I & L & L \\
\hline Cutting & N/A & N/A & $\mathrm{N} / \mathrm{A}$ & $M-B$ & $\mathrm{H}$ & N/A & N/A & N/ A \\
\hline Climbing & $\mathrm{N} / \mathrm{A}$ & N/A & N/A & $\mathrm{H}$ & $\mathrm{H}$ & N/A & N/A & N/A \\
\hline
\end{tabular}

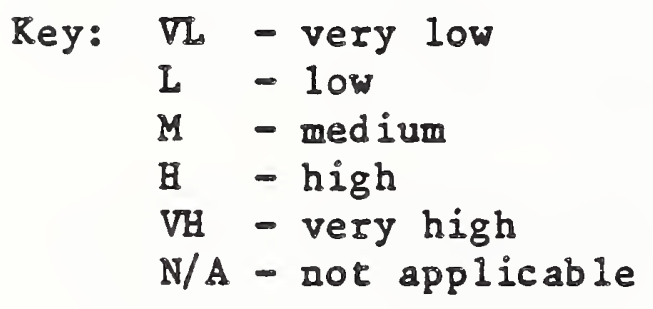


Table 4

Relative Susceptibility to Nuisance Alarms

(from Reference 39)

System

Type

Environment

ב્ב

苗
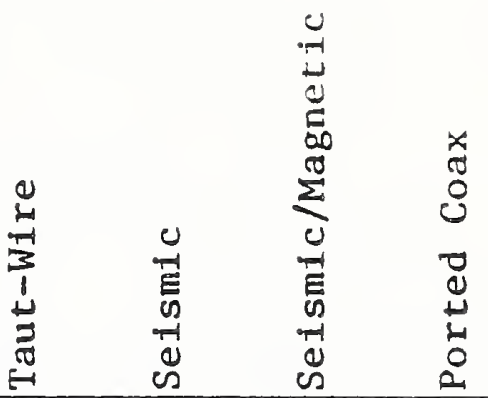

Weather

Wind $47 \mathrm{~km} / \mathrm{hI}$

L VL

VL L

VL $\quad$ L $\quad$ L $\quad$ VL

Wind $47 \mathrm{~km} / \mathrm{hr}$ WS $115 \mathrm{~km} / \mathrm{hr}$

L

L $\quad \mathrm{H}$

VL $M \quad M \quad V L$

Wind $115 \mathrm{~km} / \mathrm{hr}$

$\begin{array}{llllllll}M & \text { L-M } & \text { L-M } & \text { VH } & \text { L } & \text { H } & \text { H } & \text { VL }\end{array}$

Rain

$\begin{array}{llllllll}\text { L-E } & \text { L } & \text { L } & \text { M } & \text { VL } & \text { L } & \text { L } & \text { M }\end{array}$

Runoff, Standing Water

VL $\quad M-$

L L

VL

L

L $\quad \mathrm{H}$

Snow

M L-

Fog

VL

L $\quad M$

L

VL L

L L

Animals

Sma11 (Rabbits, Squirrels)

Large (Dogs, Deer)

$\begin{array}{llllllll}\mathrm{VH} & \mathrm{VH} & \mathrm{VH} & \mathrm{M} & \mathrm{L} & \mathrm{VH} & \mathrm{VH} & \mathrm{M}\end{array}$

Birds

Sma11

L VL

L I

VL

VI

VL VL

Large

M M

M L

VL

$\mathrm{VL} \quad \mathrm{VL}$

VL

\section{Electrical Interference}

Lightning - 1 mile

M L $\quad$ M

L . L

VL L

H . M

Overhead Power Lines

VL L

VL VL

VL

L $M \quad$ VL

Buried Power Lines

VL $\quad$ VL

VL VL

VL

M

H VL 
The New York Department of Correctional Services has set the following criteria for intrusion detection systems [38]:

- One (1) false alarm per zone per 24-hour day, for both medium and maximum security prisons;

- $95 \%$ probability of detection for medium security prisons; and

- 100\% probability of detection for maximum security prisons.

Types of Sensors. The types of exterior intrusion sensors include: microwave sensors, electric field sensors, seismic-magnetic sensors, seismic sensors, magnetic sensors, fence-associated sensors, infrared, and ported coaxial sensors.

Microwave sensors can be categorized into three classes (bistatic, monostatic, and terrain following) depending upon antenna configuration. Bistatic sensors consist of transmitting and receiving antennas at opposite ends of a microwave link; they are used for detection in long, flat narrow perimeter zones. Monostatic sensors use the same antenna, or nearly coincident antennas, for the transmitter and the receiver; they are typically used in a relatively confined volume. Terrain following sensors use other antenna configurations for which the integral antenna pattern is not line-of-sight; they are designed for use in long perimeters. Typically, a microwave perimeter alarm system will operate effectively in the range between 70 and 150 meters [40].

Electric-field fence sensors consist of an alternating-current field generator which excites a field wire, one or more sensing wires that couple into the resulting electric field, and an amplifier and signal processor to amplify and detect changes in the signal amplitude of the sensing wires. A signal is generated when an object (human body) distorts the coupling between the field wire and the sensing wires. Another method is to excite a wire or set of wires and to monitor the change (caused by an intruder) in the capacitance of the wire(s) to the ground. Electric field sensors used in perimeter applications can be either freestanding (mounted on their own posts) or fence mounted (mounted on a chain link fence). Since this system is not line-of-sight, it can be installed on uneven terrain and in an irregular line. The electric-field system provides about 300 meters of perimeter protection per segment, but shorter lengths are recommended to have effective alarm assessment and response capabilities.

Seismic-magnetic sensors consist of a buried cable sensitive to both seismic and magnetic disturbances, and a processor to evaluate signals generated in the cable. Seismic sensors are passive systems that detect seismic disturbances such as mechanical pressure, deformation, or vibration transmitted through the ground to the sensor transducer. Magnetic sensors are also passive systems and are sensitive to disturbances in the local magnetic field caused by nearby movement of ferromagnetic material such as iron and steel. 
There are four basic types of fence sensors which detect different types of fence movement. They are: mechanical, electromechanical, strain sensitive cable, and taut wire. The first three types are normally installed on an existing fence whereas the taut-wire sensor can be a freestanding fence. The mechanical fence sensors all operate on the principle that movement of the fence will cause a switch mechanism to open or close a set of contacts. The electromechanical fence sensors use a set of point transducers to detect fence motion. These transducers produce an analog signal instead of a switch closure and use an electronic signal processor to extract alarm information from the signal. Like mechanical fence sensors, they are positioned on the fence at regular intervals. The strain sensitive cables are transducers uniformly sensitive along their entire length. These cables are designed to produce a signal whenever the cable is moved or strained. A taut-wire sensor fence primarily consists of a dense screen of horizontal wires connected to a central detector post assembly and securely anchored at each end. The horizontal wires are tensioned upon installation, then attached to a sensor. Mechanical action taken against one or more of the wires, such as climbing or cutting, will generate an alarm.

Infrared sensors detect changes in the signal power of a line-of-sight infrared beam created between a transmitter and receiver. Since the infrared beam does not diverge significantly as does the microwave beam, multiple infrared beams are often used to define a "wall." The typical distance between transmitter and receiver is about 100 meters; however, some systems are capable of monitoring a distance of 300 meters under ideal conditions.

Ported coaxial sensors are active electromagnetic sensors consisting of two or three identical coaxial cables buried in the ground parallel to each other. A transmitter is connected to one cable and a receiver to the others. Because the outer conductor of the cables is ported (i.e., contains closely spaced, small holes or gaps which allow radio frequency energy to radiate), any electromagnetic energy injected into the transmitter cable is radiated into the surrounding medium, and some of this energy is coupled into the receiving cable through its ported shield. When the intruder enters the established field, the coupling is perturbed and the resultant change in received signal is processed for an alarm condition.

Test Data/Standards. Extensive testing of intrusion detection systems has been conducted by Sandia Laboratories and the U.S. military. However, because of the unavailability of these test data, as well as lack of test data more appropriate to their needs, various state Departments of Corrections have conducted limited testing of perimeter IDS. In addition, there are few, if any, nationally recognized standards for testing, purchasing, installing or maintaining these systems. The guide specifications developed by the State of New York [31] contain sections for the following types of IDS: microwave, electronic fence alarm, ported coaxial, infrared, taut wire, and E-field. Each specification section also contains tests for system acceptance. California [30] has also developed a draft section in their Design Criteria Manual on perimeter electronic detection systems. The Sandia Laboratories IDS Handbook [39] contains draft specifications for three types of exterior sensor specifications-- 
infrared, electric field, and bistatic microwave. Performance and installation criteria for various IDS are outlined in an U.S. Nuclear Regulatory Guide [40].

\section{Closed Circuit Television}

Closed circuit television (CCTV) systems provide one of the primary means of visually assessing the cause of an intrusion detection system alarm. Accurate and rapid assessment of a remote system alarm by CCTV (or by observation tower staff) is essential so that relevant information (attempted escape in progress or false alarm) can be communicated to appropriate facility staff (i.e., mobile perimeter patrols, maintenance staff, etc.). In general, CCTV systems have proven to be a cost-effective tool in monitoring fence lines, roof tops, perimeter blind spots, vehicle saliyports, etc. Most correctional administrators are quick to point out, however, that CCTV supplements staff; it does not replace staff.

A CCTV system is comprised of one or more cameras at the remote end, a display monitor at the local end, and various transmission, switching, and recording systems connecting cameras to display [39]. Many CCTV systems employ more cameras than display monitors since there will seldom be instances where all camera sectors simultaneously require viewing. For this reason, video switching equipment may be utilized between a large number of camera signal lines and a (relatively) small number of display monitors. The associated alarm sensor system should interface with the switching system so that an alarm in any sector causes the associated camera output to be automatically displayed on a local monitor. Multiple alarms are processed in a similar manner but may require additional monitors and/or priority-sensitive camera switching control equipment [39]. Video tape recorders can be valuable component of the CCTV system since they provide the capability to reconstruct alarm events for either immediate playback and assessment or future analysis.

In addition to serving as a remote alarm assessment system, a CCTV system can be equipped to detect motion. A microprocessor digitizes the image signal from a CCTV camera and, at a set interval (1-2 seconds), repeats the process with a second image from the same camera and performs a comparison for change [41]. Depending upon the sensitivity and alarm threshold, if a change is detected, an alarm is triggered. Additional information on the design and selection of CCTV systems may be obtained from the various references [39, 41-45] listed in Section VI.

\section{Exterior Lighting}

Effective perimeter security requires a good exterior lighting system. A traditional method is to place lights at 100-foot intervals along the entire perimeter, with additional lights placed at building locations both inside and outside the fence and at other locations around the facility [12]. In recent years, however, the use of fewer high-mast lighting standards (over 40 feet in height) with high-energy discharge lamps (metal halide and high pressure sodium) have become popular $[12,45]$. 
Among the design criteria for exterior lighting systems established by the California Department of Corrections [30] are the following:

- Lighting standards located in any area accessible to inmates shall not have footholds, handholds, or any protrusions to facilitate climbing.

- Luminaires mounted below 18 feet in areas accessible to inmates shall be provided with polycarbonate or other approved shields/lenses to provide resistance to vandalism.

- Area lighting systems and perimeter (fence) lighting systems shall be photo-electric controlled with manual override at central control. These systems shall use high pressure sodium lamps with high efficiency ballasts, electronically regulated.

- In-service illumination for exterior lighting systems shall provide the average illumination levels listed. Minimum to maximum rates shall not exceed five to one.

Area

1) Inmate Exercise Yard

2) Open Areas Secured Perimeter

3) Vehicle Sallyports

4) Perimeter Fence
Maintained Illumination (Footcandles)

5 horizontal plane at ground level

2 horizontal plane at ground level

5 vertical for $10 \mathrm{ft}$. high plane at front, rear, and both sides of position occupied by vehicle

5 on horizontal plane inside fence (20 foot wide corridor) 
1. General

The building systems which comprise the walls, ceilings, and floors of the cells, housing units, and the building envelope provide another primary security system for a correctional facility. For many jails, particularly those situated in crowded urban locations, perimeter security systems are not feasible, so the building systems comprise the only physical barriers for preventing escape. However, as indicated in Section II.B, it is still possible to have several security zones in the buildings containing the housing units. In each security zone, it is important that the building components making up that zone -- walls, floors, doors, windows, locks, etc. - have equivalent performance levels.

Building systems utilizing pre-fabricated modules and components in $j$ ail and prison construction have increased significantly in recent years to provide short-term or long-term solutions to inmate overcrowding problems. Information on the use of steel, wood-framed and concrete modules and prefabricated components in correctional facility construction may be found in various articles and publications [46-51].

\section{Walls}

General. Typically, concrete and masonry walls (interior and exterior) are being used in contemporary correctional facility construction [27]. Concrete walls may be either cast-in-place or precast [49-51]. Masonry walls are frequently constructed with concrete masonry units (CMU). Wall thickness and reinforcement will generally vary according to the loads supported, security requirements, and local codes. Where such walls serve as security barriers, they should extend all the way to a secure ceiling and be appropriately anchored.

Concrete. High strength concrete (4,000 to 5,000 psi minimum compressive strength) and normal steel reinforcement provided for shrinkage and temperature control will generally provide the necessary resistance for security. Non-loadbearing concrete walls may be 4-in. thick and loadbearing walls can be 6-in. or 8-in. thick [51].

Masonry. Where maximum security is needed, concrete masonry walls are usually 8 -in. thick, reinforced with steel bars 8 -in. on centers (both horizontally and vertically), and solidly grouted $[12,30]$. Medium or minimum security walls may be $6-i n$. thick and the steel reinforcement placed at intervals greater than 8 -in. Proper supervision of masonry construction is very important to insure that the steel reinforcement and concrete grout are properly installed.

Test Data/Standards. A special design consideration for the selection of security walls or barriers in correctional facilities is their resistance to physical attack and penetration. Assuming the use of hand tools, penetration times (i.e., time required to produce a human-size hole and one person to crawl through the hole) for different types of concrete and 
masonry walls are shown in Table 5. As indicated, concrete walls, 6 inches or less in thickness can be penetrated with hand tools in relatively short times. Similarly, hollow concrete block walls (by themselves) are easily penetrated with hand tools. If the block cores are filled with mortar or grout and the cells are reinforced, the penetration times are increased significantly against hand tools.

Although there is a national standard (ASTM E72) for determining the strength of walls subject to various loads -- compressive, lateral, impact, and racking, there is none for measuring the penetration resistance of walls. Test procedures which have been developed for determining the forced. entry resistance of structural materials and assemblies are briefly described in Appendix B.

TABLE 5

Penetration Times (Minutes) for Concrete and Masonry WaIls (from Reference 33)

4-in. concrete ( $3000 \mathrm{psi}$ ), one layer 1/4-in.x 6-x 6-inch mesh

6-in. concrete (3000 psi), one layer No. 5 bars, 6-in.o.c.

8-in. concrete ( $3000 \mathrm{psi}$ ), two layers 1/4-in.x 6- x 6- inch mesh

12-in. concrete block, cores unfilled, no rebar

8-in. concrete block with No. 8 rebar in each core, running bond, mortar filled

12-in. concrete block, cores filled with mortar, No. 6-in. rebar on 8 -in. centers
Sledge, hand hydraulic

$3.2 *$

boltcutters

Sledge, hand hydraulic

$7.6 *$

boltcutters

Sledge

12.1

(no hole)

Sledge

1.5

Sledge, cutting torch

Sledge, prybar, hydraulic 20

* Estimated penetration time based on judgement and test data from similar type barriers.

\section{Floors/Roofs}

Conventional concrete floors and concrete/metal roofs are usually sufficiently reinforced to provide the necessary security requirements. In 
general, floors offer more resistance to penetration than roofs do because they are designed to accommodate heavier loads than roofs. Based on the use of hand tools, penetration times for different types of floor and roof construction are shown in Table 6 . As is the case of walls, no nationally recognized test procedures exist for determining the penetration resistance of floor and roof construction.

TABLE 6

Penetration Times (Minutes) for Floor and Roof Construction (from Reference 33)

Construction

Tools

Mean Time

3 -in. concrete topping on

Sledge, boltcutters

$4.6 *$

top of 2.5 in. concrete slab

with 6-in. sq. mesh of No.10 wire

4-1/2 in. concrete with No. 3

Sledge, fire axe

$4.7 *$

rebar on 18-in. centers placed on

16 gauge steel decking

Asphalt built-up roof with

gravel, 3-in. vermiculite

Fire axe, shovel

3.2

concrete, 2-in.rigid insulation,

16-gauge steel decking

Asphalt built-up roof with gravel, 2-in. rigid insulation,

Mattock, fire axe, bar 4.0 $2-1 / 2$ in. lightweight concrete with $6 \times 6 \times 10$-gauge wire fabric on 22-gauge steel decking

* Estimated penetration time based on judgement and test data from similar type barriers.

\section{Doors}

General. The selection of doors, door frames, hinges, vision panels, and locks for correctional facilities is an important design consideration. Some states require all security doors to be hollow metal, steel plate or steel grillage, and all frames to be hollow metal or steel plate $[30,52,53]$. Where hollow metal doors are used for cell doors, the door face sheet thicknesses are commonly 12 or 14 gage steel, and the door frames are of a similar thickness. Steel grillage doors are usually constructed with steel bars having a minimum dimension of $7 / 8$ inches and spaced 5 or 6 -in. on centers [30,53]. The advantages of hollow metal doors over a steel grillage door are discussed in a guide specifications for detention security doors and frames published by the National Association of Architectural Metal Manufacturers (NAAMM) [54]. 
In general, sliding doors are used in medium and maximum security celis, high traffic sallyports, and holding cells. Swinging doors are usually used in minimum and medium security cells, control rooms, secure closets, low traffic sallyports, exterior doors, etc. [14].

Standards/Test Data. Numerous standards for doors are briefly described in Appendix B. Standard test methods for determining the air leakage, water penetration, fire endurance, bullet resistance, and physical security of doors are available. In regard to physical security, five tests (static load, racking load, impact load, glazing stop test, and bullet resistance) are included in the NAAMM guide specifications for detention doors cited above [54]. At the present time, an ASTM Subcommittee (A01.16 on Detention Assemblies) is developing a specification covering swinging detention door assemblies. This draft specification covers detailed construction requirements for the door, frame, and hardware, and contains test procedures for impact load, racking load, bullet resistance, and fire (refers to other existing fire tests).

Penetration times for standard industrial doors (1-3/4 in. thick with 16- or 18 gage steel face sheets) are reported to be only a few minutes when attacked with hand tools such as crowbar, axe, hammer and punch, etc. [33]. A recent article estimates that the penetration or delay time for doors meeting the minimum requirements of the NAAM guide specifications would be 4 to 5 minutes using the best tools, and 70 to 80 minutes using only limited tools [55].

\section{Windows}

General. Although windows help normalize the general atmosphere of a correctional facility by making it more "open" and humane, they are usually the weakest link in a barrier system [12,33]. Where "security-type" windows are required (e.g., housing units, control center), three options are available -- specially manufactured security windows and frames, security glazing, and concrete or steel sections placed in the clear opening [12].

Important factors in the design of security windows are: required degree of security, passing of contraband, accessibility of glass, ventilation and daylight requirements, and maintenance [56]. Most security windows are available to meet different security levels -- maximum, medium, and minimum [57]. Such windows have horizontal/vertical bar spacing and ventilators of a size to deter escape, and section size and weight to reduce deflection and damage to the window. Ventilators allow for natural ventilation and for exhausting smoke. Maximum security windows also have a built-in grille of tool-resisting bars to resist sawing, filing and drilling.

Careful attention must be given to the anchorage of the window frame in the wall. In one facility, inmates were able to escape after loosening the mortar used to anchor the frame and pushing the entire window out of the masonry opening. Wherever possible, the removable stops used for the security glazing in cells should be applied to the outside to eliminate inmate tampering. In high-rise facilities, this may not be desirable 
because of replacement costs. When stops must be used on the inside, the should be installed with an ample number of tamper-proof fasteners.

Additional information on window and glazing problems has been reported in a NIC study by Dennis Kimme [58]. Fifty jails were surveyed in this study. Problems fell into five basic and interrelated categories: (1) glazing failures; (2) weapon and tool availability; (3) window framing and detailing deficiencies; (4) differences in the size of glazed openings; and (5) staffing, operational and activity deficiencies. The most frequently cired problem in the window framing was the removable stops or the frame members used to hold the glazing in place. Lightweight framing systems also resulted in problems. The cell windows with glazed openings greater than 5 inches in the narrowest dimension suffered about 50 percent more damage than those with openings 5 inches or less. Inadequate surveillance of inmates by staff had a significant impact on cell window failures (and escapes).

Test Data/Standards. Using hand tools, penetration times through conventional windows with glass or plastic glazing (less than $1 / 2$-in. thick) are less than one minute [33]. Such times can be enhanced either by the use of steel bars and grills or by the use of security glazing (see next section).

Specific standards are available for determining the physical security of windows (Appendix B). In general, these standards (ASTM F588 and NIJ 0316) are intended for determining the resistance to forced entry of windows used in residential and small commercial buildings.

\section{Glazing}

General. The use of security glazing has greatly increased over the past 10 to 15 years, and a vast array of different products are now available. Glass products are comparatively low in strength but high in heat and scratch resistance. Plastic materials such as polycarbonate have good strength and flexibility, but compared to glass, have low resistance to heat, scratching, marring, discoloration and $a$ high coefficient of expansion. A comparative summary of the characteristics of glass and polycarbonate materials used in security glazing products is shown in Table 7 [59]. Glass, due to differences in production and treatment, will have large variations in strength as noted in Table 7.

Some problems with security glazing have been previously noted under Section III.B and the previous section pertaining to windows. In the Kimme study [58], many owners were disappointed with glazing performance because their glazing was considered to be "unbreakable" or "virtually indestructible." Given the right weapons and an adequate amount of time, all glazing products can be damaged and penetrated, as can virtually any construction material. All glazing types -- glass laminates, polycarbonate plastic, glass/polycarbonate laminates -- sustained damage from inmate attacks. Glass laminates were vulnerable to freezing (i.e., freezing blast of a fire 
TABLE 7

Characteristics of Glazing Materials (Erom Reference 59)

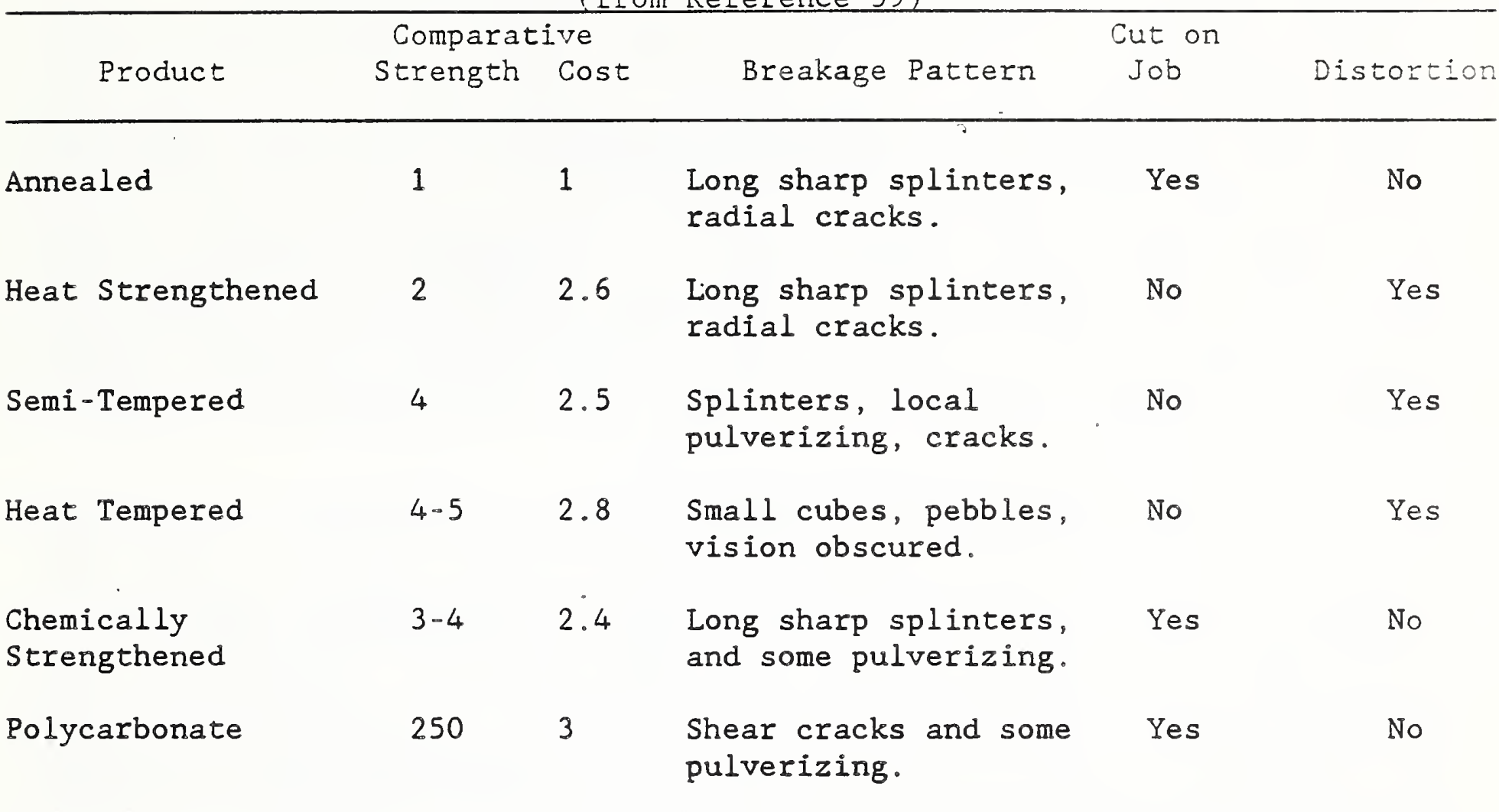

extinguisher using carbon dioxide) and tool impact. Polycarbonate plastic was susceptible to surface damage, was very vulnerable to intense heat but had relatively good resistance against, impact attack. Glass/polycarbonate laminates were found to provide a level of damage resistance comparable to glass laminates, and a level of penetration resistance comparable to the polycarbonate plastics.

Standards/Test Data. Two important considerations for the selection of security glazing in correctional facilities is their resistance to ballistic and physical attacks. Because a system's overall protective level is no better than its weakest component, the level of glazing resistances selected should be consistent with the resistances of the surrounding walls, doors, louvers, and other building components. Because of the thickness and properties of security glazing, sound transmission through such glazing is much more difficult than through ordinary glass. Where sound transmission through the glazing is a requirement, a system utilizing individual speakers and microphones should be specified.

One of widely used test methods for bullet resistance is UL 752 (see Appendix B). It recognizes four power rating levels (medium - small arms; high - small arms; super - small arms; high - rifle). Another standard, NIJ 0108.01 , utilizes a wider range of weapons and ammunition than the UL standard. 
For attack resistance, a variety of test methods are currently being used (see Table 8). As a result, there are considerable differences in the ways security glazing is specified for various correctional facilities. In some test methods $[60,61]$, the glazing is attacked by men using various assault tools, including sledge hammers, hammers, steel pipe, chisels, battering rams, propane torch, etc. In order to better determine the comparative qualities of different security glazing products, the California Department of Corrections initiated a large testing program in 1984 [59]. In this program, three panels of each of forty separate products were submitted for testing by eleven major manufacturers. As indicated in Table 8, three laboratory controlled tests were performed on each product. Testing on a product was discontinued when a six-inch round opening was produced or when thirty minutes elapsed, whichever occurred first. This test method and the results of this test program are now being used in the California new prison construction program [30].

The results of a NBS research project to develop a laboratory test method for security glazing have been recently published [62]. In this NIJ sponsored research, the test method developed evaluated the penetration resistance of glazing materials subjected to a simultaneous attack with a sharp-nosed tool and heat application (see Table 8). Currently, ASTM Committee F12 on Security Systems and Equipment is also working on a test method for security glazing materials and equipment. The draft test method under review is based on field experience and incorporates many provisions for physical and ballistic attacks which are similar to those contained in other existing test methods.

\section{Access Controls}

General. Access controls, according to one definition, are the remote control and monitoring of personnel movement into, out of and throughout a facility [63]. One of the primary objectives of access control systems is to permit only authorized persons to enter and exit controlled areas (e.g., sallyports, control rooms) [64]. Such systems not only contain components that control locking and unlocking of doors and gates but also include audible and visual communication equipment for the surveillance and protection of specific areas. The design and application of access controls in correctional facilities requires the consideration of a number of factors including: (1) the needs or purpose of the facility; (2) the level of security desired; (3) the level of life safety (fire and personal); (4) operational convenience and simplicity; (5) flexibility to meet changing facility needs; and (6) cost [63]. A study of control room operations in one correctional facility showed that one of the control room officers spent 75 percent of his/her time opening doors for staff. To improve operations in this facility, access control readers using keys were installed [65].

Locks. Locks and locking devices are important elements in the overall access control and security system of a facility since they "secure" the movable portions (doors, gates) of the barriers (walls, fences). As mentioned previously, components that make up a particular security system should have equivalent performance levels. Elaborate locks can be used for 


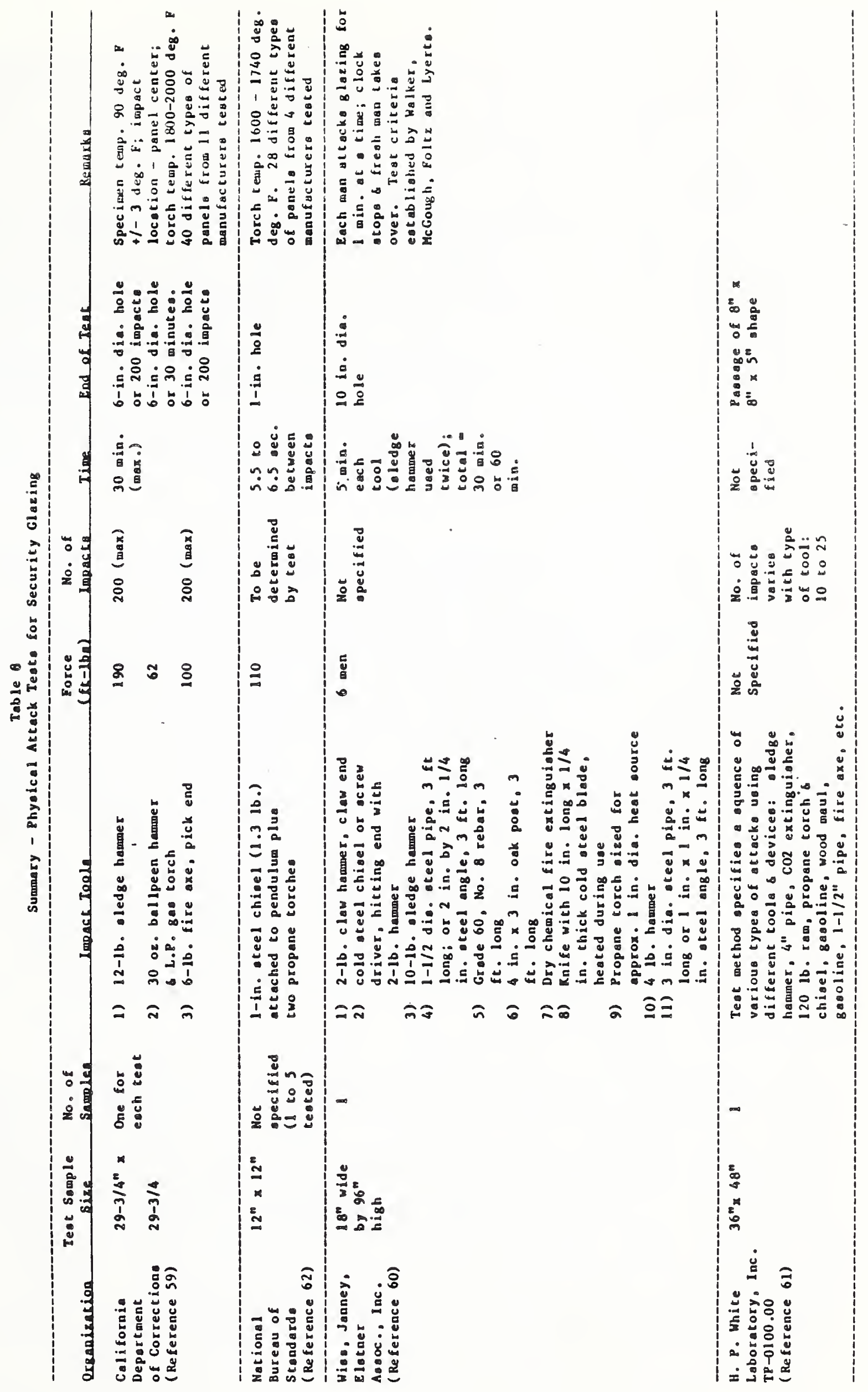


a door that can be kicked open, or a fortress-like door can have a lock that can be easily picked [66]. Where possible, however, a door that provides a 2-minute penetration delay, should be equipped with a lock that also provides a 2-minute minimum delay.

A variety of lock types -- electrical, electro-mechanical, and mechanical-are used in correctional facilities. The type to be used will depend on the level of security and control required for each specific location. Where maximum security is required, heavy duty electro-mechanical locks are generally used. Unlocking can occur by retracting the latchbolt with either a paracentric key or by the use of a remote switch in a control room which activates a solenoid or motor in the lock. The door deadlocks automatically when it is closed. Such locks are usually frame mounted and offer considerable resistance to physical attack. Where full control of a door or a group of doors is needed, locking devices or mechanisms capable of locking, unlocking, opening or closing the door(s) from a control room can also be used.

Where medium security is required, similar but smaller electro-mechanical locks are usually recommended. Mechanical locking (or unlocking) is by the use of a mogul key. For minimum security applications, heavy duty mortise cylindrical locks are commonly used. Since these locks are installed in the door, the electrical wires to the locks pass through special hollow hinges. Jamb mounted locks which can be installed in a standard door frame are also being used in minimum security applications. Where remote control of the lock and door is not required, a variety of mechanical locks (lever tumbler deadlocks, spring and deadlocks, and pin tumbler cylindrical locks) are available. Where necessary, for remote monitoring, these mechanical locks can also be equipped to indicate the locked or unlocked condition of the door.

Available standards for various types of locks are briefly described in Appendix B. Several of these standards include tests for determining the resistance of locks to expert attack for periods up to 10 minutes. As noted in a 1982 NBS study on high security locking devices [66], reliance on experts is the most reliable source to determine the performance of particular locking systems.

Card-Access Systems. Card-access systems have advantages and disadvantages when compared to the more conventional and lock-and-key systems. Some of their advantages are: improved security (literally pick-proof by conventional methods, less easily duplicated, easily voided if lost by deleting data from the central controller); readers are constantly monitored and all activities are logged on a permanent record; and various areas of access and time-of-day access are easily controlled. Some disadvantages are: higher cost; higher failure rate than mechanical lock-and-key systems; false alarms; and vulnerability to vandalism [64]. Based on this study, however, information on the use of and experiences with card-access and/or coded-credential systems in correctional facilities appears to be limited. 


\section{Interior Lighting}

General. As part of the recent major changes which have taken place in the design and management of correctional institutions, lighting design has also experienced a radical change. "No longer is the single incandescent bulb within its surrounding metal cage an acceptable source of illumination for a cell [67]?" Fluorescent lighting is now widely used in modern correctional facilities because of its proven efficiency, utility and low maintenance. There are conditions, of course, where an incandescent fixture or feature may be desirable (i.e., night light).

In facilities where there are two tiers of cells clustered about a dayroom, it is important that the circulation path immediately in front of the banks of the cells be sufficiently illuminated to facilitate detection of any movement by the correctional officer. Similarly, the lighting design for the control rooms or stations at each housing unit is very important. Three suggested rules [67] for the lighting design of these spaces are: (1) Never set illumination levels within the control room higher than the levels in the surrounding spaces. Higher light levels hinder visibility of officers and increase possibility of the "fishbowl" phenomenon. (2) Provide maximum flexibility in the lighting controls. This will improve daytime and nighttime operations, and can be accomplished with multiple switching of lamps within fixtures, or rheostat controls, or a combination of both. (3) Ask questions to determine what equipment is to be located in the control room (CCTV monitors, CRT-based computerized control system), the type of glazing to be used, etc. so appropriate light levels can be achieved:

Lighting Fixtures. Some key considerations in selecting lighting fixtures are: a lens that resists breakage under direct attack; a wraparound lens/housing that can be removed only with a special type of tool not readily available; and some provision for use flexibility (i.e., a fixture that offers more than minimum security features to accommodate possible future reclassification of the facility) [68]. According to a recent article [69], light fixture abuse and breakage is a primary reason facilities are found in noncompliance with ACA illumination accreditation requirements (i.e., Section 2-4130 requires lighting to measure at least 20 foot candles at desk level and in the personal grooming area). To prevent common abuses of cell lighting fixtures, various construction and guide specifications reviewed generally require a minimum metal thickness for the fixture housing, the lenses to be made with polycarbonate of a specified minimum thickness, and specify how the lens retention system is to be constructed, etc. As the security levels increase (minimum to maximum), more sturdy and heavier materials are specified for the lighting fixtures. However, no test methods for determining the impact and tampering resistance or durability of lighting fixtures were discovered in the standards review for this study (Appendix B).

A series of tests to ascertain the strength of five lighting fixtures was conducted in December 1985 by the Utah Division of Corrections [70]. Assault tools used were a hammer and screwdriver. Some recommendations made as a result of this testing were: (1) polycarbonate should be used as the diffuser material; (2) the prismatic layer of the diffuser should also be 
made of polycarbonate; (3) if glass must be used, beware of perpendicular lens-retaining bolts welded to the housing (i.e., they can allow excessive pressure to be applied to the glass resulting in breakage); (4) for a surface mount fixture, the steel thickness of the door should be at least the same as the housing; (5) a no-door frame design should be used for maximum security facilities; and (6) powder-coated metal is more abuse resistant than baked enamel and its impact resistance is 12 times greater.

\section{Fire Safety}

General. A study of fires in correctional facilities (1967 - 1977) indicates that a typical fire is of incendiary origin and is started in a cell [71]. The source of ignition is generally a match, smoking material, or cigarette lighter. Principal materials first ignited were mattresses, bedclothes, and personal clothing. These types of fire generate intense heat and dense smoke that quickly invades all corridors and adjoining areas, hindering safe evacuation of the occupants [72].

The National Fire Codes published by the National Fire Protection Association (NFPA) is a large set of generally accepted fire safety standards and guidelines that, if followed, will provide a high level of safety in any building. The standards range from the National Electric Code--which includes standards for selecting and installing electric wires, conduits, and the like--to the Life Safety Code--which includes minimum requirements for emergency exit capacity. Those requirements in the National Fire Codes that apply equally to jails, to prisons, and to a variety of other buildings will not be discussed in this section. Discussion will be limited to those standards that apply mainly to jails and prisons, and to those standards where there may need to be special requirements for detention occupancies. Brief summary descriptions of various standards (NFPA, ASTM, UL, etc.) relating to fire safety are contained in Appendix B.

The American Correctional Association (ACA) "Standards for Adult Correctional Institutions" [22] specify that specific fire safety features be installed in correctional institutions and that specific fire safety procedures be followed. However, it does not provide detailed requirements for these features and procedures. For example, standard 2-4162 (January 1984) requires that the institution comply with applicable fire safety code(s) and have a fire alarm and automatic detection system approved by the authority having jurisdiction. The ACA standards also indicate that "In the event local and/or state codes are not applicable, the requirements of the NFPA Life Safety Code, current edition, apply."

Life Safety Requirements. The 1981 edition of the Life Safety Code, published by NFPA, contained two new chapters specially covering $j$ ails and prisons: Chapter 14, New Detention and Correctional Occupancies; and Chapter 15. Existing Detention and Correctional Occupancies. These two chapters specify a set of fire safety features that appear to provide a combination of a high level of safety and a practical set of requirements. However, there has been no intensive effort to check on the acceptance of these standards, and the fire experience of buildings meeting the requirements. 
Retrofitting buildings to meet a new set of requirements is often difficult and expensive. The Life Safety Code (1985 edition) permits use of (and contains a description of) a new Firesafety Evaluation System for Detention and Correctional Occupancies (FSES). The FSES, developed by the NBS Center for Fire Research in a NIJ sponsored study, contains a procedure for determining if alternate combinations of fire safety features provide the level of safety required by the code. Permitting alternate combinations of fire safety features gives the architect flexibility to upgrade the fire safety to the desired level at minimal cost [73].

A key concept in the current requirements is that there are five levels of freedom of movement in jails and prisons that relate to fire safety and the ability of prisoners to evacuate to an area of safety. These range from: 1) buildings where the prisoners have free access to an area out of the building, to 2) buildings where movement from the smoke compartment is restricted by a locked door that requires staff controlled manual release. The higher levels of restricted movement require more safety features, especially better separations between adjacent rooms, rooms and corridors, and common space and other areas.

The Life Safety Code specifies that other standards be used for the design and installation of subsystems. Among these other standards are alarm systems that require the use of smoke detectors and pull boxes. The Life Safety Code permits and describes variations in the normal installation of these devices to minimize false alarms and malicious mischief. Proper application of these variations would require knowledge of both fire protection and prison operations.

Test Data. Prisons and jails vary greatly in design and function. There is a large amount of test data related to the burning of products and the growth of fire that relate to designing and furnishing all buildings including jails and prisons. (A report of this nature cannot cover this large technical literature.) On the other hand, little data exist relative to the unique situations found in jails and prisons.

One of the important ways that prison cells differ from typical bedrooms is the amount, nature, and location of the combustibles. Prisoners tend to neatly store large amount of combustibles under their beds. In case of a cell fire, the possessions under the bed are a major source of fuel for the fire. B. T. Lee, National Bureau of Standards, conducted a series of instrumented burns of a "typical cell" to obtain data regarding the amount of heat, smoke, and carbon monoxide production [74]. Since the growth of a big fire in a small room is a function of the amount of available air, Lee used four different doorway ventilation conditions. As anticipated, the study showed that the fires were ventilation controlled; that is, if there 
is a big opening--say, an open door--there can be a dramatically large fire which is called flashover 5 .

Sprinklers. Automatic sprinklers are very effective in controlling a wide variety of building fires. The idea is to apply a relatively large amount of water on or near a small fire before the fire becomes too large for the prescribed water flow to control it. The claim has been made that the use of sprinkler systems in jails and high security prisons is a problem because the prisoners are likely to attempt to vandalize the system. On the other hand, some claim that this problem is exaggerated because the vandal is likely to be known and punished by the prison authorities or by fellow prisoners who will be inconvenienced. In any event, automatic sprinklers are being installed in some jails and prisons.

NFPA Standard for the Installation of Sprinkler Systems (NFPA 13) provides detailed guidance for the design and installation of automatic sprinkler systems. The standard prescribes the locations and characteristics of the sprinkler heads. These locations depend on the geometry of the room and the characteristics of the potential fires. Where there is no vandalism problem, these well established sprinkler requirements should apply for most prison situations.

Padding. Padding on walls and floors as used in "padded cells" to limit self-harm potential are a well known fire hazard. They are usually made of combustible material. Furthermore, to obtain the desired padding characteristics the padding may be up to several inches thick which means that if there were a fire, there would be a large amount of fuel. Williamson and Fisher $[75,76]$ have analyzed the fire safety of padded cells and have conducted fire tests of the padding materials. Their results are reflected in the California Administrative Code, Title 24, Chapter 12-42.

There appear to be four approaches to providing fire safety in a cell with padding:

1. Use materials that will not readily burn. In selecting padding materials, it must be recognized that materials that will not sustain a fire on a horizontal nor a vertical surface, might burn vigorously if a flame is applied to a corner configuration.

2. Install an automatic sprinkler system in the cell. Cells with padding are likely to have little if any furniture that would separate a sprinkler head from the flame and, therefore,

5. Many definitions for "flashover" appear in the literature. The most common of which are: "(1) the transition from a local fire to the general conflagration within the compartment when all fuel surfaces are burning; (2) the transition from a fuel controlled fire to a ventilation controlled fire; and (3) the sudden propagation of flame through the unburnt gases and vapors collected under the ceiling." (From "An Introduction to Fire Dynamics," Dougal Drysdale, John Wiley and Sons, Ltd., 1985.) 
sprinklers with a sufficient water flow and proper water spray pattern should be effective. However, specific design guidelines for installing sprinklers in padded cells have not been established.

3. Separate the padded cell from the remainder of the building by doors and walls that will contain the smoke and fire for sufficient time to extinguish the fire and/or evacuate the other prisoners in the buildings; that is, safety is obtained by compartmentation.

4. Procedures for rapidly evacuating occupants who are in the same smoke area as the cell with padding must be established in each facility. Guidelines for developing these procedures need to be developed.

The Life Safety Code strongly recommends that padded cells not be used due to the record of major fires which originated in such cells. However, when padded cells are used, it requires compartmentation, sprinklers, and procedures for rapidly evacuating the prisoners. There are no requirements in the Life Safety Code for the padding material.

While the Life Safety Code requires sprinklers in padded cells and calls padded cells severe hazard areas, it does not specify which occupancy classification for determining sprinkler requirements applies.

One of the compartmentation requirements is that the padded cell have a fire resistent door ( $3 / 4$ hour rating) that is self closing and self latching. While this fire safety feature provides for the safety of other occupants of the correctional facility, its impact on the fire safety of the occupant(s) of the padded cell needs to be studied; it is likely that it will decrease the time available to safely release the prisoner from the padded cell.

Currently, there is no nationally recognized test (or set of tests) that will satisfactorily test the flammability characteristics of padding materials for installation in padded cells. A test protocol has been developed for a similar situation that may serve as a basis for a test of padding materials. Research conducted at NBS has demonstrated that fire hazards associated with the use of certain synthetic foam materials, in the insulation of the interior of submarines, can be satisfactorily assessed only with room fire testing and not with small scale laboratory fire tests which are used for measuring fire properties of materials. B.T. Lee developed a quarter-scale room fire test protocol for testing compartments with the insulation [77]. The similarities of the fire characteristics of the materials and their application to walls suggest that a similar test protocol may be used to test padded cell materials.

Mattresses and Furnishings. Mattress fires are a serious threat because mattresses contain a considerable amount of fuel--the fire does not need to spread to another object in order to have a dangerous situation. There is a national standard for the resistance of mattresses to ignition (CPSC FF4-72) 
but it measures only the resistance to a smoldering ignition such as the resistance to a carelessly discarded cigarette. In a prison, there is the problem of deliberately set fires using a flaming source of heat. A standard for determining the resistance of mattresses to flaming ignition is therefore needed.

Babrauskas $[78,79]$ compared bench scale tests to full scale tests to see how well the practical bench scale tests predict the burning characteristics of a variety of commercially available mattresses in expensive to run full scale tests. The ignition source was a burning plastic wastebasket. Based on the test results, he developed criteria for four levels of flammability. These flammability levels are based on the rate of heat release and the amount of smoke generated. Test methods for determining the rate of heat release and the smoke production needed to assign a mattress to one of the four levels were also developed and published.

A test for prison mattresses has been developed by the state of California. The California test requires a full scale instrumented fire test of a mattress in a room $10 \mathrm{ft}$.by $12 \mathrm{ft}$. by $8 \mathrm{ft}$. high. The ignition source is a bucket filled with crumpled newspapers placed beneath the center of the mattress. The three pass/fail criteria are: maximum weight loss of the mattress in the first 10 minutes - 108; maximum ceiling temperature - less than 500 degrees $\mathrm{F}$; and maximum carbon monoxide concentration - 1,000 ppm $[80]$.

Fire Response Plans. The ACA Standards for Adult Correctional Institutions requires written emergency plans, including, for example, written policy and procedures $(2-4173)$ that specify the means for the immediate release of inmates from endangered locked areas in case of emergency. The development of such plans must balance the need to protect the prisoners from injury due to fire and the need to maintain security and order. A combination of a properly designed and equipped facility and a good emergency plan can assure both safety and security.

Fire Alarm Systems. The purpose of fire alarm systems in prisons and jails is similar to that of fire alarm systems in other occupancies. The purpose is to alert the occupants, the fire department and/or the people managing the building, about the possibility of a fire emergency so that they can take the proper actions.

There are two major differences between prisons and other occupancies that affect system design. First, in many cases, the prisoners will not be allowed to leave on their own volition for security purposes; and second, in many cases, smoke detectors, heat detectors, and manual pull boxes will have to be placed out of the reach of the prisoners to avoid malicious damage and false alarms.

Currently there are a series of standards published by NFPA relating to the installation and application of fire alarm systems. None include any specific information regarding the system design for alarm systems for prisons. However, they do provide a candidate set of requirements for the 
components of such a system: some of these need to be modified to reflect the unique characteristics of prisons.

Some of the standards include requirements on the control unit (central panel) which forms the heart of a system. Others cover installation guidelines on equipment to be connected to the control unit to form the system, such as: automatic fire detectors (heat and smoke); audible signaling appliances to sound an evacuation signal during a fire; and supplementary components, (such as annunciators to identify the location of the fire, and printers to make a record for the fire department). An NFPA standard exists which includes requirements on testing and maintenance of a system.

While NFPA standards include installation criteria for the various parts of a fire alarm system, the performance of the equipment is evaluated by testing agencies, such as Underwriters Laboratories and Factory Mutual Corporation.

The use of smoke detectors in exhaust ducts appears promising in those situations where they can be maintained and tested, and are accessible to the prison staff but not to the prisoners. Underwriters Laboratories Standard UL 268A, Standard for Smoke Detectors for Duct Applications, defines the characteristics of smoke detectors installed in ducts. (If a duct receives air from a number of rooms, the smoke will be too diluted to activate the detector in a timely fashion.)

\section{F. Control Center}

General. A control center is essential for integrating the various security and communication functions for a detention or correctional facility. It is staffed around the clock, and must be secure from outside assault, and located to permit good visibility of the areas it is designed to monitor (e.g., entrance sallyports, circulation between buildings, etc.). In addition to serving as the communications center for a facility, control center activities also frequently include controlling the facility's entrance and exit traffic, recording inmate counts, key control, operation of electrically controlled doors, and coordination of the facility's internal and perimeter security network. It is also usually provided with the capabilities to control and/or monitor the operations of the following systems: fire alarm, public address, smoke and thermal detection, radio, teletype, computer terminal, surveillance alarms, walk and perimeter lighting, and other mechanical and electrical systems [12,22].

Placement of mimic panels, CRT displays, CCTV monitors, printers, and other components of the various systems noted above should permit all systems to be controlled and/or monitored from one location in the control center [30]. Use of a separate HVAC system for the control center should also be considered.

Communication Systems. The various communication systems which may used in a facility -- telephone, intercom, CCTV, public address, two-way radios, personal alarms -- should be integrated with the security systems to meet 
the functional needs of a particular facility. Historically, telephone equipment has consisted of two systems, one operating inside the facility and the other operating outside. Current technology permits a single solidstate telephone system that combines the security features of an inside system with the flexibility of an outside system [12].

All correctional facilities utilize extensive intercom systems not only for inmate control, but also as a redundant staff communications system [14]. A well designed, integrated intercom system can reduce staffing and support security and life safety. Specialized systems may also be used for door control, inmate visiting and line-up, and nurse call systems. CCTV systems for interior surveillance and door control are usually designed in conjunction with the intercom system for maximum functionality.

Public address systems allow control center staff to make general or emergency announcements or locate other staff members within the facility. A combination of portable radios and a base station provides another flexible, two-way communications link between staff members either inside or outside the facility including perimeter patrols, fire and rescue units, etc.

Personal alarm systems are provided to selected staff personnel to summon assistance in an emergency [12]. These alarms, when activated, transmit a signal to the control center. Some also have an added capability of 10 to 15 seconds of voice transmission. Specifications for personal alarm systems, which include functional tests, have been developed by the California Department of.Corrections [81].

Although this study. did not review and evaluate existing standards pertaining to communication systems, there does appear to be a lack of detailed guidance available for selecting such systems for correctional facilities. In addition, there is a need for criteria to assist architects and correctional officials in planning and designing control centers.

G. Economic Evaluations

Since there are many opportunities in correctional facility design to select alternate materials, equipment and systems (i.e., glazing, plumbing and lighting fixtures, perimeter security, etc.) with different levels of performance and durability, the economic impact of these design decisions are very important and need to be evaluated. A typical breakdown of the initial construction costs (excluding land acquisition) for a correctional facility is about as follows $[13,82]$ : 
- Architectural fees

- Owner administration \& insurance

- Site preparation (surveys, testing)

- Equipment \& furnishings

- Plumbing \& electrical

- Heating, ventilation \& air conditioning

- General construction

- Total construction costs
$100 \%$

The average cost per cell for medium security prisons in 1986 was reported as $\$ 60,342$ [83]. Although these initial construction costs for new prisons are high, the operating costs for a facility may be 16 times the cost of construction over a 30-year to 40-year period $[28,84]$. As discussed previously, staffing, utility and maintenance costs comprise about 808 of the life-cycle costs for a facility.

Standard practices for evaluating various economic measures (life-cycle costs, benefit-to-cost and savings-to-investment ratios, payback for investments, etc.) for buildings and building systems have been developed by ASTM Committee E- 6 on Performance of Building Construction (see Appendix B). Although these ASTM practices would be very useful in correctional facility design, no references to their availability and use was found in the articles and reports reviewed in this study. 


\section{Discussion and Conclusions}

A. General

Prior Study Recommendations. In one of the DOJ studies [28] cited previously, the following items were included in a list of 14 recommendations offered concerning the selection of materials, hardware and equipment:

- "Needs and expectations for the equipment and components are clearly defined. Definitions of needs are an integral part of the architectural program.

- "Facility security personnel are consulted in assessment of needs and selection of security systems and components.

- "Selection of security systems and facility equipment addresses physical and functional capability of each item or part. A package is included in the architectural program.

- "A system of establishing materials capabilities that includes 'failure parameters' for hardware is achieved through testing and setting specifications by the manufacturer, vendor, and independent $\mathrm{lab}$ and/or the buyer, and whenever possible, use of components on a trial basis.

$\circ$

"Facility materials, hardware and equipment are selected consistent with the philosophy and mission statement of the facility, and include consideration of: security levels needed; staff-inmate interaction/contact; and possible shifts in mission over time.

- "Factors in the selection of hardware and equipment are: staff capabilities for operating components; training of staff in the proper operation and use of equipment and components prior to facility opening and regularly thereafter; operating costs and servicing requirements; maintenance capabilities, including the size, availability and skills of the maintenance group, and the funds available for purchase of supplies, parts, tools and replacement items."

In regard to the materials and equipment problems reported in small jails [29], it is noted that such facilities usually do not have the experienced maintenance personnel to cope with "state-of-the-art" security/detention. equipment. Accordingly, architects should simplify systems whenever possible for remote small county jails. Similarly, owners should ensure that someone is trained to perform routine maintenance to avoid equipment breakdown. Small jails typically do not have adequate personnel for inmate programs or supervision. Inmates, therefore, have more opportunity to vandalize furnishings, equipment, etc. 
Correctional Official Recommendations. In conjunction with this study, various state correctional officials were asked for recommendations for specific studies or research needed to improve the state-of-the-art of selecting materials equipment and systems for correctional facilities. Responses received are contained in the following paragraphs.

\section{State E}

"1. The owners and planners need to set a clear program statement with regard to the needs the facility is to serve, security needs, type of equipment and hardware to meet those needs and a realistic staffing commitment.

"Often times the architect and their consultants are put on line first and tell the owners what they will give and they can make a case for not buying in to their plan as everything else will cost more, and the planners are not willing to pursue other courses of action.

"A program statement can be set by using (our) county staff. . . at no cost. When this is done, the county has control and can tell the architects what they want.

"2. When plans and specifications are approved by all parties involved, it must be understood that is what the county wants to buy. I have had problems with changes being made in the specifications by bidders when they have to submit 'shop drawings'. This is more true with detention equipment suppliers. There must be a second approval by a technician person to catch any changes before actual construction to avoid costly change orders or permitting the wrong installation that could be unsafe or not secure.

"3. During the construction phase there must be a person on the site to assure proper installation. In many cases where there is special equipment such as detention systems, a general contractor does not know what to look for and things can be deleted or installed improperly and not found out until the installers are done and gone.

"4. A good installer of detention equipment is vital. The owners must insist the firm that is successful with the bid insure that the installers are part of their firm or totally responsible to them in the contract.

"All detention firms that I have had dealings with have a basic good product, but in some case the installer was not tied to the detention firm and they tried to cut corners and in two cases, the projects were delayed at a cost to the owners. Installers must remain on the job unless released by owners.

"5. Perimeter security of any facility is vital. The staff must control everything that comes and goes in the jail. If the inmates 
cannot make or get in material to vandalize equipment, the equipment should not fail.

"For medium and maximum security all openings must be protected with bars or masonry, if the opening is over $51 / 2$ inches. The openings than must also be protected against small items of contraband with security screen or in the case of window that don't need to open by security glass.

"Walls and ceilings must be masonry or steel to prevent escape. All doors must have security locks. Builders hardware equipment and locks must never be used in a detention facility."

\section{State $F$}

"Based on (our) experience since 1980, which includes the design and construction of all levels of security from minimum to maximum .... most functional problems have been caused by the quality of workmanship or installation, not equipment, materials or systems. It is suggested that the execution portion of the specification sections and its enforcement be focused on.

"No standard criteria can be addressed until the diversity of design philosophies from state to state is dealt with. It is our feeling that the only way this can be achieved is to deal with it through a mandatory accreditation program with Federal assistance funds to match."

\section{State $G$}

"Studies which focus on specific construction materials, systems and equipment, the potential problems and track record of each under actual operating conditions would be most helpful. The abuse which a prison receives under actual operating conditions is very hard to duplicate in a research facility or a non-prison environment. There is a wealth of data waiting to be collected and presented which could prevent millions of dollars in design errors being committed in the future. There are lessons that we have learned... which I am certain could be of use to other states around the country and vice versa; however, the clearinghouse for this information is, to my knowledge, not yet available. Until this type of information become readily accessible it seems a certainty that the same incorrect material and equipment selections will continue to be made time after time by different governing authorities. The application of more consistent standards, uniformly accepted and adhered to by the security industry are of primary importance in ensuring a certain level of statistical data collected under actual prison operating conditions can, in the long run, guarantee a product's long term usability. This usability being defined not only by a product's mechanical properties, which can be properly determined in a laboratory, but also by the overall design of the product. This includes it's ability to resist tampering with by inmates, how easily it can be worked on and understood by typical 
corrections maintenance personnel, the level of field support provided by the manufacturer or supplier (parts and service availability) and the degree of user sophistication required. Until all of these considerations are taken into account, it is very difficult to determine with any certainty how usable a particular product will be."

\section{B. Conclusions}

As discussed in Section III, few standards (test methods, specifications, practices) are available which directly relate to special materials, equipment and systems used in detention and correctional facilities. Accordingly, when the architect and correctional official specify and select equipment and systems for a new facility, they rely, in most instances, on data from non-standard test methods, performance information based on prior use, recommendations from manufacturers and consultants, and their own judgement. The evaluation of innovative or new systems is also difficult because of the absence of test methods. In addition, the lack of standards makes if difficult, if not impossible, to match performance levels of the various components which comprise a particular system. Similarly, where equipment, etc. is specified for different security levels (i.e., maximum, medium, minimum), the general approach is to use prescriptive standards instead of performance standards because of the lack of performance test methods.

Based on data and information presented in this study, it is therefore concluded, that performance criteria and standards are needed for improving the state-of-the-art of selecting materials, equipment and systems to be used in detention and correctional facilities. Activities for developing these performance criteria and standards are discussed in the following sections.

\section{Performance Criteria for Correctional Facilities}

Objectives. Because of the broad range of problems and needs identified (Section II and III), criteria for the performance of building materials, equipment and systems to be used in correctional facilities should be developed. These criteria would have the following objectives:

1. Establish performance levels for building materials, equipment and systems which are consistent with the security and custody levels used in correctional facilities.

2. Establish standard performance measures with regard to security, safety and durability for building materials, equipment and systems.

The performance criteria would serve as a technical resource and reference for correctional officials, architects, engineers, material and equipment manufacturers, contractors, etc. The criteria would also benefit correctional facility building programs by providing a technical performance assessment base from which project specifications and uniform methods for evaluating materials, equipment and systems can be developed. 
Scope. The criteria would consider aspects of planning, design and construction different from conventional building by reason of their security, safety and durability considerations. They would, within the framework of their development, generate new knowledge relating building design, construction and security and are intended to:

1. Verify, refine and further develop security performance requirements of correctional facilities as building design, and building materials, equipment and systems used in those designs are modified.

2. Through performance standards development, and an updated data base of performance data, help ensure that the systems, materials, components, hardware and equipment are durable, reliable, readily maintainable, constructed in accordance with good practice, and meet the requirements for the rigors of use within the facility.

3. Provide appropriate instructions and information to help operate and service security systems and equipment.

4. Provide accepted practices which facilitate improved security system and equipment installation and performance.

Organization and Format. The performance criteria document would be organized on the basis of performance criteria dealing with security systems, components, equipment, and materials and their integration into the building(s) or facility.

Performance statement entries would be presented in the Requirement, Criterion, Evaluation, and Commentary format [85]. The Requirement is a qualitative statement giving the user need or expectation for the item being addressed. It is a general statement of what the system or its components shall be able to do. The Criterion is generally a quantitative statement giving the level of performance required to meet the application or expectation for the item being addressed. The criteria associated with each requirement state those considerations necessary to meet the requirement. Due to limitations in the state-of-the-art, a quantitative statement would not always be contained in each criterion. In addition, quantitative statements would be omitted in some criteria where values are to be provided by the designer. The Evaluation sets forth the record of experience, methods of test and/or other information upon which an evaluative judgement of compliance with a criterion will be based. It states the standards, inspection methods, analyses, review procedures, historical documentation, or other methods that may be used in evaluating whether not the system and its components comply with the criterion. The Commentary provides background information and presents the rationale behind the selection of specific data presented in the Requirement, Criterion or Evaluation. The Commentary is intended for informational purposes and in some instances, provides design guidelines. Such guidelines are only one suggestion of appropriate methods; in most instances, there will be other methods equaily as effective. Including a commentary ensures a workable process of updating performance criteria, and when questions arise as to the basis for a 
particular criterion, the reader will have available the rationale for its selection.

Content. At the programming level, criteria would be developed to address the overall facility, its functional operations, interrelationships between various systems, and security levels that are required for various spaces and systems. For instance, quantification of performance for maximum level security may require, from a functional point of view, that no prisoner is left unobserved for over fifteen minutes. The medium security level may have a different criterion. Development of general functional criteria for security levels, spatial relationships, building systems, etc. would assist the "owner" in defining specific functional needs for a given facility. Also, for the architect, such criteria would assist in establishing performance requirements for the facility and for specific materials, systems and equipment. Criteria at this level will help ensure that the systems, materials, and equipment specified and selected will be consistent with the security levels, mission, and staffing of the proposed facility.

Criteria would also be developed for the major perimeter and building systems used in correctional facilities. These criteria would indicate the performance (security, durability, etc.) levels needed for the particular system (e.g., fence, intrusion detection, wall, lighting) under consideration. The establishment of criteria at the system level would also provide a better basis for defining performance requirements for the various materials, components and equipment which constitute a specific system. Criteria for installation, testing, operation and maintenance of different equipment and systems would also be addressed.

The performance criteria should also contain guidelines for post occupancy evaluation of the facility. Such evaluations, made at various intervals after a newly constructed facility has been put into use, would identify problems or potential problems which need to corrected and provide valuable information for the design of new facilities at some future date.

\section{Standards for Materials, Equipment, and Systems}

Standard test methods are important evaluative tools to measure the performance of materials, equipment and systems. Standards can also simplify the specification of materials, etc. and provide guidance on various analysis, construction, installation and testing practices. Based on the performance problems and the lack of adequate standards identified in this study, activities should be undertaken to develop new standards or modify existing standards as discussed in the following paragraphs. (For background information on the different types of standards (i.e., test methods, specifications, practices, guides) and the development of national consensus standards, the reader may wish to refer to Appendix A.)

Since this report is the result of an initial study, it is anticipated that the following list will be revised as suggestions and comments are received from correctional officials, architects, engineers, manufacturers, standards development committees, professional groups and associations, etc. 
Guide for the Physical Security of Correctional Facilities. Although a few guides and recommendations are available for selecting different types of equipment and systems, there is no overall guide (as identified in this study) for determining or assessing the overall physical security of a correctional facility. Such a guide would aid architects and correctional officials in evaluating physical security requirements during the planning and design of a new or modified facility. The guide could be a narrative description, a series of check lists of factors to be considered, a computer model, etc. Where appropriate, the development of this guide should draw upon relevant information and methodologies prepared for other types of facilities (military, nuclear, commercial) where physical security is a major consideration.

Guide for a Post-Occupancy Evaluation of a Correctional Facility. Based on this study, it is not clear how many correctional agencies have developed formal guides, practices, or programs for conducting post-occupancy evaluations of facilities. One state which has such a program is California. In this program, Post-Occupancy Evaluation (POE) is "the practice of using qualitative and quantitative methods to evaluate spaces and operations to determine how well buildings support their activities and users [86]:" Some evaluations are conducted before the facility is completed and others two or three years after the institution is fully activated. One of the evaluations is a "design analysis" which focuses on the design and operations of a completed area. It assesses various systems and components such as lighting, furnishings, security hardware and communications, both individually and as they relate to other features and operations in the building. A guide for conducting a POE would be a valuable tool in providing data which could be used in making betterinformed planning, design, construction and operational decisions.

Guide for the Integration of Electronic Security/Communication/Safety Systems. The selection and integration of electronic security. communication, and safety systems is one of the most difficult and important design challenges to providing a secure and safe facility. Information on the performance of a particular system can be obtained from the manufacturer of that system. However, little information is available to assist the architect and owner in selecting systems which work effectively in a given environment with other systems or how they should be integrated with other systems. A guide outlining factors to be considered in this selection and integration process would be very useful document for correctional facility designers.

Guide for the Maintenance of Equipment and Systems. Training of maintenance staff, good operating and maintenance manuals, and scheduling of routine and preventative maintenance are important elements in keeping equipment and systems functioning at expected performance levels. This recommended guide would address the above mentioned elements and describe considerations for developing an effective correctional facility maintenance program. 
Specifications for Security Fences and Gates. As reviewed in Section III.D.2, twenty four (24) existing standards were identified in this study pertaining to fences, gates, barbed tape, etc. Although no major problems with perimeter fences and gates were noted, it would be desirable to develop a standard specification specifically covering security fences and gates for correctional facilities. Such a specification would address performance areas important for jails and prisons, and assist in establishing improved and more uniform requirements for fences and gates used in these facilities. Using the existing standards as a base, this standard specification could cover requirements for materials (fence fabric, posts, barbed tape, etc.) as well as their installation. Needed tests for barbed tape attachments and fabric tension could be included in either this standard or another test method standard.

Test Methods for Intrusion Detection Sensors and Systems. Considerable problems (false alarms, difficult maintenance, etc.) have been reported with intrusion detection systems [28]. Although some states $[30,31]$ have developed guide specifications and acceptance tests for such systems, there are no national standards for testing these systems. Since performance requirements (false alarm rates, probability of detection) are used by some agencies to select these systems, standard test methods are needed to determine compliance with these requirements. For fence sensors and systems, performance tests should include response to climbing (fast and slow), cutting, and deformation. For other types of sensors and systems (Section III.D.3), test methods should include response to walking, running, crawling, and rolling. Tests for evaluating sensor and system performance under different environmental conditions should also be included.

Specifications for Perimeter Intrusion Detection Systems. For the various types of intrusion detection systems discussed in Section III.D.3, standard specifications should be developed. Among requirements to be included in these specifications are: minimum performance levels (false alarm rates, probability of detection), alarm assessment and reporting, and installation practices. Test methods for sensors and systems (discussed above) would be included in these specifications by reference.

\section{Building Systems}

Test Methods for Security Doors and Hardware. As noted in Section II.E.4, guide specifications are available for detention security hollow metal doors [54]. In addition, an ASTM Subcommittee (A01.16) is currently preparing a specification covering swinging detention door assemblies. These standards development activities should be continued to prepare national standards. Test methods and specifications are also needed to cover security doors and hardware constructed to meet various levels of performance (maximum, medium, and minimum).

Laboratory Test Methods for Security Glazing. Various physical attack test methods for security glazing were briefly reviewed in section III.E.6. In addition to completing the current ASTM Committee F12 work on a field-type 
physical attack test, a laboratory test method for physical attack resistance of security glazing should also be prepared. Since considerable laboratory testing has been completed $[59,62]$, there is an excellent starting basis for preparing a standard test method.

Test Methods for Locks and Access Control Systems. Several lock standards developed by Underwriters Laboratories, Inc. (UL) and Builder Hardware Manufacturers Association, Inc. (BHMA) are cited in product literature and correctional facility specifications. However, these standards do not describe any unique tests for determining the performance of locks, locking devices, or access control systems used in correctional facilities. Considering the number of problems previously cited (Section III.B), additional stúdies should be undertaken to develop improved performance test methods for locks, locking devices, and access control systems used in jails and prisons.

Laboratory Test Methods for Durability of Lighting Fixtures. To provide a better basis for determining performance levels for the durability of lighting fixtures used in correctional facilities (especially those used in cells), laboratory test methods should be developed. These test methods should address the impact and tamper resistance of the fixture (lens and housing), the combustibility of the lens, etc.

Specifications for Security Lighting Fixtures. As in the case of security doors, various existing specifications and recommendations for security lighting fixtures contain prescriptive requirements for their construction (Section III.E.8). Using this information, a standard specification should be developed to indicate minimum acceptable materials (type and thickness) and construction types for lighting fixtures used in areas with different security levels.

\section{Fire Safety}

Test Methods for Flaming Ignition of Mattresses. As discussed in Section III.E.9, a test procedure to measure the flaming ignition of mattresses has been developed by California [80]. Because this test procedure is a fullscale fire test, it is very expensive to conduct. Based on prior NBS research involving bench scale tests of mattresses $[78,79]$, it is feasible to develop standard bench scale test methods. These tests would: be less expensive to run; allow more properties of materials and their combustion products to be evaluated; and use standard test equipment.

Specifications/Guidelines for Fire Detectors and Alarms. Standards are available which give general guidance for the application and installation of fire alarms and smoke detectors. Proposed changes to these standards (or separate guidelines) should be developed to give specific guidance for designing and locating alarms and detectors in correctional facilities.

Guide for Developing Fire Emergency Plans. tailored for the conditions and fire safety or prison. However, because there are facilities, guidelines should be prepared
A fire emergency plan must be features of the individual $j a i l$ similarities in correctional to assist in developing fire 
emergency plans for individual institutions. conducted to determine if and how specific information conditions can aid correctional officers in initiating For example, if the his monoxide levels are low (as determined from sensors), it may be safe to delay unlocking certain cells, etc.

Revisions to Life Safety Code. As experience is gained in using any set of requirements, information is obtained that can be used to improve those requirements. As mentioned previously, a new Firesafety Evaluation System for Detention and Correctional Occupancies was incorporated into the NFPA Life Safety Code in 1985. Since it takes years between the publication of a new standard and the completion of buildings meeting the standard, it appears that sufficient time has now passed to determine who has applied the current requirements and to learn of their experiences and insights. Information gained in these efforts would be developed into recommended revisions to the Life Safety Code.

3. Data Base for the Performance of Materials, Equipment and Systems

As an important corollary effort for performance criteria and standards development activities, there is also a need for a continuing activity to collect performance data on materials, equipment, and systems used in detention and correctional facilities. Information collected would provide a data base which would be valuable for identifying problems and successes with various systems, as well as developing guides to assist in future facility design and construction activities. These data and information could be compiled into "lessons learned" bulletins and provide a technical resource for recommended performance criteria and standards development activities discussed previously.

\section{Economic Guide or Handbook}

Because of the many opportunities (and challenges) for selecting materials, equipment and systems with different performance and durability levels, there is a need for a guide or handbook which would document and illustrate the use of available standard economic analyses and practices (Appendix B). This guide would be a valuable tool for assisting designers and correctional officials in evaluating the life-cycle cost impact of alternate materials, equipment, and systems. 
V. Recommended Priorities for Future Activities

As a part of this study, a Review Committee was organized by NBS and a Review Committee meeting was held at NBS, Gaithersburg, MD, on July 28-29, 1987. (For names of Review Committee members, see Acknowledgements). The objectives of this meeting were to obtain: (1) comments and suggestions on a preliminary draft of this report; (2) assistance in finalizing a list of future criteria and standards development activities; and (3) recommended priorities for these future activities. For setting priorities, no specific criteria were established. Accordingly, each committee member was permitted to rank each activity according to his (or her) own professional background and experience, discussions at the meeting, etc. Except as noted below, the priority of each criteria and standards development activity listed is based on a weighted average of the individual committee member rankings.

\section{Criteria and Standards Development Activity}

- Tést Methods for Locks and Access Control Systems

- Test Methods for Flaming Ignition of Mattresses

- Performance Criteria for Correctional Facilities

- Test Methods for Security Doors and Hardware

- Laboratory Test Methods for Security Glazing

- Data Base - Performance of Materials, Equipment, \& Systems

- Specifications for Perimeter Intrusion Detection Systems

- Guide for the Integration of Electronic Security/ Communication/Safety Systems

- Guide for the Physical Security of Correctional Facilities

- Test Methods for Intrusion Detection Sensors \& Systems

- Specifications/Guidelines for Fire Detectors \& Alarms

- Guide for Developing Fire Emergency Plans

- Specifications for Security Lighting Fixtures

- Guide for a Post-Occupancy Evaluation of a Correctional Facility

- Economic Guide or Handbook
Priority

High

High

High

High

High

High

High

Medium

Medium

Medium

Medium

Medium 6

Low

Low

Low

6. Priority established by authors; not determined by Review Committee members. 
- Laboratory Test Methods for Durability of Lighting Fixtures

Low

- Specifications for Security Fences and Gates Low

- Revisions to the Life Safety Code Low

- Guide for the Maintenance of Equipment and Systems Low 
VI. References

1. "The 1983 Jail Census," U.S. Department of Justice, Bureau of Justice Statistics Bulletin, NCJ-95536, Washington, DC, November 1984.

2. "State and Federal Prisoners, 1925-85," U.S. Department of Justice, Bureau of Justice Statistics Bulletin, NCJ-102494, Washington, DC, October 1986.

3. "Prisoners in 1986," U.S. Department of Justice, Bureau of Justice Statistics Bulletin, NCJ-104864, Washington, DC, May 1987.

4. "Jail Inmates, 1985," U.S. Department of Justice, Bureau of Justice Statistics Bulletin, NCJ-105586, Washington, DC, July 1987.

5. "New Construction Methods for Correctional Facilities," Charles B. DeWitt, National Institute of Justice (NIJ) Construction Bulletin, NCJ 100121, Washington, DC, January 1986.

6. "Tougher Laws Fuel Prison Demand," Engineering News Record, McGrawHill, Inc., February 26, 1987, p. 17.

7. "Building on Experience," Charles B. DeWitt, NIJ and National Institute of Corrections (NIC), NCJ 103869, Washington, DC, January 1987.

8. "Prison Outlays Spawn Work," Engineering News Record, McGraw-Hill, Inc., January 8, 1987, p. 12 .

9. "Corrections' Strength and Vision," T. Don Hutto, Corrections Today, American Correctional Association (ACA), College Park, MD, October 1986, p. 42 .

10. Letter dated April 8, 1985 from Edgar A. Smith, Assistant Executive Officer, California State Board of Corrections, to Lawrence Eliason, National Bureau of Standards.

11. "Planning of New Institutions," NIC Jails Division, Boulder, CO, 1986.

12. "Design Guide for Secure Adult Correctional Facilities," American Correctional Association, College Park, MD, 1983.

13. "Jail Planning \& Construction Guide," Nebraska Jail Standards Board, Nebraska Commission on Law Enforcement and Criminal Justice, 1987.

14. "More For Le\$\$ - Jail Construction Cost Management Handbook," prepared by Kitchell CEM for State of California Board of Corrections, 1987.

15. "Correctional Facility Planning and Design," Jay Farbstein, Van Nostrand Reinhold Company, Inc., Second Edition, 1986. 
16. "Small Jail Special Issues," KIMME Planning \& Architecture, Champaign, Illinois, prepared for NIC, February 1986.

17. "Designs for Contemporary Correctional Facilities," NIC Facilities Monograph Project, Capital Publishing Company, 1985.

18. "Jail Security -- A Unique Challenge," Thomas R. Barry, Corrections Today, American Correctional Association, College Park, MD, July 1987.

19. "Prison Classification -- A Model Systems Approach," NIC, Washington, DC, 1983.

20. "Security" Systems - Making an Intelligent Choice," Robert I. Turner, NIC National Academy of Corrections Lesson Plan, June 23, 1986.

21. "Correctional Standards Supplement," American Correctional Association, College Park, MD, January 1986.

22. "Standards for Adult Correctional Institutions," American Correctional Association, College Park, MD, Second Edition, January 1981.

23. Quotation from Fred Moyer, Moyer Associates, in "Insecurities About Security: Face to Face with the Building-Protection Crisis," Architectural Record, August 1987, p.127.

24. "1983 Architecture for Justice. Exhibition," Committee on Architecture for Justice, American Institute of Architects, Washington, DC, 1983.

25. "1984 Architecture for Justice Exhibition," Committee on Architecture for Justice, American Institute of Architects, Washington, DC, 1984.

26. "1985. Architecture for Justice Exhibition," Committee on Architecture for Justice, American Institute of Architects, Washington, DC, 1985.

27. "National Directory of Corrections Construction, First Edition," Charles B. DeWitt, NIJ, Washington, DC, August 1986.

28. "Correctional Facility Design and Construction," Dale K. Sechrest, Shelley J. Price, NIJ, Washington, DC, February 1985.

29. "The Nature of New Small Jails: Report and Analysis," KIMME Planning \& Architecture, Champaign, Illinois, prepared for NIC, October 1985.

30. "Design Criteria Manual," Planning and Construction Division, Department of Corrections, State of California, Sacramento, CA, (with revisions through Dec. 15, 1986).

31. "D\&C Master Specifications," Design and Construction Group, New York Office of General Services, Albany, NY, March 2, 1987.

32. "Stopping Escapes: Perimeter Security," George and Camille Camp, NIJ Construction Bulletin, NCJ 104600, Washington, DC, March 1987. 
33. "Barrier Technology Handbook," SAND77-0777rev, Sandia National Laboratories, Albuquerque; NM, 1981.

34. "Electronic Perimeter Security," Martin Weeden, Corrections Today, American Correctional Association, College Park, MD, April 1985.

35. "The Perimeter Security Sensor Dilemma," David E. Moore, Corrections Today, American Correctional Association, College Park, MD, April 1986.

36. "Perimeter Security: New Technologies," C. Richard Brogan, Corrections Today, American Correctional Association, College Park, MD, April 1987.

37. "Perimeter Security -- Electronic Options," Corrections Today, American Correctional Association, College Park, MD, April 1987.

38. "Electronic Perimeter Security: Have You Purchased a Solution or a Problem?," Francis J. Sheridan, Presentation at the 1986 ACA 116 th Congress of Correction, Las Vegas, Nevada.

39. "Intrusion Detection Systems Handbook," SAND76-0554, Sandia National Laboratories, Albuquerque, New Mexico, August 1983.

40. "Perimeter Intrusion Alarm Systems," Regulatory Guide 5.44, Revision 2, U.S. Nuclear Regulatory Commission, Washington, DC, May' 1980.

41. "Commercial Intrusion. Detection Systems (IDS)," Design Manual 13.02, Naval Facilities Engineering Command, Alexandria, VA, September 1986.

42. "Closed-Circuit Television -- Components of Surveillance; Applying Electronic Vision; Making Systems from Components; Terminology and Resources," Security, Cahners Publishing Company, Newton, MA, July 1987.

43. "The Basics of CCTV," Herman Kruegle, Security Management, American Society for Industrial Security, Arlington, VA, June 1981.

44. "Lighting Requirements for CCTV," Mark Glicksman, Security Management, American Society for Industrial Security, Arlington, VA, June 1981.

45. "Design for Security," Richard J. Healy, John Wiley \& Sons, Second Edition, 1983.

46. "Evaluation of Pre-Manufactured Housing for Correctional Purposes," Carter-Goble Associates, Inc., National Institute of Corrections, Washington, DC, February 1984.

47. "Florida Sets Examples With Use of Concrete Modules," Charles B. DeWitt, NIJ Construction Bulletin, NCJ 100125, Washington, DC, March 1986. 
48. "Prefabrication -- How Well Does it Work," Robert S. George, Corrections Today, American Correctional Association, College Park, MD, July 1987.

49. "Precast Concrete Construction Cuts Prison Costs," Fromy Rosenberg, Corrections Today, American Correctional Association, College Park, MD, April 1984.

50. "California Tests New Construction Concepts," Charles B. DeWitt, NIJ Construction Bulletin, NCJ 101593, Washington, DC, June 1986.

51. "Precast and Prestressed Concrete for Justice Facilities, "Walker McGough Foltz Lyerla and The Consulting Engineers Group, Inc., Prestressed Concrete Institute, 1985.

52. "Minimum Jail Standards," Texas Commission on Jaịl Standards, Robert 0. Viterna, Austin, Texas, January 31, 1984.

53. "County and Municipal Detention Facilities," Chapter 33-8, Florida Department of Corrections, Tallahassee, FL, October 1986.

54. "Guide Specifications for Detention Security Hollow Metal Doors and Frames," NAAMM Standard HMMA 863-87, The National Association of Architectural Metal Manufacturers (NAAMM), Chicago, Illinois, 1987.

55. "Swinging in Your Favor," Donald C. Smeltzer and H.W. Wehe, Security Management, American Society for Industrial Security, Arlington, VA, June 1987.

56. "Choosing the Best Security Window," Ryne R. Johnson, Corrections Today, American Correctional Association, College Park, MD, April 1984.

57. "Steel Windows -- Specifications," Steel Window Institute, Cleveland, Ohio, May 1983.

58. "Windows and Glazing: A Summary of 10 Years of Controversy," Dennis A. Kimme, Washington Jail Architectural Symposium and Materials Fair, October 1, 1980.

59. "Security Glazing Testing Program and Recommendations," prepared by Kitchell/CEM for the State of California Department of Corrections, July $10,1985$.

60. Various reports on the testing of security glazing, Wiss, Janney, Elstner Associates, Northbrook, Illinois.

61. "Transparent Materials and Assemblies for Use in Forced Entry or Containment Barriers," HPW-TP-0100.00, Revision B, H.P. White Laboratory, Street, Maryland, December 10, 1983. 
62. "Development of a Test Method to Evaluate the Penetration Resistance of High-Security Glazing Subjected to Mechanical Impact and Heat," L.I. Knab, S. Fischler, J.R. Clifton, N.E. Waters, NIJ Report 300-85, National Institute of Justice, Washington, DC, November 1986.

63. "Design Criteria for Correctional Facility Access Control Systems," Carl Dean, Corrections Today, American Correctional Association, College Park, MD, April 1984.

64. "Entry-Control Systems Handbook," SAND77-1033 Revised, Sandia National Laboratories, Albuquerque, NM, September 1980.

65. "Electronic Access -- The Key to Better Security," Bill Lynch, Corrections Today, American Correctional Association, College Park, MD, July 1987.

66. " "High Security Locking Devices -- A State-of-the-Art Report," John S. Stroik, NBSIR 81-2233, NBS, Gaithersburg, MD, January 1982.

67. "Lighting for Corrections," Eddis M. Goodale, Lighting Design + Application, Illuminating Engineering Society of North America, New York, NY, September 1987.

68. "Lighting Leads to Security," Robert W. Chism, Corrections Today, American Correctional Association, College Park, MD, April 1985.

69. "Lighting - First Step to Safety," Joseph 'R. Claffy, Corrections Today. American Correctional Association, College Park, MD, April 1986.

70. "Security Lighting - - Testing for Better Design and Construction," Horton Conrad, Jr., Corrections Today, American Correctional Association, College Park, MD, April 1986.

71. "A Study of Penal Institution Fires," NFPA No. FR78-1, National Fire Protection Association, Boston, MA, 1977.

72. "Fire Safety in Correctional Facilities," Annotated Edition, prepared by NFPA for NIC, 1981.

73. "The Development of a Fire Evaluation System for Detention and Correctional Occupancies," H.E. Nelson, A.J. Shibe, NBSIR 84-2976, NBS, Gaithersburg, MD, December, 1984.

74. "Effect of Ventilation on the Rates of Heat, Smoke, and Carbon Monoxide Production in a Typical Jail Cell Fire," B.T. Lee, NBSIR 82-2469, NBS, Gaithersburg, MD, March, 1982.

75. "A Preliminary Analysis of Padded Cells Fire Safety," R.B. Williamson, F.L. Fisher, Prepared for State of California Bureau of Corrections, UCB Engineering 4808, University of California, Berkeley, CA, March, 1980 . 
76. "Fire Test for Wall and Ceiling Materials and Assemblies for Use in Padded Safety Cells," R.B. Williamson, F.L. Fisher, University of California, Berkeley, January, 1982.

77. "Fire Hazard Evaluation of Shipboard Hull Insulation and Documentation of a Quarter-Scale Room Fire Test Protocol," B.T. Lee, NBSIR 83-2642, NBS, Gaithersburg, MD, August, 1983.

78. "Combustion of Mattresses Exposed to Flaming Ignition Sources; Part I. Full-Scale Tests and Hazard Analysis," V. Babrauskas, NBSIR 77-1290, NBS, Gaithersburg, MD, September, 1977.

79. "Combustion of Mattresses Exposed to Flaming Ignition Sources; Part II. Bench-Scale Tests and Recommended Standard Test," V. Babrauskas, NBSIR 80-2186, NBS, Gaithersburg, MD, February, 1981.

80. "Flammability Test Procedure for Mattresses for Use in High Risk Occupancies," Technical Information Bulletin No. 121, State of California, Department of Consumer Affairs, Bureau of Home Furnishings, North Highland, California, April 1980.

81. "Technology Transfer," Robert $H$. Lawson, The American Justice Institute, A Report Prepared for the California Department of Corrections, January 1984.

82. "Building Construction Cost Data 1985," R.S. Means Company, Inc., Kingston, MA 02364.

83. "Survey: 1986 Prison Construction Tops $\$ 3$ Billion," Corrections Compendium, Contact Center, Inc., Lincoln, NE, May 1986.

84. "Life Cycle Costs as a Consideration for State Corrections Construction," J. Michael Pitts, Ed Killingsworth, Patrick R. Anderson, Advancing Building Technology, Proceedings of the 10th Triennial Congress of the International Council for Building Research, Studies and Documentation, Volume 9, September 22-26, 1986, p.3981.

85. "Performance Criteria for Solar Heating and Cooling Systems in Commercial Buildings," Center for Building Technology, NBS Technical Note 1187, NBS, Gaithersburg, MD, April 1984.

86. "Post-Occupancy Evaluation Program," California Department of Corrections/Kitchell CEM, May 4, 1987. 
Appendix A - An Overview of Standards Terminology and the Standards Development Process

\section{Overview of Standards}

The American Society for Testing and Materials (ASTM) defines a standard as "a rule for an orderly approach to a specific activity, formulated and applied for the benefit and with the cooperation of all concerned [1]." In terms of building design and construction, a standard may be a specific set of requirements or instructions for the testing, design, manufacture, installation, and use of a building material, component or system [2]. A standard exists when an agreement has been obtained on its content. The level of agreement may range from a consensus of employees of an organization (company standard) to a full consensus developed by representatives of all sectors that have an interest in the use of the standard (consensus standard); see figure A.

Types of Standards. ASTM develops six different types of full consensus standards which are defined in the following paragraphs [1]. Other standards developing organizations such as the American Society of Mechanical Engineers (ASME), Building Hardware Manufacturers Association (BHMA), National Fire Protection Association (NFPA), etc. produce similar types of standards which may have different names and definitions.

"A standard test method is a definitive procedure for the identification, measurement, and evaluation of one or more qualities, characteristics, or properties of a material, product, system, or service that produces a test result." An example of this type of standard is ASTM E119, Methods of Fire Tests of Building Construction and Materials, which is used to determine the duration that various types of assemblies (floors, walls, etc.) will contain a fire.

"A standard specification is a precise statement of a set of requirements to be satisfied by a material, product, system, or service that also indicates the procedures for determining whether each of the requirements is satisfied." An example of a standard specification is ASTM A629, Specification for Tool-Resisting Steel Flat and Shapes for Security Applications. It contains requirements for performance characteristics and simulated service tests for determining such characteristics for homogeneous steel bars and shapes.

"A standard practice is a definitive procedure for performing one or more specific operations or functions that does not produce a test result." A good example of this type of standard is ASTM E917, Standard Practice for Measuring Life-Cycle Costs of Buildings and Building Systems. This practice describes step-by-step procedures for using the life-cycle cost method.

"Standard terminology documents contain definitions and descriptions of terms, or explanation of symbols, abbreviations, and acronyms." ASTM E631, Terminology Used in Building Construction, is such a standard. 


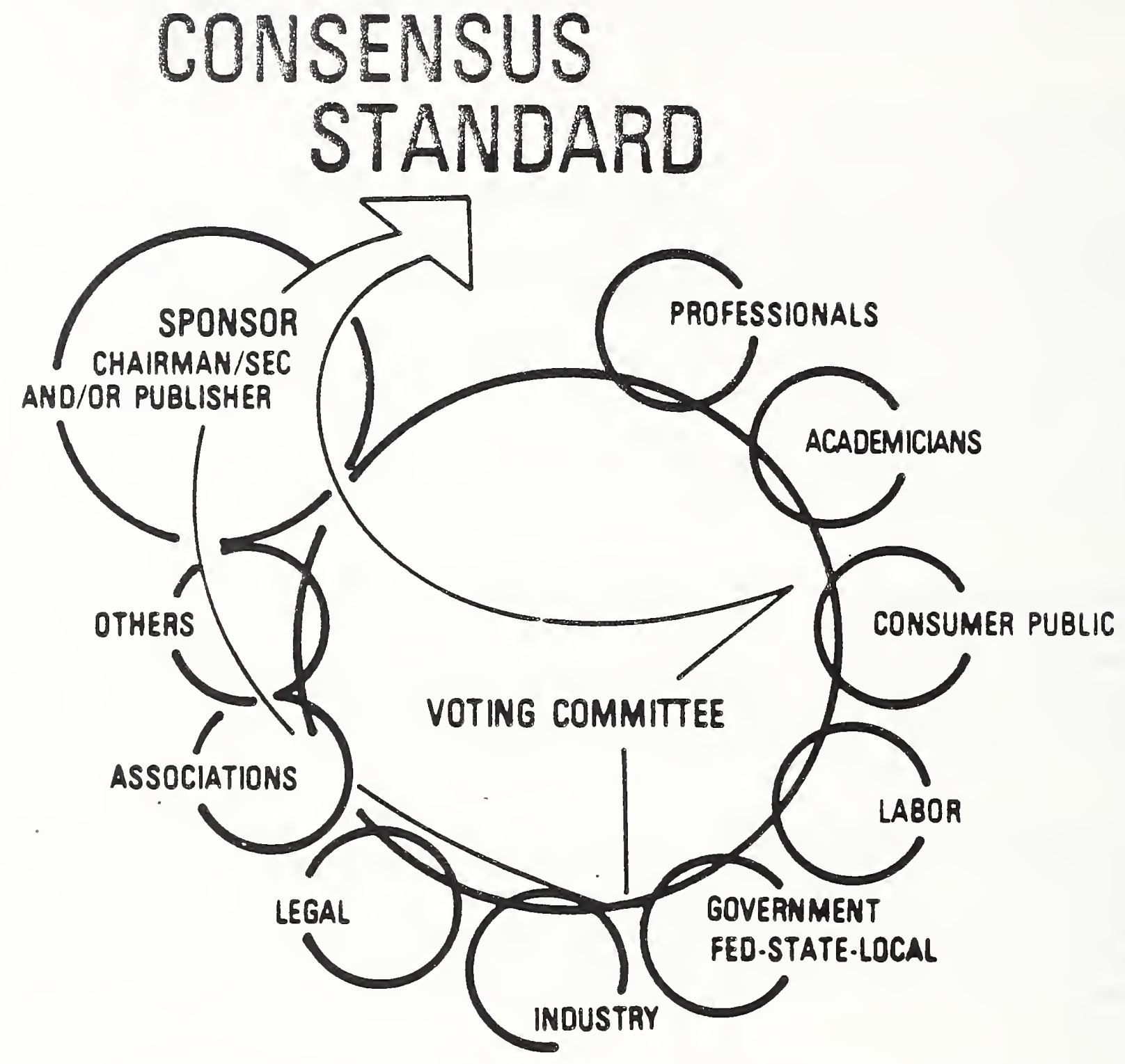

ALL NEGATIVE VOTES MUST BE SUBSTANTIATED \& RESOLVED

Figure A. Consensus Standards Development Process 
"A standard guide offers a series of options or instructions, but does not recommend a specific course of action. Where a standard practice prescribes a general usage principle, a guide only suggests an approach." A recently developed standard guide is ASTM F1029, Guide for the Selection of Physical Security Measures for a Facility. It contains information to aid in the selection of effective security measures to deter or detect an attack on a facility. These measures depend upon the threat level and the asset ( $r i s k$ ) level of the facility.

"A standard classification is a systematic arrangement or division of materials, products, systems, or services into groups based on similar characteristics such as origin, composition, properties, or use." An example of this standard type is ASTM F793 which contains a classification of wallcoverings based on durability.

Performance vs. Prescriptive Standards. A prescriptive standard is quite specific in nature giving details of usage or design procedures for a building material, component or system. An example of a prescriptive requirement would be that timber wall framing shall be $2 \times 4$ studs on 16inch centers. A performance standard prescribes objectives, conditions and criteria to be accomplished and allows broad leeway for the designer to achieve results. The performance statement for the above condition would be that the wall system shall be designed to specified loading and deformation criteria allowing the innovative designer freedom to select the materials and other specific construction details.

\section{Standards Development Process}

Organizations Involved. In 1983 approximately 420 nongovernment organizations maintained an estimated 32,000 standards. These constitute approximately 40 percent of the total inventory of U.S. standards, which exceeds 80,000 . There are about 49,000 standards developed by Federal agencies. More than 38,000 of these have been prepared by the Department of Defense (DoD); 6,000 are Federal standards and specifications developed for Federal procurement under the auspices of the General Services Administration (GSA). Additional standards have been prepared by U.S. Government departments and independent agencies. Some state purchasing departments have developed significant numbers of standards. These are not included among the total quantity of standards because they are not applied nation-wide [3].

Twenty years ago there were 39,500 government standards and less than 14,000 nongovernment standards. About 2,000 (17 percent) of the nongovernment standards were designated American National Standards (ANS). Today, more than 8,500 standards, 25 percent of the nongovernment standards, have been processed through the American National Standards Institute (ANSI) and designated ANS.

At any time during the past 20 to 30 years some 400 private sector organizations have been developing standards. Approximately 260 (65 percent) have ongoing standardization programs. The remainder have prepared 
a few standards, occasionally update them, but are not actively or routinely engaged in standards development.

The 26,000 standards issued by the 20 organizations listed in Table A are, for the most part, distinct with respect to subject matter and content. Only a relatively small portion are redundant or overlap other standards. In contrast, a greater fraction of the remaining 6,000 nongovernment standards show evidence of redundancy: This is most apparent in standards used in the building and construction sector.

Legal Aspects. In addition to its technical credibility, a standard must rest on sound legal principles if it is going to stand the tests of time and use. In the United States, there are four principles which impact standards development: due process, restraint of trade, authority and responsibility, and liability. Among other important points, due process provides everyone on a standards committee with a voice in the development of a standard, including an opportunity for anyone to appeal if they are dissatisfied. In order for standards to avoid restraint of trade violations, measures must be taken to prevent them from unreasonably restricting competition by stifling innovation or by excluding potential competitors from established markets. The third principle, authority and responsibility, requires that organizations have authorization in their charters for developing standards, have written procedures for developing, promulgating and maintaining standards, etc. The fourth legal principle, liability, is especially of interest to individuals working on standards development committees. In the case of ASTM, which is a nonprofit corporation chartered in Pennsylvania, members of $a$ nonprofit corporation are not personally liable for debts, liabilities, or obligations of the corporation.

\section{Benefits of Standardization}

In addition to improving safety and safeguarding health, standards serve to greatly simplify commerce in a highly industrialized society and provide a common language that promotes the flow of goods between buyer and seller. Thousands of standards are available for referencing in building codes, construction specifications, purchase orders, etc. Other commercial benefits of standards include [1]:

- Greater user confidence in commodities purchased.

- Better understanding of how to use commodities.

- Improved organizational integration, especially between sites.

- Better quality control.

- Lower inventories for both producer and user through elimination of unnecessary grades.

- Earlier delivery because of the ability to stock standard items.

- Better performance at lower prices through reduced need for negotiations and more efficient inspection and testing. 
TABLE A. 20 MAJOR NONGOVERNMENT STANDARDS DEVELOPERS

Number of

Standards

Aerospace Industries Association

2,800

American Association of Blood Banks

280

American Association of Cereal Chemists

American National Standards Institute

$1,330^{*}$

American Oil Chemists Association

American Petroleum Institute

American Railway Engineers Association

American Society for Testing and Materials

7,200

American Society of Mechanical Engineers

Association of American Railways

1,350

Association of Official Analytical Chemists

1,500

Cosmetic, Toiletry and Fragrance Association

Electronic Industries Association

Factory Mutual

600

Institute of Electrical and Electronics Engineers

National Fire Protection Association

Society of Automotive Engineers

4,200

Technical Association of the Pulp and Paper Industry

Underwriters Laboratories

U.S. Pharmacopeia

2,900

*Published and copyrighted by ANSI. 


\section{$\underline{\text { References }}$}

1. "Standards Make the Pieces Fit," ASTM, 1916 Race Street, Philadelphia, PA 19103.

2. "Standards -- Tools for Excellence," Robert D. Dikkers, Corrections Today, American Correctional Association, April 1987.

3. "Standards Activities of Organizations in the United States," Robert B: Toth, Editor, NBS Special Publication 681, August 1984, National Bureau of Standards, Gaithersburg, MD 20899. 
Appendix B -- Brief Descriptions of Selected Standards for Materials, Equipment, and Systems

\section{$\underline{\text { ACRONYMS }}$}

$\begin{array}{ll}\text { ACI } & \text { American Concrete Institute } \\ \text { ANSI } & \text { American National Standards Institute, Inc. } \\ \text { ASHRAE } & \text { American Society of Heating, Refrigerating \& Air- } \\ & \text { Conditioning Engineers, Inc, } \\ \text { ASTM } & \text { American Society for Testing and Materials } \\ \text { BHMA } & \text { Builders Hardware Manufacturers Association } \\ \text { CEGS } & \text { Corps of Engineers Guide Specification } \\ \text { CFR } & \text { Code of Federal Regulations; or Center for Fire } \\ & \text { Research, NBS } \\ \text { CPSC } & \text { Consumer Product Safety Commission } \\ \text { EIA } & \text { Electronic Industries Association } \\ \text { FCGS } & \text { Federal Construction Guide Specification } \\ \text { HPW } & \text { H.P. White Laboratory, Inc. } \\ \text { ICBO } & \text { International Conference of Building Officials } \\ \text { IES } & \text { Illuminating Engineering Society of North America } \\ \text { LESL } & \text { Law Enforcement Standards Laboratory, NBS } \\ \text { NAAMM } & \text { National Association of Architectural Metal } \\ & \text { Manufacturers } \\ \text { NBS } & \text { National Bureau of Standards } \\ \text { NEMA } & \text { National Electrical Manufacturers Association } \\ \text { NFPA } & \text { National Fire Protection Association } \\ \text { NIJ } & \text { National Institute of Justice } \\ \text { NILECJ } & \text { National Institute of Law Enforcement \& Criminal } \\ \text { NWWDA } & \text { Justice, now NIJ } \\ \text { SD } & \text { Uational Wood Window and Door Association } \\ \text { SDI } & \text { Steel Door Institute } \\ \text { SWI } & \text { Steel Window Institute } \\ \text { UBC } & \text { Uniform Building Code (of ICBO) } \\ \text { UL } & \text { Underwriters Laboratories, Inc. } \\ & \end{array}$

GENERAL

ASTM F967-86 Practice for Security Engineering Symbols

Scope: Practice for using symbols to depict security systems and equipment requirements for architectural or engineering drawings. Nine pages of symbols. Symbol categories are: Annotation, Access Control, Annunciation: Console/Panel, Annunciation: Devices, Barriers and Vehicle Controls, Communications, Electrical, Lighting, Miscellaneous, Sensors, Surveillance, Switches, and Door and Locking Hardware. 
ASTM F1029-86 Guide for the Selection of Physical Security Measures for a Facility

Scope: Aid in the selection of effective security measures to deter or detect an attack on a protected facility. Four threat levels based on skill of attacker and four asset (risk) levels -- residential, commercial, industrial, and very high risk facilities are defined. A threat/physical security matrix identifies protective measures and instrumentation applicable for protecting the above facilities from the various threat levels.

\section{ASTM F832-83 Classification for Security Seals}

Scope: Covers categories of commercially available seals. Classification is based on their configuration and the material from which they are made. Types of seals are: Wire, Padlock, Strap, Cable, Bolt, Cinch, Twist, Scored, and Label.

\section{SITEWORK}

FENCING AND GATES:

ELECTRIC FENCE CONTROLLERS:

UL 69-85 Electric Fence Controllers

Scope: Covers electric fence controllers to be employed on lighting or power circuits in accordance with the National Electrical Code, NFPA 70. Covers both battery operated and lighting or power circuits of 125 volts or less, or combination controllers. 10 performance tests specified.

CHAIN LINK FENCE:

ASTM A116-81 Spec. for Zinc-Coated (Galvanized) Steel Woven Wire Fence Fabric

Scope: Covers fabric suitable for farm field, railroad, and highway, rightof-way and similar fencing, having a series of horizontal (line) wires with vertical (stay) wires woven or wrapped around the line wires, forming rectangular openings. Mostly design. One test is weight of zinc coating.

ASTM A392-84 Spec. for Zinc-Coated Steel Chain-Link Fence Fabric

Scope: Covers fence fabric, zinc-coated before or after weaving. Tests for weight of coating in accordance with A90 and shall meet minimum breaking strengths specified in A817 when tested in accordance with A370. 
ASTM A491-84 Spec. for Aluminum-Coated Steel Chain-Link Fence Fabric

Scope: Covers fence fabric, aluminum-coated before weaving. Test for weight of coating as specified in A817.

ASTM A584-82 Spec. for Aluminum-Coated Steel Woven wire Fence

Fabric

Scope: Covers fence fabric suitable for such uses as railroad or highway right-of-way and similar fencing, having a series of horizontal (line) wires with vertical (stay) wires woven or wrapped around the line wires, forming rectangular openings. Test for minimum weight of coating.

ASTM A70.2-84 Spec. for Steel Fence Posts and Assemblies, Hot Wrought

Scope: Covers steel fence posts and assemblies manufactured from hotwrought sections and intended for use in field and line fencing. The posts are available in tee, channel, or $U$ or $Y$-bar shapes or angle shapes. Tests are for tensile strength, hardness, weight and zinc coating.

ASTM A783-81 Spec. for Aluminum-Zinc Alloy-Coated Steel Chain-Link Fence Fabric

Scope: Covers fence fabric, aluminum-zinc alloy-coated before weaving. Tests for weight of coating, and minimum breaking strengths ( 4 diameters with corresponding strengths from 750 - $2170 \mathrm{lbf}$.) when tested in accordance with $\mathrm{A} 370$.

ASTM A817-86 Spec. for Metallic-Coated Steel Wire for Chain-Link Fence Fabric

Scope: Covers steel wire ( 3 types of coatings) used for the manufacture of chain-link fence fabric. Tests for weight of coating and adherence of coating.

ASTM F552-83 Definitions of Terms Relating to Chain-Link Fencing

Scope: About 50 items defined and 16 illustrations provided.

ASTM F567-84 Practice for Installation of Chain-Link Fence

Scope: Covers installation procedure including site preparation, post location and setting, terminal post bracing, top rail and tension wire, chain-link fabric, barbed wire, gates, etc. 
ASTM F573-84 Spec. for Residential Zinc-Coated Steel Chain-Link Fence

Scope: Covers 11 1/2-gage $(2.87 \mathrm{~mm})$ steel chain-link fence fabric, zinccoated after weaving. Specifies weave, size of mesh (2 $1 / 8$ in.), breaking strength $(750 \mathrm{lbf})$, size of wire, height of fabric (up to 60 inches).

ASTM F626-84 Spec. for Fence Fittings

Scope: Covers materials, coating requirements, and inspection of fence accessories: post-line caps, rail/brace ends, sleeves-top rail, tie wires and clips, tension and brace bands, tension bars, truss rods, and barb arms.

ASTM F668-84 Spec. for Poly (Vinyl Chloride) (PVC)-Coated Steel

Chain-Link Fence Fabric

Scope: Covers fabric coated before weaving. Nominal heights $3,3.5,4,5$, $6,7,8,9,10$ and 12 feet. Largely design spec. in which class of PVC coating, the color, the size of mesh, size of wire, the height and length of fabric in each roll of fabric must be identified.

ASTM F669-85 Spec. for Strength Requirements of Metal Posts and Rails for Industrial Chain-Link Fence

Scope: Covers strength requirements of metal posts and rails for heavy and light industrial chain-link fence up to 12 feet high with a spacing of posts not exceeding $10 \mathrm{ft}$. Posts and rails may have any cross-sectional shape that will meet this spec's requirements. Heavy industrial fence - most rigid and mechanically durable. Light industrial fence - $80 \%$ of load bearing capability of heavy industrial fence. Strength and stiffness criteria specified. Satisfactory designs are classified by product/special requirement as follows: A120, steel pipe, aluminum pipe, steel pipe, roll formed steel shapes, hot-rolled shapes, and alternative designs.

ASTM F761-85 Spec. for Strength Requirements of Steel Posts and Rails for Residential Chain-Link Fence

Scope: Same as F669 except strength and stiffness are somewhat less.

ASTM F900-84 Spec. for Industrial and Commercial Swing Gates

Scope: Covers detailed requirements for chain-link fence gates, gate posts and accessories for both single and double swing-type gates for industrial and commercial application. 
FCGS 02444-85 Fence, Chain-Link

Scope: Design spec. that relies heavily on RR-F-191 specs. Provides general guidance for installation. No performance specs. or test methods.

RR-F-191-81 Fencing, Wire and Post, Metal (Chain-link Fencing Fabric)

Scope: A Federal Spec. similar to ASTM standard spec F669. Cites A370Mechanical Testing of Steel Products.

RR-F-221/GEN - 73 Fencing, Wire, Fence Posts and Accessories (Barbed Wire, Woven Wire, Netting)

Scope: A Fed. Spec. covering general requirements for barbed wire, woven wire, netting, posts and accessories for the erection of farm field, railroad right-of-way and similar fencing. Mostly a design spec. Tests are only for chemical composition.

BARBED WIRE/TAPE:

ASTM A121-81 Spec. for Zinc-Coated (Galvanized) Steel Barbed Wire

Scope: Covers zinc-coated steel barbed wire, consisting of a strand of two wires, in a number of sizes and constructions with three classes (weights) of zinc coating. Orders must identify number of spools, size and construction, class of coating, copper-bearing steel, if required. Specifies size and permissable variations. Test methods for weight of coating (A90) and breaking strength.

ASTM A585-81 Spec. for Aluminum-Coated Steel Barbed Wire

Scope: Covers aluminum-coated steel barbed wire, consisting of a strand of two wires, coated before fabrication, with 4-point barbs. Two types are specified. Test methods for weight of coating (A90) and breaking strength.

MIL-B-52775 - 81 Barbed Tape, Obstacle, General Purpose and Barbed Tape, Fence Topping

Scope: Covers three types of stainless steel barbed tapes. References MERADCOM drawings TA13220E8351, Barbed Tape, Obstacle, General Purpose, Stainless Steel (another MERADCOM drawing is referenced in California prison design specs). Inspection for breaks or cracks is required using at least $10 \mathrm{x}$ magnification. If defects are not clearly identifiable, then E165 for liquid penetrant inspection is required. QA section defines acceptable quality levels ( 8 defective). 
RR-F-191/1A - 76 Fencing Wire (Barbed Wire)

Scope: Covers specific requirements for barbed wire of five rypes: zinccoated, aluminum coated, aluminum clad, copper clad, plastic coated. Mostly a detailed design spec. although tests are specified for coating weight and thickness and "breaking strength" (a non-standard tensile test).

INTRUSION DETECTION:

UL 639-86 Intrusion-Detection Units

Scope: Covers intrusion detection equipment for burglary-protection signaling systems to be employed in outdoor and indoor locations to automatically indicate the presence of an intruder by actuating electrical control circuits. Numerous performance tests.

UL 1076-83 Proprietary Burglar Alarm Units and Systems

Scope: Applies to construction, performance and operation of equipment for use in proprietary burglar alarm units/systems employed to protect against burglary. Normally intended for indoor use. Numerous performance tests.

CEGS 16750 - 85 Intrusion Detection Equipment

Scope: General guidance, but not much in the way of detailed requirements, for the installation and operation of intrusion detection equipment. Relies heavily on voluntary standards of ANSI, ASTM, EIA, NFPA, and UL.

LESL-RPT-0305.00 - 74 Terms and Definitions for Intrusion Alarm Systems

Scope: Several terms related to intrusion alarm systems are defined.

NIJ-0308 - 77 Sound Sensing Units for Intrusion Alarm Systems

Scope: Establishes performance requirements and methods of test for sound sensing devices that respond to attack noises at frequencies up to $10 \mathrm{kHz}$ and are intended for use in intrusion alarm systems to provide premiseprotection of vaults and other secure areas. These devices cause the initiation of a local audible alarm or the transmission of an alarm signal to a central station. Characteristics addressed are those that affect the reliability of the device, with emphasis on those that affect its false alarm susceptibility and its tamper resistance. 
Scope: Establishes performance requirements and test methods for intrusion alarm control units used in protecting residential and commercial premises. Upon actuation of an intrusion sensing device or the detection of a trouble condition, the control unit may initiate a local audible alarm, transmit an alarm signal to a central station. The performance characteristics addressed are those that affect the reliability of the device with emphasis on those that affect false alarm susceptibility and tamper resistance.

W-A-00450B - 73 Alarm System, Interior, Security, Components for

Scope: Covers security alarm system units which are designated to conform to the standards for security equipment as set forth in National Security directives. Highly resistive to neutralization and compromise by covert or surreptitious attack. Types included:

1) balanced magnetic switch;

2) conductive foil

3) breakwire

4) light threshold motion detector

5) infra-red light beam detector

6) passive IR detector

7) vibration detector

8) capacitance detector

9) ultrasonic motion detector

10) microwave-radio frequency motion detector

11) pressure motion detector

12) closed-circuit television motion detector.

Performance tests include:

Neutralization and Compromise test: "various methods shall be attempted using tools and devices not exceeding the quantity capable of being carried in two cases (not more than $10^{\prime \prime} \times 20^{\prime \prime} \times 27^{\prime \prime}$ per case)." Shall withstand attempts to neutralize or compromise for not less than 12 hours.

Stability: high temperature (120 degrees $F$ for 4 hours);

low temperature ( 32 degrees $F$ for 36 hours);

humidity (over 858 relative humidity for 240 hours). 
WALLS/FLOORS

GENERAL:

ASTM E72-80 Methods of Conducting Strength Tests of Panels for Building Construction

Scope: Cover procedures for determining the structural properties of segments of wall, floor, and roof constructions.

Wall tests: compressive load, tensile load, transverse loads, concentrated load, impact load, racking loads

Floor tests: transverse load, concentrated load, impact loads (E695 and E661)

Roof tests: transverse load, concentrated load

ASTM E90-85 Method for Lab. Measurement of Airborne Sound Transmission Loss of Building Partitions

Scope: Covers measurement of walls, floor-ceiling assemblies, doors, windows, roofs and other space dividing elements; not appropriate for determining sound insulating performance of a partition exposed to a sound field that contains only a small range of angles of incidence, nor is it applicable to sounds produced by direct mechanical contact or impact. Not a field rest. For field test see ASTM E 336.

ASTM E336-84 Test Method for Measurement of Airborne Sound Insulation in Buildings

Scope: Determines noise reduction between two rooms.

ASTM E413-80 Classification for Determination of Sound Transmission Class

Scope: Provides single-figure rating used for comparing partitions for general building design purposes. The rating is designed to correlate with subjective impressions of the sound insulation provided against the sounds of speech, radio, TV, music, and similar sources of noise.

ASTM E492-77 Method of Lab. Measurement of Impact Sound Transmission Through Floor-Ceiling Assemblies Using the Tapping Machine

Scope: Covers measurement of impact sound transmission of floor-ceiling assemblies. A single figure classification rating "Impact Insulation Class, IIC" is determined. 
ASTM E695-85 Method of Measuring Relative Resistance of Wall, Floor, and Roof Construction to Impact Loading

Scope: Covers the measurement of the relative resistance of wall, floor, and roof construction to impact loading. Not applicable to doors. Intended to be applied to relatively light construction, including but not limited to wood floor and roof systems, partitions framed with wood or steel studs, steel floor or roof decking systems, steel siding and wall panels.

HPW-TP-0400.01 - July 1985 Forced Entry Resistance of Structural Materials (Opaque and Transparent); Test Procedures and Acceptance Criteria

Scope: Sets forth test requirements for determining the forced entry resistance of materials and/or devices to be used in structures. Field-type tests are conducted with a six-member team of young, muscular males using a variety of tools (sledge, crowbar, hammer, chisels, battering ram, etc.). Test specimen is considered to be forcibly entered when it has a hole which allows passage of either a solid, incompressible object (12" $\mathrm{x} 12^{\prime \prime} \times 8^{\prime \prime}$ ) or a solid, incompressible, right cylinder (12" $\left.\mathrm{x} 12^{\prime \prime}\right)$. Similar to SD-STD01.01 .

SD-STD-01.01 - May 1983

Forced Entry Resistance of Structural Materials (Opaque and Transparent); Test Procedures and Acceptance Criteria

Scope: Sets forth test requirements for determining the forced entry resistance of materials and/or devices to be used in structures. Similar to HPW-TP-0400.01.

\section{DOORS/WINDOWS}

GENERAL:

ASTM E283-84 Test Method for Rate of Air Leakage Through Exterior Windows, Curtain Walls, and Doors

Scope: Determines resistance of exterior windows, curtain walls, and doors to air infiltration resulting from air pressure differences. Rates of air leakage are sometimes used for comparison purposes, which may not be valid unless the components being tested and compared are of essentially the same size, configuration, and design. No precision and bias statement. 
ASTM E 330-84 Test Method for Structural Performance of Exterior Windows, Curtain Walls, and Doors by Uniform Static Air Pressure Difference

Scope: Determines structural performance using a test chamber. Applicable to areas of curtain walls or to windows and doors alone. When structural performance of glass is to be evaluated, procedure in Annex Al is to be used. Intended to represent the effects of wind load on exterior building surface elements.

ASTM E331-86 Test Method for Water Penetration of Exterior Windows, Curtain Walls and Doors by Uniform Static Air Pressure Difference

Scope: Determines resistance to water penetration when water is applied to the outside face simultaneously with a static air pressure at the outdoor face higher than the pressure at the indoor face.

ICBO - $85 \quad$ Uniform Building Security Code

5360 S. Workman Mill Road, Whittier, CA 90601

Scope: Establishes minimum standards to make dwelling units resistant to unlawful entry. Allows jurisdictions to enact the code as Chapter 41 of the Uniform Building Code. Addresses, obstructing exits, tests and identification entry vision, swinging doors, sliding doors and windows. Includes UBC Standard No. 41.1 - Tests for Doors and Locking Hardware Used for Security:

Part I - Swinging Doors and Locking Hardware on Such Doors

Deadbolt Lock Tests: static dead-bolt load test, lock impact, cylinder core tension test, cylinder torque, bolt impact.

Door and Bolt Impact Tests: impacts to panels and flush face doors; bolt and rail or stile impact test.

Part II - Horizontal Sliding Door Assemblies

Hand manipulation; tool manipulation; static load

UBC No. 41.2 - Tests for Window Assemblies

Hand manipulation; tool manipulation; static load and locking device test

NBS Pub 480-22 - 77 Terms \& Definitions for Door and Window Security

Scope: Glossary of definitions for those terms most frequently encountered concerning door and window security. Terms for alarm systems are not included. 
Scope: Covers installation and maintenance of fire door assemblies, windows, glass blocks, and shutters for the protection of openings to restrict the spread of fire and smoke within buildings. Not intended to establish the degree of protection required or to constitute the approval of any product. Has detailed design criteria (size, ratings and methods of operation). Appendix F discusses classification systems (hourly rating, letter designation or a combination of both). Fire protection ratings of doors meeting this standard must be as determined by a testing agency in accordance with NFPA 252, ASTM E152, UL 10B, ANSI A2.2 and ULC-S104.

DOORS :

ANSI/SDI-A123.1-82 Nomenclature for Steel Doors and Steel Door Frames

Scope: Numerous terms and symbols defined.

ANSI/SDI $100-85$ Recommended Specs. for Standard Steel Doors and Frames

Scope: For swinging steel doors and frames, offers a number of choices in both regular and fire door and frame construction and design. The user must select from the specification the specific grades of doors and frames that best apply to the project. References several ASTM, ANSI, and other SDI standards. Those that may be useful include:

SDI 107 Hardware on Steel Doors (Reinforcement -- Application)

SDI 109 Hardware for Standard Steel Doors and Frames

SDI 119 Proposed Performance Test Procedures for Steel Doors Frames and Frame Anchors

ANSI A151.1 Test Procedure and Acceptance Criteria for Physical Endurance for Steel Doors and Hardware Reinforcing

ASTM E152-81 Methods of Fire Tests of Door Assemblies

Scope: Applicable to door assemblies of various materials for use to retard the passage of fire. Determines suitability for use in locations where fire resistance of a specified duration is required. Method uses standard fire exposure, followed by application of a specified standard fire hose stream. A door assembly shall be considered as meeting the requirements of acceptable performance when it remains in the opening during the fire endurance test and hose-stream test. No precision and bias statement. 
ASTM F476-84 Test Methods for Security of Swinging Door Assemblies

Scope: Cover door assemblies of various materials and types of construction for use in wall openings to deter unwanted intruders \& "break-in" crimes. Eleven tests: Static Bolt Load, Jamb/Wall Stiffness, Knob Impact; CylinderCore Tension; Cylinder-Body Tension; Knob Torque; Cylinder Torque; CylinderImpact; Door Impact; Hinge Impact, Hinge Pin Tensile Load; Bolt Impact. Pass/fail tests. Based on NILECJ 0306.00. Sets out door assembly minimum requirements (Grades 10, 20, 30, and 40). References California Building Security standards study on means of forcible entry. Sets out acceptance criteria recommended in NILECJ 0306.00.

ASTM F571-79 Practice for Installation of Exit Devices in Security Areas

Scope: Information for installing exit devices used in areas of security to achieve the greatest security possible without violating the requirements and spirit of ANSI/NFPA 101 Code for Safety to Life from Fire in Buildings and Structures.

\section{References:}

ASTM F476

ANSI/BHMA A156.3 for Exit Devices - should be consulted

ANSI/BHMA A156.5 for Auxiliary Locks and Associated Products

ANSI/NFPA 80 for Fire Doors and Windows

ANSI/NFPA 101 Code for Safety ...

UL 305 Panic Hardware - should be consulted

ANSI/UL 1034 referenced after Electric strikes (see 6.2.3) but not under applicable documents. 
ASTM F842-83 Test Methods for Measurement of Forced Entry Resistance of Horizontal Sliding Door Assemblies

Scope: Methods determine the ability to restrain, delay, or frustrate forced entry. Methods apply to horizontal sliding door assemblies for use in single and multi-family residential dwellings. Three types are classified. Intended to establish a measure of resistance to attacks by unskilled or opportunistic burglars. The following tests are included:

1) Disassembly - tools used for 5 minutes from exterior

2) Hand Manipulation - 2 adult males for 5-10 minutes

3) Tool Manipulation - 1 individual with tools for 5 or 10 minutes

4) Static Load on Panels and Locking Device Resistance

5) Glazing Impact - uses impactor described in CPSC 16 CFR 1201.

The appendix provides suggested measured performance for 4 Grade levels (10, 20, 30, and 40). The appendix also cites documents of the following organizations:

National Woodwork Manufacturers Association

Architectural Aluminum Manufacturers Association

ICBO

NILECJ

California Crime Technological Research Foundation Report

ANSI/BHMA A156.1-81 Butts and Hinges

Scope: Provides cyclical, lateral, and vertical wear tests, together with finish tests requiring salt spray exposures. Individual. hinge types are described and identified with code numbers.

ANSI/BHMA A156.9-82 Cabinet Hardware

Scope: Provides cyclical, operational, and strength tests, together with finish tests requiring salt spray and humidity exposures. Hinges, pulls, knobs, catches, drawer slides and rollers, rotating shelves, tracks and guides for sliding panels, and shelf rests, standards and brackets are described and identified with type numbers.

ANSI/BHMA A156.4-86 Door Controls - Closers

Scope: Contains requirements for door closers surface mounted, concealed in the door, overhead concealed and concealed in the floor. Also included are pivots and thresholds. Criteria for conformance include cycle, operational, closing force and finish tests. Optional tests which must be specified separately are also included. 
ANSI/BHMA A156.8-82 Door Controls - Overhead Holders

Scope: Establishes requirements for overhead door holders and includes performance tests covering operational, cyclical, strength and finish criteria.

ANSI/BHMA A156.14-85 Sliding and Folding Door Hardware

Scope: Establishes requirements for sliding and folding door hardware. Cycle tests, static load, static friction, kinetic friction and finish tests are included. Hardware for light to very heavy doors is covered, including both residential and industrial applications.

ANSI/BHMA A156.3-84 Exit Devices

Scope: Provides requirements for exit devices. Included are cycle, operational, strength and finish tests.

ANSI/BHMA A156.16-81 Auxiliary Hardware

Scope: Establishes requirements for auxiliary hardware and includes performance tests covering operational, cyclical, strength and finish criteria.

NAAMM HMDF-1 - 87 Guide Specifications for Detention Security Hollow Metal Doors and Frames

National Association of Architectural Metal Manufacturers; 600 S. Federal Street, Chicago, IL 60605.

Scope: Provides background on advantages of using hollow metal doors versus bar-grilie construction. Intended to be used for developing job specifications. It must be edited to fit specific job requirements.

Includes 5 performance tests:

static load, rack test, impact load (requires security hinge to withstand 50 impact blows of $200 \mathrm{lb}$-ft directed at the door within 6 inches of the hinge), removable glazing stops test and bullet resistance (cites procedure in UL 752, Bullet-Resisting Equipment); and 2 tests for surface finish (ASTM B117 salt spray for 150 hrs. and D1735 water fog test for organic coating for 200 hours).

Metal must meet ASTM A366 or A569.

For fabrication methods and product quality, doors must meet standards set out in NAAMM Fire-Rated Hollow Metal Doors and Frames, 2nd Edition, 11/83; and NAAMM Hollow Metal Manual, 2/87. 
NFPA 252-84 Fire Tests of Door Assemblies

Scope: Equivalent to ASTM E152 and UL 10B. Cites UL as the developer of the test methods (fire endurance and hose stream).

NWWDA I.S.1-86 Series: Industry Standard for Wood Flush Doors

Scope: Each standard in the series describes a particular aspect of door construction or manufacture. Test methods include moisture, bonding, warpage, etc. However, there are no "security"-type requirements.

SDI 106 - 66 Recommended Standard Door Type Nomenclature

Scope: Identifies various door types.

SDI 107 - 78 Hardware on Steel Doors (Reinforcement-Application)

Scope: Furnishes users of standard steel doors with practical information regarding accepted design methods of reinforcing for recommended practices for proper field preparation and installation of builders' hardware. Pertains to doors and frames manufactured in accordance with SDI-100. Recommends minimum gauges for various hardware items including hinges, locksets, bolts, closers, plates, panic devices, and pivots. No tests.

SDI 108 - 72 Selection and Usage Guide for Standard Steel Doors

Scope: Guide for selecting proper grade and model door per SDI 100 spec.

UL 14B-79 Sliding Hardware for Standard Horizontally Mounted Tin-Clad Fire Doors

Scope: Applies to hardware for horizontally sliding fire doors which have demonstrated fire resistive properties warranting their use with two-ply or three-ply tin-clad fire doors. Does not cover automatic releasing or closing mechanisms. Virtually all design-type requirements.

UL 14C-79 Swinging Hardware for Standard Tin-Clad Fire Doors Mounted Singly and in Pairs

Scope: Applies to hardware for swinging fire doors which have demonstrated fire resistive properties warranting their use with two-ply or three-ply tin-clad fire doors. Does not cover automatic releasing or closing mechanisms. Virtually all design-type requirements. 
Scope: Applies to swinging door closers equipped with integral electromechanical or electromagnetic holders and which may be provided with integral smoke detectors. Also applies to electromagnetic door holder units which are for use with a separate door closer and separate automatic fire detector. References NFPA 80 and 72E for installation requirements.

AA-D-600-73 Door, Vault, Security

Scope: Covers security vault doors designed to conform to the standards for security equipment as set forth in the "National Security Council Directive Covering the Classification, Declassification and Safeguarding of National Security Information." Doors are rated for protection against unauthorized entry for periods of time specified. References several government specs. and one voluntary standard (UL 768 for Combination Locks). Mostly design requirements, however there are four performance tests: door test for sturdiness; surreptitious and forced entry test (elaborate empirical test); entry by radiological techniques; and finish tests.

NILECJ-STD-0306.00 - 76 Physical Security of Door Assemblies and Components

Scope: Performance requirements and test methods for resistance of doors to forced entry. Concerned with typical entry doorways in residences and some small businesses (single pedestrian use, hinged swinging doors). Included are requirements for both the total door assembly and individual components, such as the hinges, lock, door, jamb/strike, and jamb/wall. Addresses capability to frustrate the "opportunity" crimes. Skilled methods of entry used to gain access are not addressed. Door assemblies and components are classified by relative resistance to forced entry. Door assembly tests: bolt projection strike hole, bolt pressure, jamb/wall stiffness, knob impact, cylinder core tension, cylinder body tension, knob torque, cylinder torque, cylinder impact, door impact, hinge impact, bolt impact. 
NIJ Std $0318.00-80 \quad$ Physical Security of Sliding Glass Door Units

Scope: Performance requirements and test methods for resistance to forced entry of sliding glass door units intended for use in residences. Two classes of units:

Class I - minimum level of physical security (designed to prevent entry by unskilled burglars)

Class II - moderate level (designed to prevent entry by most semiskilled burglars). Does not address rarely used methods of gaining entry nor those only used by skilled burglars.

Class III - requires higher latch loading resistance, door panel removal resistance (vertical only), locking device strength, fixed panel fastening strength, meeting stile fastening strength as well as glazing impact strength.

WINDOWS:

ASTM E163-84 Methods of Fire Tests of Window Assemblies

Scope: Applicable to window assemblies, including glass block and other light transmitting assemblies, for use in wall openings to retard the passage of fire. Evaluates ability of a window to remain in an opening during a predetermined test exposure of 45-min. duration. The tests expose a standard fire exposure followed by a specified standard fire hose stream.

ASTM E773-83 Test Method for Seal Durability of Sealed Insulating Glass Units

Scope: Provides tests for performance of preassembled permanently sealed insulating glass units against accelerated weathering and fogging. Only applicable to "glass" units. Cites ASTM E 546 - Test Method for Frost Point of Sealed Insulating Glass Units. Intended to provide a means for evaluating the durability of the sealing system of sealed insulating glass units.

ASTM E774-84a Specification for Sealed Insulating Glass Units

Scope: Covers specimen size, test duration, and performance requirements. Provides a basis for judgment of acceptability. Associated certification program with the Insulating Glass Certification Council (IGCC). Three Classes. Cites thickness tolerance of DD-G-451. 
ASTM F588-85 Test Methods for Resistance of Window Assemblies to Forced Entry, "Excluding Glazing"

Scope: Cover window assemblies of various materials and types of construction for use in wall openings to deter unwanted intruders. Five types of window assemblies are classified. Intended to establish a measure of resistance for window assemblies subjected to attacks (other than impacting glazing materials) by unskilled or opportunistic burglars. Annex A1 provides suggested guidelines for acceptance criteria for performance levels. Tests include: hand manipulation, tool manipulation, static load and locking device strength resistance.

\section{UL 9-79 Fire Tests of Window Assemblies}

Scope: Applicable to window assemblies, including glass block and other light transmitting assemblies, for use in wall openings to retard the passage of fire. Two tests: fire endurance and hose stream. Equivalent to ASTM E163.

NIJ $0316.00-80 \quad$ Physical Security of Window Units

Scope: Performance requirements and test methods for the resistance of forced entry of window units intended for use in residences and some small businesses. The skilled or rarely used methods of gaining entry is not addressed.

Four Classes - I - minimum level of physical security

II - moderate level of physical security

III - medium level of physical security

IV - relatively high level of physical security

Mode of Operations

Type A (Sliding,), Type B (Outswinging), Type C (Inswinging), Type D (Pivoted), Type E (Fixed), and Type F (Security window: defined as units having metal bars fastened to the exterior of the window frame for the purpose of preventing entry.)

Includes performance tests for: resistance to loiding, locking device stability, locking device strength, window strength, impact strength for glazing, sash frame, and security bars.

\section{NIJ $0319.00-80$ Metallic Window Foil for Intrusion Alarm Systems}

Scope: Provides performance requirements and methods of test for metallic window foil used in intrusion alarm systems as a sensor to detect the breakage of glass. Standard only applies to metallic foil for use on glazing materials consisting solely of glass. 
GLAZING :

ANSI 226.1-83 Safety Code for Safety Glazing Materials for Glazing Motor Vehicles Operating on Land Highways

Scope: Includes numerous performance test methods for impact, abrasion resistance, chemical resistance, flexibility, flammability, penetration resistance, ballistics, etc.

ANSI 297.1-84 Performance Specs. and Methods of Test for Safety Glazing Material Used in Buildings

Scope: Promotes safety and minimizes injury when broken by human contact. Impact test designed to emulate energy levels generated by humans running into glazing. Impact test is equivalent to 16 CFR 1201. Also includes weathering and aging tests. [Safety Glazing Certification Council (SGCC) administers certification program for glazing materials to meet 297.1 and 16 CFR 1201.]

ASTM C158-84 Standard Methods of Flexural Testing of Glass (Determination of Modulus of Rupture)

Scope: Methods applicable to annealed and pre-stressed glasses. Method A is a test for modulus of rupture of flat glass, designed to include the condition of the surface of the specimen as a factor in the measured strength. 11 pages

ASTM C162-85a

Standard Definitions of Terms Relating to Glass and Glass Products

Scope: Prepared jointly by American Ceramic Society and ASTM; 16 pages

ASTM C920-86 Specification for Elastomeric Joint Sealants

Scope: Covers properties of a cured single- or multi-component cold-applied elastomeric joint sealant for sealing, caulking, or glazing operations on buildings, plazas, decks, etc. Types, classes, grades and uses are defined. Essential that the applicable type, grade, class and use be specified so that proper sealant is provided for the intended use.

ASTM C962-86 Guide for Use of Elastomeric Joint Sealants

Scope: Covers use of sealants covered by $\mathrm{C} 920$. 
Scope: Covers the quality requirements for cut sizes of flat, transparent, clear glass for glazing, mirrors, and general architectural a similar uses. Types, classes, styles, forms, qualities, and finishes must be specified. Test methods include ream, strings and distortion; ream, strings, lines, and waves; scratches, rubs, stones, and gaseous inclusions; transmittance - color or tint, luminous transmittance (Practice. E308), solar transmittance (E903); shading coefficient (ASHRAE Handbook for Fundamentals).

ASTM C1048-85 Specification for Heat-Treated Flat Glass-Kind HS, Kind FT Coated and Uncoated Glass

Scope: Covers requirements for flat heat strengthened and flat fully tempered coated and uncoated glass used in general building construction. Kinds, conditions, types, classes, styles, forms qualities and finishes must be specified. Fabrication requirements must be specified. Also, requirements for fittings and hardware, specific location of tong marks, custiom design or texture required, glass thickness, surface or edge compression test, break pattern test, color or tint, luminous transmittance and surface treatment. Tests include expansion fit, durability of coating, adherence (C 346), alkali resistance, fallout resistance work load, fracturing C 1036 tests, strength compression or load strength, impact (ANSI 2.97.1 and 16 CFR 1201).

ASTM F12- Draft Oct 86 Test Method for Security Glazing Materials and Systems

Scope: ASTM Committee F12 is preparing a standard to evaluate resistance of security glazing against: ballistic impact; blunt tool impacts; sharp tool impacts; thermal stress; chemical deterioration.

HPW TP-0300.00 - May 1984

Ballistic Resistance of Structural Materials (Opaque and Transparent); Test Procedures and Acceptance Criteria

Scope: Sets forth requirements for determining the ballistic resistance of building materials intended for use in buildings and structures (or portions thereof) which may be attacked by small arms fire. Three ratings are specified: Minimum (Submachine gun and 12 gauge shotgun); Rifle; and Rifle (Armor Piercing). Similar to SD-STD-02.01. 
Scope: Requirements cover materials, devices, and fixtures used to form bullet-resisting barriers designed to protect against robbery or holdup. "Bullet-resisting" signifies that protection is provided against complete penetration, passage of fragments of projectiles, or spalling (fragmentation) of the protective material to the degree that injury would be caused to a person standing directly behind the bullet-resisting barrier. Ratings: medium-small arms, high-small arms, super-small arms, and highpowered rifle. Several test methods included. 57 pages.

UL 972-85 Burglary Resisting Glazing Material

Scope: Requirements cover clear, translucent, or opaque glazing material intended for indoor/outdoor use principally as a substitute for plate glass windows or show case panels and intended to resist burglarious attacks of the "hit and run" type. Four types of impact tests:

1) Multiple impact (shall withstand five 50 foot-1b. impacts of a steel ball, 3-1/4" diameter, weighing $5 \mathrm{lb}$., dropped from $10 \mathrm{ft.}$ )

2) Thermal Conditioning for Outdoor Use (shall withstand five 40 foot-lb. impacts of a steel ball, 3-1/4" diameter, weighing $5 \mathrm{lb}$., dropped from $8 \mathrm{ft}$. onto thermally conditioned samples - 120 degrees F and 14 degrees $F$ )

3) Thermal Conditioning for Indoor Use (shall withstand five 50 foot-lb. impacts of a steel ball, 3-1/4" diameter, weighing 5 lb., dropped.from $10 \mathrm{ft}$. onto thermally conditioned samples -- 95 degrees $F$ and 55 degrees $F$ )

4) High-Energy Impact (shall withstand one impact of over 200 foot-1b. of a steel ball, 3-1/4" diameter, weighing $5 \mathrm{lb}$, dropped from $40 \mathrm{ft}$.)

CPSC 16 CFR 1201 Safety Standard for Architectural Glazing Materials

Scope: Requirement for safety for any of the following: 1) storm doors or combination doors; 2) doors; 3) bathtub doors and enclosures; 4) shower doors and enclosures; 5) [reserved]; and 6) sliding glass doors (patio type). Includes glazing materials used in such products. Tests: 1) Impact (uses well-specified test equipment); 2) Accelerated environmental durability. Reference ANSI Z97.1 - 1972 and 1975 as acceptable alternative. States certification and labelling requirement generically.

\section{NIJ $0108.01-85 \quad$ Ballistic Resistant Protective Materials}

Scope: Establishes minimum performance requirements and methods of test for all ballistic resistant materials (armor) intended to provide protection against gunfire, with the exception of police body armor and ballistic helmets. Six levels of performance are classified depending on weapons and ammunition used ranging from a 38 caliber handgun to an armor piercing rifle. 
Ballistic Resistance of Structural Materials (Opaque and Transparent); Test Procedures and Acceptance Criteria

Scope: Sets forth requirements for determining the ballistic resistance of building materials intended for use in buildings and structures (or portions thereof) which may be attacked by small arms fire. Three ratings are specified: Minimum (Submachine gun and 12 gauge shotgun); Rifle; and Rifle (Armor Piercing). Similar to HPW-TP-0300.00.

\section{ACCESS CONTROL}

\section{GENERAL:}

UL 294-87 . Access Control System Units

Scope: Apply to construction, performance and operation of systems intended to regulate/control (1) entry into an area or (2) access to or the use of a device(s) by electrical, electronic or mechanical means. Contains numerous tests including destructive and nondestructive attack tests of 5 minute duration. If alarm is activated during attack, duration is reduced to 2 minutes.

\section{LOCKS:}

ASTM F471-82 Definitions of Terms Relating to Combination Locks

Scope: About 50 terms used to describe various aspects of combinations locks are defined.

\section{ASTM F883-84 Performance Specs. for Padlocks}

Scope: Contains environmental, functional, operational, security requirements. Included are function descriptions, cycle tests, operational tests, environmental tests, forcing tests, and surreptitious entry tests. No effort has been made to include criteria for specially made padlocks used by the Defense Department or others in highly sensitive locations. Describes grades and various levels of performance to provide users with criteria upon which to select suitable padlocks.

\section{ANSI/BHMA A156.2-83 Bored and Preassembled Locks and Latches}

Scope: Establishes requirements for bored and preassembled locks and lock trim. Includes performance tests, operational, strength and finish tests, and dimensional criteria. Levels of performance for bored locks are set forth, and an appendix with a users guide is provided. 
Scope: Contains requirements for auxiliary bored and mortise locks, rim locks, and cylinders. Included are security tests, operational tests, finish tests, and dimensional criteria. Refers to UL 1034 in regard to electric strikes. Test criteria specified for three grades of locks.

ANSI/BHMA A156.11-85 Cabinet Locks

Scope: Establishes requirements for cabinet locks used on doors, drawers, and furniture. Included are cycle, operational, strength, and finish tests; and dimensional criteria.

ANSI/BHMA A156.12-86 Interconnected Locks and Latches

Scope: Establishes requirements for interconnected locks and includes security tests, operational tests, cycle tests, finish tests, and dimensional criteria.

ANSI/BHMA A156.13-80 Mortise Locks and Latches

Scope: Establishes requirements for mortise locks and latches and includes performance tests, security tests, operational tests, finish tests, and dimensional criteria.

UL 305-79 Panic Hardware

Scope: Covers releasing devices actuated by a cross-bar for outward-opening doors, designed to facilitate the egress of persons from buildings in the event of panic or other emergency. Two performance tests: endurance tests $(100,000$ cycles without failure or excess wear) \& emergency operation test.

UL 437-86 Key Locks

Scope: Covers key locks categorized as follows: door locks, locking cylinders, security container key locks, and two-key locks. Four performance tests including endurance test, attack resistance tests, salt spray corrosion test, and polymeric materials tests. Attack resistance test time for door locks and locking cylinders is 10 minutes for picking and impression; and 5 minutes for forcing, drilling, sawing, prying, pulling, and driving using various hand tools. Effective date of many of these requirements is September 1, 1987. 
Scope: Requirements apply to the construction, performance and operation of burglary-resistant electric locking mechanisms and their related devices, such as control unit, control switch, power supply, and the like, used to secure and release doors, and the like by applying or removing electrical power. About 30 performance tests including: forcing tests (pushing and torque) and tool attack tests ( 5 minute duration with specified hand tools).

\section{CEGS-08701 - 86 Hardware: Prison-Locking Devices}

Scope: Specifies four types of deadlocks:

A. for swinging doors with or without gang-locking device;

B. for swinging doors without gang-locking device;

C. for swinging doors of cabinets;

D. for sliding doors, with or without gang-locking device.

This is a design spec. No performance tests are included.

FF-P-110 - 72 Padlock, Changeable Combination (Resistant to Opening by Manipulation and Surreptitious Attack)

Scope: Covers both dial and push button designs. Required to resist opening by surreptitious, and manipulation techniques for specified periods of time. No forced entry requirements. Test methods include:
a) manipulation technique;
b) surreptitious attack;
c) radiographic;
d) direct tension;
e) jar test with tension;
f) jar test without tension;
g) padlock shackle; and
h) drop test.

MIL-L-29151 - 75 Locks and Lock Sets, Exterior, Ordnance, High Security

Scope: Covers key operated, high security, dead-bolt locks and lock sets, for the securing of sensitive ordnance materials. Uses several test methods including: hardness (E18), fog (B117), picking and bypassing test, key integrity test, operational test, impact test (lock shall be... substantially struck six times in different directions with a mallet weighing no more than 12 ounces), operational temperature test, drop test, wear test, and forced entry tests (specifies 10 types of tools, each not exceeding $10 \mathrm{lb}$. and with other restrictions, to be used to defeat the lock in less than 7 man-minutes). 
MIL-H-29181 - 78 Hasp, High Security, Shrouded, for High and Medium Security Padlock

Scope: Covers two styles of hasps for high security padlocks. Uses tivo tests including: hardness (E18) and impact (E23 - notched bar impact testing of metallic materials).

MIL-P-43607 - 80 Padlock, Key Operated,.High Security, Shrouded Shackle

Scope: Covers one type of key operated, high security, shrouded shackle padlock that employs a dead bolt locking mechanism. Uses several test methods including: surreptitious neutralization test (can the padlock be compromised without it appearing to be such), wear resistance, drop tests, shackle pull-out test, low temperature shock test, forced entry tests (specifies using, but not limited to, 6 sets of tools, not exceeding a total of $20 \mathrm{ib}$. and with other restrictions, to be used to defeat the padlock in less than 5 minutes of accumulated work time, excluding preparation, rest, and safety precaution periods), heat resistance, low temperature operation, key integrity test, fog test, key hardness, key deformation resistance, operating key function, control key function, cylinder interchangeability.

TELEVISION SYSTEMS:

ASTM F572-83 Practice for Application of Photographic Security Cameras in Financial Institutions

Scope: Guide for use in determining the type (continuous, demand, or special application) of cameras that can be used adequately in financial institutions. Contains minimum standards to be exercised in the placement and installation of these cameras.

UL 983-83 Surveillance Camera Units

Scope: Covers surveillance cameras and accessories intended for use at mercantile and banking premises to provide a means of recording images of holdup attempts or other activities in the area. May take single frame, rapid sequence or motion pictures. 


\section{ELECTRICAL}

\section{GENERAL:}

NFPA 70 - 84 National Electrical Code (NEC)

Scope: Basic Wiring, Equipment, Special Occupancies, etc.

UL 634-85 Connectors and Switches For Use With Burglar-Alarm Systems

Scope: Covers connectors and switches for use with burglar-alarm systems in mercantile premises, mercantile safes and vaults, bank safes and vaults, and residences. Intended to be used in circuits of limited energy in accordance with NFPA 70. Switches are intended for use in protective circuits to supervise doors, windows, hatches, vents, etc. to initiate an alarm signal when actuated.

EMERGENCY POWER:

NFPA $110-85 \quad$ Emergency and Standby Power System

Scope: Covers performance requirements for power systems providing an alternative source of electrical power to loads in buildings and facilities in the event that the normal power source fails. Includes power sources, transfer equipment, controls, supervisory equipment, and all related electrical and mechanical auxiliary and accessory equipment needed to supply electrical power to the load terminals of the transfer equipment. Also covers installation, maintenance, operation, and testing requirements as they pertain to performance of an emergency power supply system. 


\section{LIGHTING :}

UL $57-80$

Electric Lighting Fixtures

Scope: Covers high intensity discharge lighting fixtures for commercial, industrial, or residential use in location in accordance with the NEC.

UL 924-85 Emergency Lighting and Power Equipment

Scope: Covers battery powered emergency lighting and power equipment for use in ordinary indoor locations in accordance with NEC. Such equipment is intended to supply automatically illumination or power or both to critical areas and equipment in the event of failure of the normal supply or in the event of accident to elements of a system intended to supply, distribute, and control power and illumination essential to safety of human life.

UL 1570-86 Fluorescent Lighting Fixtures

Scope: Covers general use fluorescent electric lighting fixtures for commercial, industrial, or residential use in ordinary locations in accordance with NFPA 70 .

UL 1571-86 Incandescent Lighting Fixtures

Scope: Covers general use incandescent electric lighting fixtures for commercial, industrial, or residential use in ordinary locations in accordance with NFPA 70.

\section{FIRE SAFETY}

CPSC FF4-72 - 73 Standard for the Flammability of Mattresses and Mattresses Pads

Scope: Prescribes requirements for testing of prototype designs of mattresses and mattress pads before the sale of such items subject to the standard. Specifies a test to determine the ignition resistance when exposed to a lighted cigarette. Does not include how a mattress reacts when exposed to open flame ignition.

NFPA $13-85$ Installation of Sprinkler Systems

Scope: Contains minimum requirements for design and installation to provide a degree of protection for life and property from fire. 
NFPA 101 - 85 Code for Safety of Life from Fire in Buildings and Structures Scope:

Chapter 14

Chapter 15

Chapter 31

Appendix E
New Detention and Correctional Occupancies

Existing Detention and Correctional Occupancies

Operating Features

Fire Safety Evaluation System for Detention and Correctional Occupancies

ASTM E84-84a Test Method for Surface Burning Characteristics of Building Materials

Scope: Comparative surface burning behavior of building materials tested in the ceiling position. Provide comparative measures of surface flame spread and smoke density with that of select grade red oak and reinforced cement board surfaces. May not be appropriate for some cellular plastic materials.

\section{ASTM E108-83 Methods of Fire Tests of Roof Coverings}

Scope: Measure relative fire characteristics of roof coverings including: intermittent flame exposure test; spread of flame test; burning brand test; flying brand test; rain test. Three test classes. Provides a basis for comparison for simulated fire exposure to the outside only.

ASTM E119-83 Methods of Fire Tests of Building Construction and Materials

Scope: Applicable to assemblies of masonry units and to composite assemblies of structural materials for buildings, including bearing and other walls and partitions, columns, girders, beams, slabs, and composite slab and beam assemblies for floors and roofs. Intended to evaluate the duration for which these types of assemblies will contain a fire. "Protective Membrane Performance" reported. Sometimes the hose stream test is used following the fire endurance test.

ASTM E136-82 Test Method for Behavior of Materials in a Vertical Tube Furnace at $750^{\circ} \mathrm{C}$

Scope: Determination of combustion characteristics of building materials. It is not intended to apply to laminated or coated materials. Assists in indicating those materials which do not act to aid combustion or add appreciable heat to an ambient fire. 
ASTM E162-83 Test Method for Surface Flammability of Materials Using a Radiant Heat Energy Source

Scope: Used for R\&D purposes. Not intended for use as a basis of ratings for building code purposes.

ASTM E286-85 Test Method for Surface Flammability of Building Materials Using an 8-ft. (244 m) Tunnel Furnace

Scope: Provides comparative measurement of surface flame spread of building materials when exposed to thermal radiation and natural draft conditions. Includes a photoelectric measurement of the light attenuation produced by the smoke during burning. Not primarily intended as a basis for regulatory purposes. Intended for use in product development and manufacturing control of building materials.

NFPA 72A- 85 Installation, Maintenance and Use of Local Protective Signaling Systems for Guard's Tour, Fire Alarm and Supervisory Service

Scope: Sets the requirements for a system where the only alarm indication is automatic activation of the evacuation signal. The alarm does not go outside the building. Such a limited system would have limited use in prisons and jails. However, the standard also provides specifications for components of more sophisticated detection and alarm systems. A major problem in following this standard, without modification, is that the required pull boxes would be an attractive nuisance unless located only in area not accessible to prisoners such as the guard office.

NFPA 72B- 86 Installation, Maintenance and Use of Auxiliary Protective Signaling Systems

Scope: Defines the requirements to connect a $72 \mathrm{~A}$ system to simultaneously trip a municipal alarm system connected to the fire department when the fire department uses a system covered by NFPA 1221, Standard for Public Fire Service Communications. This is no longer the most common type of municipal fire alarm system.

NFPA 72C-86 Installation, Maintenance and Use of Remote Station Protective Signaling Systems

Scope: Defines the requirements for the connection of a $72 \mathrm{~A}$ system to a fire department system where there will be someone on duty to take appropriate action, e.g., to send fire fighters and equipment. 
NFPA 72D- 86 Installation, Maintenance and Use of Proprietary Protective Signalling Systems

Scope: Covers those systems where the facility maintains a central supervising station to coordinate security and/or fire alarm signalir.g functions. The entire system is under the control of the user, hence the use of the word "proprietary". While the central supervising station may be responsible for more than just fire, this standard covers only fire related information. However, fire related information would include such items as the arrival of guards at reporting stations.

The central supervising station must be staffed at all times. The staff will determine the response to be taken. Actions to be taken include retransmission of indication of the fire to the local fire department (or other location acceptable to the authority have jurisdiction). The system is usually designed so that one central supervising station can cover many buildings or floors.

NFPA 72E- 84 Automatic Fire Detectors

Scope: Assists in the proper application of automatic fire detectors. It is concerned with such items as location of the detectors and choice of an appropriate type of detector. In other words, it is concerned with how the detector operates as part of a protective signalling system. It supplements UL268, UL 268A, and UL 521 which set the performance requirements for the detectors themselves. The guidelines in this standard generally apply to prisons and jails but need to be modified to account for the unique characteristics of the occupancy, e.g. detectors may need to be placed differently to minimize vandalism. Since the guidelines are based on the known characteristics and sensitivities of the detectors and the physical and chemical characteristics of the fire, modifications should be made only with the assistance of technical experts.

NFPA 72F- 85 Installation, Maintenance and Use of Emergency Voice/Alarm Communication Systems

Scope: Covers the installation, power supply and power backups, and some of the required design features for Voice/Alarm Signaling Service and Two-Way Telephone Communication Service. This is used when the fire emergency plan involves phased evacuation, relocation within the building, etc., where you need to communicate with the people who do not evacuate.

NEPA 72G- 85 Guide for the Installation, Maintenance, and Use of Notification Appliances for Protective Signalling Systems

Scope: Covers the performance, location, mounting, testing and maintenance recommended for protective signaling systems. 
NFPA 72H- 84 Guide for Testing Procedures for Local, Auxiliary, Remote, Station and Proprietary Signaling Systems

Scope: Establishes procedures for acceptance and periodic testing of installed protective signaling systems.

UL 268-84 Smoke Detectors for Fire Protective Signaling Systems

Scope: Defines the performance characteristics of the smoke detectors. If the detector contains an auditory alarm, this standard defines the minimum sound characteristics of the alarm.

UL 268A-83 Smoke Detectors for Duct Application

Scope: Defines the performance characteristics of smoke detectors installed in ducts. Given the potential vandalism problem with reachable detectors, the use of smoke detectors in the exhaust or ventilation systems is promising. The design challenge is to locate the detectors so that they cannot be reached by the prisoners but are satisfactorily accessible for installation, maintenance, and testing.

UL $464-86$

Audible Signal Appliances

Scope: Covers electrically and electronically operated bells, buzzers, horns, and similar audible signal appliances, rated 300 volts or less, for general or fire-protective signaling service and intended for both indoors and outdoors in accordance with NFPA 70,71, 72A, 72C,72D, 72G, and 74.

UL 497B-87 Protectors for Data Communication and Fire Alarm Circuits

Scope: Protectors consist of single and multiple pair air gap arresters, gas tube arresters, or solid state arresters, with or without fuses or other voltage limiting devices. Intended to protect against lightning. Thirteen performance tests included.

UL 521-86 Heat Detectors for Fire Protective Signaling Systems

Scope: Covers heat detectors for fire protective signaling systems to be installed in ordinary indoor and outdoor locations in accordance with NFPA 72E. Smoke detectors are more sensitive than heat detectors and, therefore, are usually preferred. However, there are situations where smoke detectors will give too many false alarms and a heat detector is a valuable alternative safety device, e.g., in kitchens and furnace rooms. 
Scope: Covers electrical control units and accessories for fire protective signaling systems intended to be employed in ordinary indoor locations in accordance with the following NFPA standards $(12,12 \mathrm{~A}, 12 \mathrm{~B}, 70,71,72 \mathrm{~A}$, $72 \mathrm{~B}, 72 \mathrm{C}$, and 72D). Numerous performance tests specified.

UL 1480-87 Speakers for Fire-Protective Signaling Systems

Scope: Covers electrically and electronically operated speakers that provide speech communication and distinctive sounds in conjunction with fire-protective signaling systems for indoor or outdoor locations or both, in accordance with NFPA 70, 71, 72A-72D, and 74. Several tests included.

\section{ECONOMICS}

ASTM E833-84 Definitions of Terms Relating to Building Economics

Scope: Contains definitions relating to the economic evaluation of building construction as used in other standards under the jurisdiction of ASTM Comittee E6 on Performance of Building Constructions.

ASTM E917-83 Practice for Measuring Life-Cycle Costs of Buildings and Building Systems

Scope: Establishes a procedure for evaluating the life-cycle costs (LCC) of buildings and building systems. Procedures for use of the LCC method are described step-by-step. The LCC method results in an economic evaluation that encompasses the net effect, over time, of designing, purchasing, leasing, constructing/installing, maintaining, operating, repairing, replacing, and disposing of buildings or building systems.

ASTM E964-83 Practice for Measuring Benefit-to-Cost and Savings-toInvestment Ratios for Buildings and Building Systems

Scope: Provides a recommended procedure for calculating and interpreting the benefit-to-cost ratio (BCR) and saving-to-investment ratio (SIR) of building designs and systems. The BCR and SIR are numerical ratios that indicate the economic value of a project by the size of the ratio.

ASTM E1057-85 Practice for Measuring Internal Rates of Return for Investments in Buildings and Building Systems

Scope: Establishes a procedure for calculating and interpreting internal rate-of-return's (IRR) for building designs and systems. The IRR provides the compound rate of interest that equates the stream of dollar benefits or savings to dollar costs over some defined study period. 
ASTM E1074-85 Practice for Measuring Net Benefits for Investments in Buildings and Building Systems

Scope: Provides a recommended procedure for calculating and interpreting the net benefits (NB) method in the evaluation of building designs and systems. The NB method, sometimes called the net present value method, calculates the difference between discounted benefits (or savings) and discounted costs as a measure of the cost effectiveness of a project.

\section{ASTM E1121-86 Practice for Measuring Payback for Investments in Buildings and Systems}

Scope: Provides a recommended procedure for calculating and applying the payback method in evaluating building designs and building systems. The payback method accounts for all monetary values associated with an investment up to the time at which cumulative net benefits, discounted to present value, just pay off initial investment costs. 
NBS. 114A (REV. 2-AC)

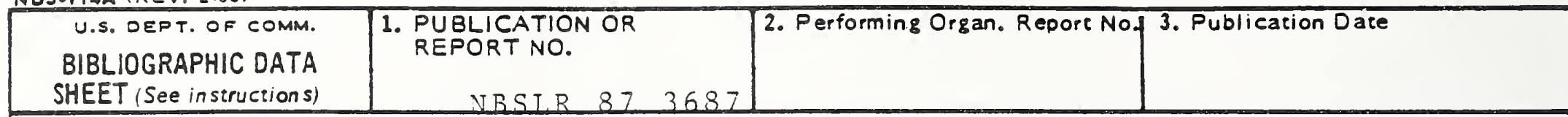

4. TITLE AND SUBTITLE

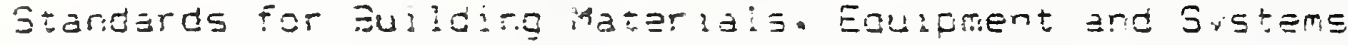

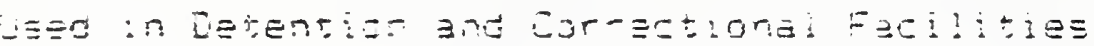

5. AUTHOR(S)

Robert D. Dikker's, Belinda C. Reeder

6. PERFORMING ORGANIZATION (If joint or other than NBS, see instructions)

NATIONAL BUREAU OF STANDARDS

U.S. DEPARTMENT OF COMMERCE

GAITHERSBURG, MD 20899

9. SPONSORING ORGANIZATION NAME ANO COMPLETE ADORESS (Street, City. State, ZIP)

7. Conerace/Grane No.

23

8. Type of Report \& Period Covered

U.S. DEPARTMENT OF JUSTICE

NATIONAL INSTITUTE OF CORRECTIONS

WASHINGTON, DC 20534

10. SUPPLEMENTARY NOTES

Document describes a computer program: SF-185, FIPS Software Summary, is attached.

11. ABSTRACT (A 200-word or less factual summary of most significant information. If document includes a significant bibliography or literature survey, mention it here)

Because of equipment and system performance problems wich have occurred in jail.s and prisons, the National Institute of Corrections (NIC), U.S. Department of Justice, initiated a study at the Center for Building Technology, National Bureau of Standards (NBS) in September 1986. The general objective of this study is to develop guidelines, test methods and the tectinical bases for standards which would assist in the selection, application, and maintenance of building materials, equipment and systems for use in detention and correctional

facilities.

During the first year of this study, the primary focus has been on determining the state-of-the-art in the design and construction of detention and correctional facilities. Specific emphasis was placed on identifying performance problems associated with various materials, equipment and systems, as well as reviewing available guidelines, standards, etc. which are or can be used by architects and correctional officials in the planning and design of new correctional facilities. Based on information presented, there are many important eriteria and standards which need to be developed for improving the selection of materials, equipment and systems.

12. KEY WOROS (Six to twelve entries: alphabetical order: capitolize only proper names; and separate key words by semicolons)

Building materials; equipment; fire safety; jails; performance eriteria; prisons; standards; security systems: test methods.

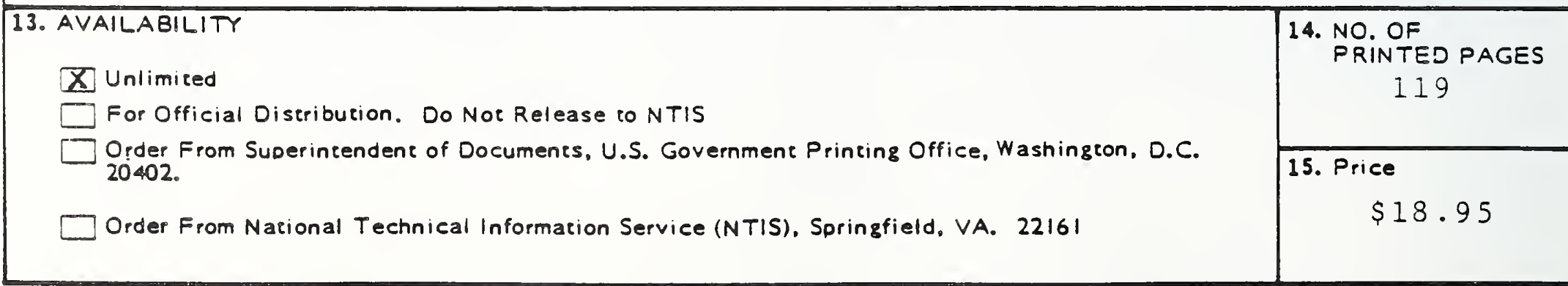



